University of South Florida

DIGITAL COMMONS

Digital Commons @ University of

@ UNIVERSITY OF SOUTH FLORIDA

South Florida

2006

\title{
Generalized non-dimensional depth-discharge rating curves tested on Florida streamflow
}

Auristela Mueses-PÃ@rez
University of South Florida

Follow this and additional works at: https://digitalcommons.usf.edu/etd

Part of the American Studies Commons

\section{Scholar Commons Citation}

Mueses-PÃ@rez, Auristela, "Generalized non-dimensional depth-discharge rating curves tested on Florida streamflow" (2006). USF Tampa Graduate Theses and Dissertations.

https://digitalcommons.usf.edu/etd/2639

This Dissertation is brought to you for free and open access by the USF Graduate Theses and Dissertations at Digital Commons @ University of South Florida. It has been accepted for inclusion in USF Tampa Graduate Theses and Dissertations by an authorized administrator of Digital Commons @ University of South Florida. For more information, please contact digitalcommons@usf.edu. 
Generalized Non-Dimensional Depth-Discharge Rating Curves

Tested on Florida Streamflow

by

Auristela Mueses-Pérez

A dissertation submitted in partial fulfillment

of the requirements for the degree of

Doctor of Philosophy

Department of Civil Engineering

College of Engineering

University of South Florida

\author{
Major Professor: Mark Ross, Ph.D. \\ Ahmed Said, Ph.D. \\ Jeffrey Cunningham, Ph.D. \\ Muhammad Rahman, Ph.D. \\ Jeff Geurink, Ph.D. \\ Mark Stewart, Ph.D. \\ Billy Lewelling, B.S.
}

Date of Approval:

November 1, 2006

Keywords: rating curve, runoff, open channel flow, data management, West Central Florida, non-dimensional streamflow

(C) Copyright 2006, Auristela Mueses-Pérez 


\section{DEDICATION}

Mary Kay Ash used to say “If you think you can, you can. If you think you can’t, you’re right”. Today I know “I can” and I owe this fruit of my labor: To God for his strength and support, to Eduardo and my babies, Adriana and Alfonso, for their unconditional love and to my wonderful advisor, Dr. Mark Ross, for his help and encouragement. 


\section{ACKNOWLEDGMENTS}

The author graciously acknowledges the invaluable assistance provided by Bill

Lewelling, David Fulcher, Donald Herndon, Michael Holmes and Richard Kane, at U.S.

Geological Survey. They provided data, interpretation, and insight concerning rating

relationships and analysis that was greatly appreciated. 


\section{TABLE OF CONTENTS}

LIST OF TABLES iii

LIST OF FIGURES $\quad$ v

ABSTRACT vii

1. INTRODUCTION 1

1.1 Description of Simple Rating Curves 1

1.2 Scope of Research 2

2. LITERATURE REVIEW 5

3. DATA 11

4. METHODOLOGY 12

4.1 Identification of Most Significant Variables 12

4.2 Approaches for the Determination of the Non-Dimensional Ratings $\quad 14$

4.2.1 Approach 1: Normalization by Drainage Area 14

4.2.2 Approach 2: Normalization by Discharge and Depth $\begin{array}{ll}\text { at Full Channel } & 17\end{array}$

4.2.3 Approach 3: Normalization of Discharge and Depth at Ten Percent Exceedence Flow $\quad 19$

5. MODEL DEVELOPMENT 24

5.1 Theoretical Background for Model Development 24

5.1.1 Analysis for Simple Control Sections 26

5.1.2 Analysis for Compound Control Sections 31

5.2 Model for the Intermediate-Flow Region 34

5.3 Model for the High-Flow Region 37

6. MODEL VERIFICATION $\quad 40$

7. MODEL VALIDATION 41

8. RESULTS AND DISCUSSION 49

9. CONCLUSIONS 59 
APPENDICES

Appendix A: Results from Weir Analysis in Channel Controlled by a Horizontal_Uncontracted Section

Appendix B: Results from Weir Analysis in Channel Controlled by a Horizontal_Contracted Section

Appendix C: Results from Weir Analysis in Channel Controlled by a V-Notch Section

Appendix D: Results from Weir Analysis in Channel Controlled by a Broad Crested Weir

Appendix E: Results from Weir Analysis in Channel Controlled by a Compound Weir consisting of a V-Notch and a Trapezoidal Weir

Appendix F: Basin Characteristics Data and Relative Error for Stations in Calibration Data Set for Intermediate-Flow Region

Appendix G: Basin Characteristics Data and Relative Error for Stations in Calibration Data Set for High-Flow Region

Appendix H: Basin Characteristics Data and Relative Error for Stations in Verification Data Set for Intermediate-Flow Region

Appendix I: Drainage Area and Relative Error for Stations in Validation Data Set for Intermediate-Flow Region

Appendix J: Drainage Area and Relative Error for Stations in Validation Data Set for High-Flow Region 


\section{LIST OF TABLES}

Table 1. Ranges of Values for Hydraulic Parameters for Calibration Data

Table 2. Matrix Correlations for Discharge for Variables in the Calibration Data

Table 3. Results from the Stepwise Procedure "Maximum $\mathrm{R}^{2}$ Improvement"

Table 4. Discharge and Depth for the 10\% Discharge Exceedance and the Slope of the Corresponding Rating for Calibration Data Set

Table 5. Statistics of the Regression Model for the Intermediate Flows Region

Table 6. Ranges of Values for Hydraulic Parameters for Verification Data

Table 7. Discharge and Depth for the 10\% Discharge Exceedance and the Slope of the Corresponding Rating for Validation Data Set

Table 8. Results of T-test for 43 Stations in West-Central Florida

Table 9. Relative Percent Error for Some Stations in West-Central Florida for the Intermediate and High-Flow Region

Table 10. Results from Weir Analysis in Channel Controlled by a Horizontal_Uncontracted Section

Table 11. Results from Weir Analysis in Channel Controlled by a Horizontal_Contracted Section

Table 12. Results from Weir Analysis in Channel Controlled by a V-Notch Section

Table 13. Results from Weir Analysis in Channel Controlled by a Broad Crested Weir

Table 14. Results from Weir Analysis in Channel Controlled by a Compound Weir consisting of a V-Notch and a Trapezoidal Weir 
Table 15. Basin Characteristics Data and Relative Error for Stations in Calibration Data Set for Intermediate-Flow Region

Table 16. Basin Characteristics Data and Relative Error for Stations in Calibration Data Set for High-Flow Region

Table 17. Basin Characteristics Data and Relative Error for Stations in Verification Data Set for Intermediate-Flow Region

Table 18. Drainage Area and Relative Error for Stations in Validation Data Set for Intermediate-Flow Region

Table 19. Drainage Area and Relative Error for Stations in Validation Data Set for High-Flow Region 


\section{LIST OF FIGURES}

Figure 1. $\quad$ Location of USGS Stations in West Central Florida 4

Figure 2. Relative Discharge Versus Relative Stage for Stations in West-Central Florida for Approach 1

Figure 3. Relative Discharge Versus Relative Stage for Stations in West-Central Florida for Approach 2

Figure 4. Relative Discharge Versus Relative Stage for Stations in West-Central Florida for Approach 3

Figure 5. Correlation Between Discharge as $\mathrm{Q}_{10}$ and Drainage Area for Approach 3

Figure 6. Correlation Between Depth as $\mathrm{d}_{10}$ and Square Root of the Drainage Area for Approach 3

Figure 7. $\quad$ Relative Discharge (Log Q') Versus Relative Depth (Log d')

for the Intermediate-Flow Region

Figure 8. Relative Discharge (Log Q’) Versus Relative Depth (Log d') for the High-Flow Region

Figure 9. Q' vs. H' for Horizontal_Uncontracted Section for Varying Coefficients C

Figure 10. Q' vs. H’ for Horizontal_Contracted Section for Varying Coefficients C

Figure 11. Q’ vs. H’ for V-Notch Section for Varying Coefficients C

Figure 12. Q’ vs. H’ for Broad Crested Section for Varying Coefficients C

Figure 13. Q’ vs. H’ All Control Sections for Typical Values for C

Figure 14. Q' vs. H' for Uncontracted and V-Notch Weirs and Manning's Equation 
Figure 15. Q' vs. H' for Compound Weir Consisting of a V-Notch and a Trapezoidal

Figure 16. Generalized Log-Linear Rating Behavior $\quad 34$

Figure 17. Data and Regression Equation for $\mathrm{Q}_{10} \quad 36$

Figure 18. Data and Regression Equation for $d_{10}$

Figure 19. Data and Regression Equation for Discharge of Departure $\left(\mathrm{Q}_{\mathrm{dep}}\right) \quad 39$

Figure 20. Data and Regression Equation for Depth of Departure $\left(\mathrm{d}_{\mathrm{dep}}\right) \quad 39$

Figure 21. Location of USGS Stations in the Areas of North Florida, Georgia and Alabama

Figure 22. Data and Regression Equation for $\mathrm{Q}_{10}$ Including Validation

Data Set

Figure 23. Data and Regression Equation for $\mathrm{d}_{10}$ Including Validation Data Set

Figure 24. Relative Discharge (Log Q') Versus Relative Depth (Log d') for Stations in North Florida, Alabama and Georgia

Figure 25. Relation Between Drainage Area and Channel Slope and Water Depth $\left(\mathrm{d}_{10}\right)$ for Some Stations in Florida, Georgia and Alabama

Figure 26. Some Stations that Partially Matched the USGS Rating Data Using Approach 3

Figure 27. Comparison of USGS Rating with Model Results, for the Intermediate- Flow Region, for Some Stations in the Study Area

Figure 28. Comparison of USGS Rating with Model Results, for the High-Flow Region, for Some Stations in the Study Area 


\title{
GENERALIZED NON-DIMENSIONAL DEPTH-DISCHARGE RATING CURVES TESTED ON FLORIDA STREAMFLOW
}

\section{Auristela Mueses-Pérez}

\begin{abstract}
A generalized non-dimensional mathematical expression has been developed to describe the rating relation of depth and discharge for intermediate and high streamflow of natural and controlled streams. The expressions have been tested against observations from fortythree stations in West-Central Florida. The intermediate-flow region model has also been validated using data from thirty additional stations in the study area. The proposed model for the intermediate flow is a log-linear equation with zero intercept and the proposed model for the high-flow region is a log-linear equation with a variable intercept. The models are normalized by the depth and discharge values at 10 percent exceedance using data published by the U.S. Geological Survey. For un-gauged applications, $\mathrm{Q}_{10}$ and $\mathrm{d}_{10}$ were derived from a relationship shown to be reasonably well correlated to the watershed drainage area with a correlation coefficient of 0.94 for $Q_{10}$ and 0.86 for $d_{10}$. The average relative error for this parameter set shows that, for the intermediate-flow range, better than $50 \%$ agreement with the USGS rating data can be expected for about $86 \%$ of the stations and for the high-flow range, better than $50 \%$ for $44 \%$ of the stations. Testing the model outside West Central Florida, in some stations at North Florida, and South Alabama and Georgia, show some reasonable relative errors but not as good as the results obtained for West Central Florida. Using a model with a different slope, developed specific for those particular stations improved the results significantly.
\end{abstract}




\section{INTRODUCTION}

A discharge rating is a relationship between stage and discharge at a specific point in a river stream or lake outlet structure. The rating relations for a site are created from periodic field measurements of discharge and stage and are the industry standard for continuous flow measurement of streamflow via stream stage. These measurements are used to produce a unique mathematical relation which allows, for a particular location and usually for a period of time, continuous stage measurements to be converted into discharge. The resulting rating curves are useful for interpolating or extrapolating flow measurements and for modeling.

\subsection{Description of Simple Rating Curves}

The simplest form of a rating curve is a two-parameter stage-discharge relation. Discharge is calculated from field measurements of velocity and channel cross section. To properly develop rating curves, discharges must be measured at all representative stages, using at least 10 to 12 points covering the range of low to high flows (Gupta, 2001). If there is a direct relation between discharge and gage height, the discharge rating is called simple. A simple rating may be only one curve but is more often a compound curve consisting of three segments, one each for the low, medium and high water ranges (Kennedy, 1984). 
A simple stage-discharge relation has a power form given by the following equation:

$$
Q=A(h \pm a)^{n}
$$

where,

$\mathrm{Q}=$ discharge

$\mathrm{h}$ = gage height

$\mathrm{a}=$ gage height at zero flow

$\mathrm{A}, \mathrm{n}=$ constants

When plotting this equation in log-log paper, the rating is transformed to a straight line. A straight line is preferred because (1) it can be extended or extrapolated, and (2) it can be described by a simple mathematical equation (Gupta, 2001).

The resulting stage-discharge curve represents $\mathrm{Q}$ as a function of stage, datum correction, channel slope and Manning’s Coefficient (n). The procedure is costly and time consuming, and dangerous or impractical during high floods. Thus typically, streamflow rating only exists for limited station locations and with limited data at high flow conditions.

\subsection{Scope of Research}

As it will make clear from the literature review, most of the conventional methods to determine stage-discharge ratings are based on open channel flow, uniform flow and Manning's equation and channel properties. These methods require a roughness coefficient, estimation for the channel cross sectional area and slope, field survey measurements, or some other data specific to the channel. The difficulty in estimating an 
adequate Manning's roughness coefficient or discharge coefficient incorporates some uncertainty to these empirical models. Also, channel cross sectional flow data is expensive to acquire and often is not available, particularly for un-gauged streams, limiting the widespread use of these methods.

Although the existing methodologies cited in the references explain general concepts and traditional approaches to determine rating curves such as the variables involved in the ratings, scaling factors and non-dimensional parameters, and discharge as a function of area, none of the mentioned studies investigated non-dimensional discharge rating curves related to watershed characteristics.

This study proposes a generalized mathematical expression to describe nondimensional depth-discharge relations from the perspective of the watershed characteristics, particular flow indices and the general behavior of stage-discharge curves. Forty-three stations in West-Central Florida have been analyzed. Locations of USGS stations in West Central Florida are shown in Figure 1. Data used in this study were obtained from USGS known rating data reported between 1987 and 1998 and correspond to the best fit rating curves used by USGS to translate stage to discharge. The accuracy of the prediction capability of the proposed model is evaluated using statistical errors of the estimated values compared to USGS rating data. 


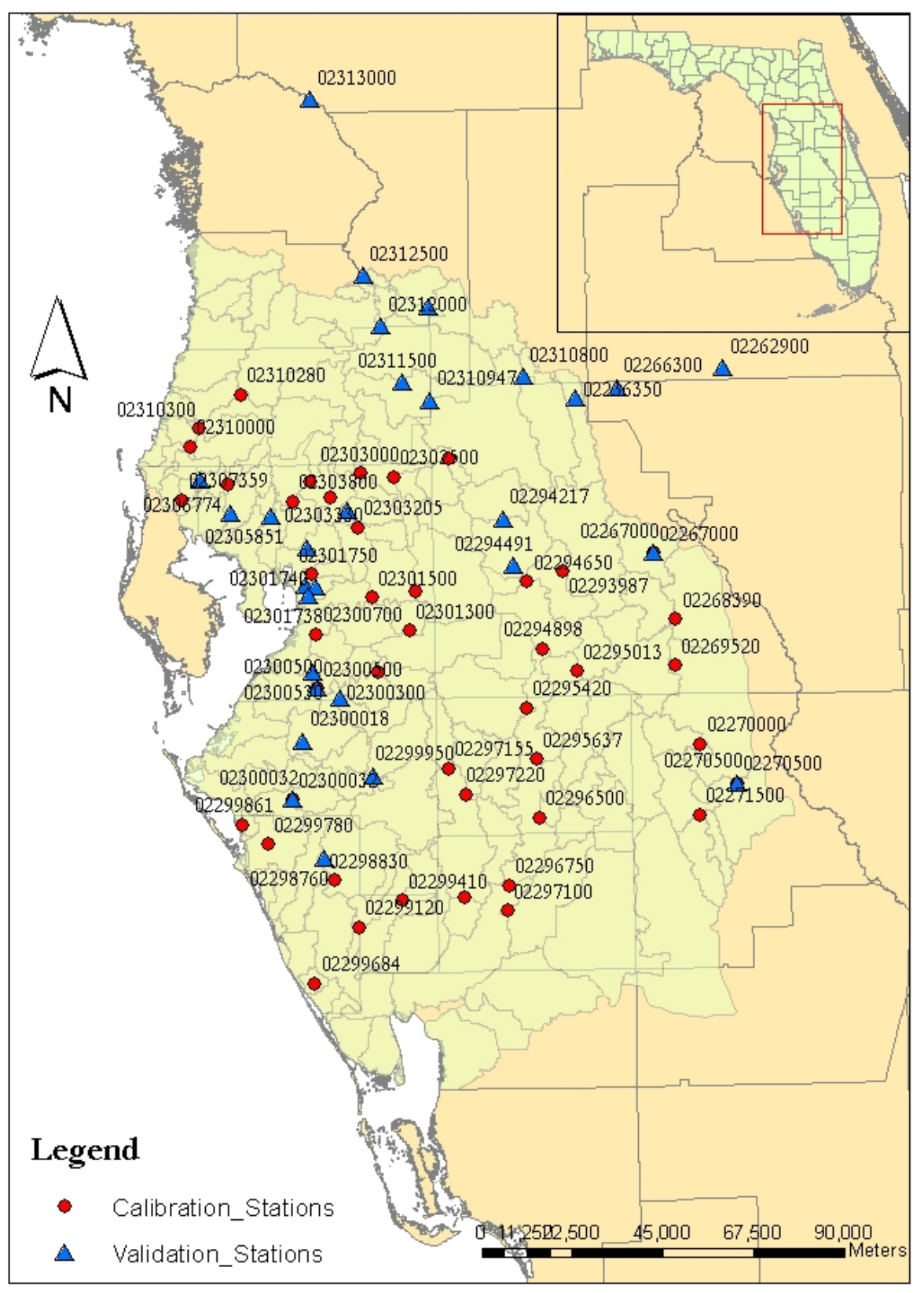

Figure 1. Location of USGS Stations in the West Central Florida 


\section{LITERATURE REVIEW}

Several methods have been studied to explain the empirical relation among the variables involved in the rating relations. Most of these methods have been developed by the U.S. Geological Survey and are summarized in the work by Kennedy (1984) and Rantz et al. (1982), among others.

Many of the current empirical methodologies that explain the relationship between the variables involved in the rating curves define the relation between the stage and discharge by assuming the discharge as uniform open channel flow with constant slope, and incorporating the Manning's equation and roughness coefficient (Kennedy, 1984; Rantz et al., 1982; Atabay and Knight, 1999; Dawdy et al., 2000). Others have treated the discharge as flow in a constricted weir section (Kennedy (1984), Rantz et al (1982)).

Although the rating curves are commonly used to convert stage into discharge, the literature recognized that there are errors associated with the development of ratings curves. Dymon and Christian (1982) identified three types of errors influencing the random error of a single discharge measurement. These were rating curve error, water level measurement errors and an error caused by ignoring the physical parameters that affect discharge. They reviewed the methods for evaluating the three types of errors. Similarly, Tillery et al. (2001) derived potential errors for individual measurements and rating relations for 17 stations in Arizona. In the study, they explored the errors 
associated with developing rating curves based on direct measurements of discharge and stage, indirect measurements of discharge and theoretical weir and culvert computations. They concluded that errors are greater when based on indirect measurements.

In more recent attempts at defining a theoretical relation based on the channel properties Dingman et al. (1997) proposed a multiple-regression equation that is independent of the roughness coefficient. The discharge is described in terms of the cross sectional area, hydraulic radius and water surface slope. Dingman (1999) extended his work to incorporate acquisition of remotely sensed channel data. The method can be applied to un-gauged streams in the New Hampshire area, with values of width and slope similar to the ones considered in developing the model.

The idea of non-dimensional stage-discharge rating curves has not been widely studied. Some investigations involving scaling factors for discharge were made by Ervine et al. (1993), Savage et al. (2001), and Sivapalan et al. (2001). Ervine et al. (1993) used a non-dimensional discharge coefficient to quantify the effect of the main parameters affecting conveyance in meandering compound river channels. Bruce et al. (2001) used non-dimensional discharge curves to compare results from their study on flow parameters calculation over a standard ogee-crested spillway using a physical model, a numerical model and existing literature. Sivapalan et al. (2002) used a scaling relationship based on area to explain the non-linear response of the watershed due to the dependence of a catchment hydrological property on area. A recent investigation by Shesha et al. (2003) developed a generalized linear head-discharge relationship for flow over sharp-crested inclined inverted V-notch weirs. In those studies, the scaling factor was introduced to present and compare their results and not as part of the methodology. 
Another investigation describing a theoretical expression for non-dimensional rating relations was made by Kamula (2000). He established a new procedure for fish ways design and suggested a different equation for each of the main existing fish way types. In his procedure, he created a general scaling equation for dimensionless discharges, based on the depth of flow over the weir and the effect of pool length (Kamula, 2000).

The determination of discharge from theoretical ratings considering the effect of unsteady, non-uniform flow in the stage-discharge relation was examined by Schmidt (2002). In his work, Schmidt addressed the rating hysteresis problem and the effects of different downstream backwater conditions. The rating relations are calculated from Hydraulic Performance Graphs (HPG) curves and require the channel cross section and the stage data points at each end of a stream reach. Westphal et al. (1999) also explored the hysteresis effect by recognizing that stage-discharge relations for the rating curve are not single-valued, in measurements in the Middle Mississippi River. He also attributed to replication errors as the possible cause for the stage-discharge pattern.

Some investigations present methodologies to determine discharge and stage in ungauged stations. Moramarco and Singh (2001) proposed a simple method for relating local stage and remote discharge. The method reconstructs the discharge hydrograph at a river section, based on water level recorded at the cross section and a discharge value recorded at another upstream cross section. Results show the method as reliable when the hydraulic conditions at the site are unknown. Similarly, Franchini et al. (1999) proposed a methodology for synthesizing the rating curve provided with stage data, when a reliable rating curve and stage data is available in an upstream cross section. The proposed 
methodology uses the Muskingum-Cunge model for routing the flood wave to the site of interest. Szilagyi et al. (2003) proposed a similar approach but using a reservoir-cascadetype formulation. The method allows for stage predictions using physically based flow routing of known discharges from an upstream station, in river sections where no values of discharge are available.

Some studies explored the adequacy of the rating curves in converting water levels to flow rates for high flows. Fenton and Keller (2001) found that rating curves errors impose severe limitations in developing methods to estimate floods due to the bias introduced at site and regional flood frequency estimates. They proposed some improvements in the existing practices to be able to obtain a more reliable estimate of high flows. On the same topic, Lewis (1998) proposed some enhancements of river flood forecasts by using a dynamic hydraulic flow routing technique to properly extend the rating curve to account for hydraulic conditions that may cause overbank flow.

Jothityangkoon and Sivapalan (2003) investigated changes in the rating curve due to the effects of overbank flows during the transition from normal to high flows. The authors attributed the changes in the rating to the effects in the interactions between the main channel and floodplain sections and proposed a distributed flood routing model based on non-linear storage-discharge relationship to account for the effects.

Discharge has also been calculated based on channel characteristics of streams. This is particularly useful for ungauged streams where a bankfull channel can be identified by use of field indicators and related to discharge. Cinotto (2003) used channel dimensions to develop regional curves from the regression analyses of the relations between drainage area and the cross-sectional area, mean depth, width, and streamflow of 
the bankfull channel (Cinotto, 2003) at 14 stations in Pennsylvania and Maryland. The analysis showed bankfull cross sectional area and bankfull discharge with the strongest correlation to drainage area. Bankfull width and depth showed a moderate linear correlation to area.

Leopold and Maddock back in 1953 already recognized the physiographic implications of the hydraulic geometry of stream channels. In their study, they related discharge and some hydraulic characteristics of a given cross section - depth, width, velocity and suspended load - with a power function. They found that in a hydrologically homogeneous region there is a pattern when plotting these hydraulic characteristics against discharge. Interestingly, they also found that among the stations, the respective lines are generally parallel. The station curves differed much in ordinate but were similar in slopes. The rest of the study focused on exploring the relations of depth, with and velocity as a function of the load transported in the channel.

Some studies involving basin characteristics were developed using the U.S. Geological Survey (USGS) flood-regionalization procedures (in Florida, Hammet and DelCharco, 2005) that relate flood characteristics to watershed and climatic characteristics through the use of regression analysis. These equations use hydrologic characteristics like drainage area, channel slope, percent wetlands and rainfall, to estimate the magnitude of flows for specific recurrence interval, such as the 2-, 10-, 25-, 50-, 100-, and 500-year. These procedures are particularly useful for predicting or estimating flood flows at stream sites where little or no streamflow information is available. These equations do not represent a stage-discharge rating relation and are limited to specified recurrence intervals. 
Mazvimavi et al. (2006) also explored the influence of basin characteristics on the spatial variation of river flows. The study investigated the correlation of three basin characteristics and river flows. The study identified mean annual precipitation, mean annual potential evaporation and median slope as the most important basin characteristics affecting the variation of river flows.

More complex analyses have been done using artificial neural network (ANN) and fuzzy neural network (FNN). ANN has been widely used in water-related research with reasonable good results. Bhattacharya and Solomatine (2000) applied ANN to develop a stage-discharge relationship for river Bhagirathi in India. The model provided a solution to the random fluctuations often exhibited by the ratings by using more data generated from the ANN model. Deka and Chandramouli (2003) presented a FNN model to derive a stage-discharge relationship. The study shows the advantage of using a FNN approach by simplifying the amount of information required in terms of the number of inputs. The study also shows that the FNN model has a better prediction ability that the single ANN and conventional methods. However, despite the high efficiency of ANN's and FNN's in modeling non-linear relationships, creating and training the network is still complex and difficult to interpret. 


\section{DATA}

Forty-three stations located in West-Central Florida were used to develop the model as the calibration-data set. The verification data-set consisted of thirty additional stations, also within the West Central Florida study area. Following standard practice, the stations in the verification data set were not used to develop the model. Stations in the calibration and verification data set were selected randomly, based on the stations where rating and basin characteristics data were available.

Table 1 gives the range of values for hydraulic parameters for the calibration data set. Locations of all USGS stations in the study area are shown in Figure 1. The rating data for the calibration set corresponds to USGS known data reported between 1987 and 1998. Data for the verification set corresponds to the rating data actually in use by the USGS for 2005-2006.

Table 1. Ranges of Values for Hydraulic Parameters for Calibration Data

\begin{tabular}{lcccccc}
\hline Parameter & & Units & Mean & Std Dev & Minimum & Maximum \\
\hline Discharge & Q & CMS & 31 & 64 & 0 & 790 \\
\hline Depth & d & $\mathrm{m}$ & 1.99 & 1.44 & 0.03 & 6.65 \\
\hline Drainage Area & $\mathrm{A}$ & $\mathrm{Sq} . \mathrm{mi}$ & 138.32 & 214.31 & 4.3 & 1373 \\
\hline Channel Slope & $\mathrm{ChS}$ & $\%$ & 3.41 & 1.62 & 1.23 & 7.01 \\
\hline Watershed Slope & $\mathrm{S}$ & $\mathrm{m} / \mathrm{m}$ & 0.00743 & 0.00426 & 0.001 & 0.025 \\
\hline \%Wetland & $\mathrm{W}$ & $\%$ & 18.58 & 8.22 & 5.1 & 36.82 \\
\hline DTWT & $\mathrm{WT}$ & $\mathrm{m}$ & 1.19 & 0.24 & 0.92 & 2.07 \\
\hline
\end{tabular}




\section{METHODOLOGY}

\subsection{Identification of Most Significant Variables}

To identify all variables that could be considered as most significant predictors for the

model, a statistical analysis was performed using the SAS statistical software package. The six watershed characteristics considered as potential predictors of discharge were: water depth, drainage area, percent wetlands, depth to water table, watershed slope and channel slope. A correlation matrix was constructed using values of $\mathrm{Q}_{10}$ for discharge and $d_{10}$ for depth, because these were measured values at each station. The average $10 \%$ exceedence discharge values, $\mathrm{Q}_{10}$, and corresponding depths, $\mathrm{d}_{10}$, are readily available (i.e. normally reported) for measured flow stations from annual data summaries and published rating tables, respectively. The $\mathrm{Q}_{10}$ value was taken from the station record, from the Water Resources Data of Florida, USGS (2003). The average depth corresponding to that discharge was calculated from the published USGS rating for that station. Table 2 summarizes the correlations among the variables in the calibration data; results showed water depth and drainage area with the highest correlation to discharge. However, the correlation was very low to other expected parameters including basin slope and percent wetlands.

A least square regression analysis was used to develop the discharge model. The stepwise procedure “maximum $\mathrm{R}^{2}$ improvement” in SAS was used to identify which of the potential predictor variables besides water depth, would be included in the regression 
model. The stepwise procedure combines the variables to develop the best two-variable model, three-variable model and so forth, that produces the highest correlation coefficient $\mathrm{R}^{2}$. Other statistical measurements as $\mathrm{Cp}$ and F-value were also used to define the best model. The stepwise procedure was performed using the rating data from the 43 stations in the study area. Results from this analysis (Table 3) showed that, again, the most significant variables are water depth and drainage area; any additional variable included did not improve the $\mathrm{R}^{2}$ significantly. Thus, the model development focused on a twovariable model including only water depth and drainage area.

Table 2. Matrix Correlations for Discharge for Variables in the Calibration Data

\begin{tabular}{cccccccc}
\hline & $\mathrm{Q}$ & $\mathrm{d}$ & $\mathrm{A}$ & $\mathrm{ChS}$ & Slope & $\mathrm{W}$ & $\mathrm{WT}$ \\
\hline $\mathrm{Q}$ & 1.00 & 0.77 & 0.97 & -0.42 & 0.07 & -0.07 & 0.02 \\
\hline $\mathrm{d}$ & 0.77 & 1.00 & 0.70 & -0.26 & -0.13 & -0.14 & 0.06 \\
\hline A & 0.97 & 0.70 & 1.00 & -0.45 & 0.21 & -0.05 & 0.08 \\
\hline ChS & -0.42 & -0.26 & -0.45 & 1.00 & -0.06 & -0.45 & 0.09 \\
\hline S & 0.07 & -0.13 & 0.21 & -0.06 & 1.00 & -0.20 & 0.57 \\
\hline W & -0.07 & -0.14 & -0.05 & -0.45 & -0.20 & 1.00 & -0.07 \\
\hline WT & 0.02 & 0.06 & 0.08 & 0.09 & 0.57 & -0.07 & 1.00 \\
\hline
\end{tabular}

Table 3. Results from the Stepwise Procedure "Maximum $\mathrm{R}^{2}$ Improvement"

\begin{tabular}{llccc}
\hline \multicolumn{1}{c}{ Variables } & $\mathrm{R}^{2}$ & $\mathrm{Cp}$ & F value \\
\hline $\mathrm{Q}$ & 0.46 & 203.2 & 802.4 \\
\hline $\mathrm{d}, \mathrm{A}$ & 0.55 & 12.3 & 576.5 \\
\hline $\mathrm{d}, \mathrm{A}, \mathrm{S}$ & 0.55 & 8.7 & 388.0 \\
\hline $\mathrm{d}, \mathrm{A}, \mathrm{S}, \mathrm{ChS}$ & 0.55 & 7.8 & 292.4 \\
\hline $\mathrm{d}, \mathrm{A}, \mathrm{S}, \mathrm{ChS}, \mathrm{W}$ & 0.55 & 5.3 & 235.6 \\
\hline $\mathrm{d}, \mathrm{A}, \mathrm{S}, \mathrm{ChS}, \mathrm{W}, \mathrm{WT}$ & 0.55 & 7.0 & 196.3 \\
\hline
\end{tabular}




\subsection{Approaches for the Determination of the Non-Dimensional Ratings}

Three different approaches were examined for the determination of a non-dimensional relationship between discharge and depth. The approaches are explained below.

\subsubsection{Approach 1: Normalization by Drainage Area}

It was first hypothesized that discharge and depth could be normalized as a function of basin drainage area and total annual rainfall. The logic for this was that discharge would increase by increasing drainage area and/or increased long term annual rainfall if all other factors were equal. Hence, the stream cross section characteristics and resulting rating would be function of these variables. The general non-dimensional equations for discharge and depth for this hypothesis are given by:

$$
\begin{aligned}
& Q^{\prime}=\frac{Q}{R A} \\
& d^{\prime}=\frac{d}{A^{0.5}}
\end{aligned}
$$

where $Q^{\prime}$ is dimensionless (relative) discharge, $Q$ is measured discharge $\left(\mathrm{L}^{3} \mathrm{~T}^{-1}\right), R$ is annualized rainfall intensity $\left(\mathrm{LT}^{-1}\right), A$ is watershed area $\left(\mathrm{L}^{2}\right), d^{\prime}$ is dimensionless (relative) water depth and $d$ is stream water depth (L). For the analysis, annualized rainfall intensity was assumed constant, considering that the long-term annual rainfall intensity in West-Central Florida was fixed and readily determined from gage record.

A fundamental departure from USGS rating curves was that the proposed relation in Equation (2) uses depth of water instead of stage elevation. This is desirable because:

- $\quad$ The stream stage is measured from an arbitrary datum that is not always defined to a standard datum, e.g., National Geodetic Vertical Datum of 1929 (NGVD-29). 
This makes it difficult to correlate to a reference when using a generalized relation in an un-gauged stream (i.e., the streambed elevation are not known).

- Equations that define the hydraulic behavior of streams are based on depth, thus this would be more realistic in terms of the physical representation of the system.

- Live bed environments typical of natural streams are always changing, greatly affecting low flows. However, it was hypothesized that the streambed inverts change while, on a long-term basis in natural channels, similar slope and friction conditions prevail. Thus, absolute depths should be similar in long-term record to maintain a fixed Q (d) relationship.

The use of water depth instead of stage is inconvenient since a change in depth (as hydraulic depth) does not necessarily produce the corresponding change in discharge, as opposed to measured stage. For example, the average hydraulic depth may decrease as the flow transitions out-of-banks in increasing flood flow conditions. This will result in a misrepresentation of the rating relation. To overcome this inconvenience, an effective depth (d) related to stage was defined using the following equation:

$$
d=d_{0}+\left(h-h_{0}\right)
$$

where,

$\mathrm{d}=$ effective depth $(\mathrm{L})$

$\mathrm{d}_{0}=$ minimum hydraulic depth (L)

$\mathrm{h}=$ stage $(\mathrm{L})$

$\mathrm{h}_{0}=$ stage at zero flow $(\mathrm{L})$ 
The minimum hydraulic depth was estimated from USGS field data, where depths are the average values calculated from cross sectional area and channel width. The stage is the data point from the USGS rating curves and the relative stage at zero flow was determined from the USGS rating data.

The relative discharge and depth were used to derive a log-linear relation of the form:

$$
\log Q^{\prime}=m \log d^{\prime}+b
$$

In this general relationship, the values of the parameters $m$ and $b$ must accurately represent the overall behavior of the stage-discharge ratings for a great number of stations. Figure 2 shows the relative discharge versus relative depth for all stations used in this study, using the USGS rating data. Noteworthy is that most of the stations have similar slopes. This gives credibility to the idea that a unique relation can be determined to represent the depth-discharge characteristics of many stations. An average value of the slopes and intercepts was used as the $m$ and $b$ parameters for the generalized nondimensional relation. The final equation is defined as:

$$
\log Q^{\prime}=1.72 \log d^{\prime}+6.79
$$

Results from this model were compared to the USGS rating data. Some stations provided a "good fit" for only a portion of the data, other stations differed completely. Discharge values estimated with the model were subtracted from the USGS known rating data and divided by the USGS data to obtain the relative error. The average relative error 
compared to the USGS data varied from $18 \%$ to $50 \%$ for $46 \%$ of the stations, $51 \%$ to $100 \%$ in $30 \%$ of the stations and more than $100 \%$ in the remaining $24 \%$.

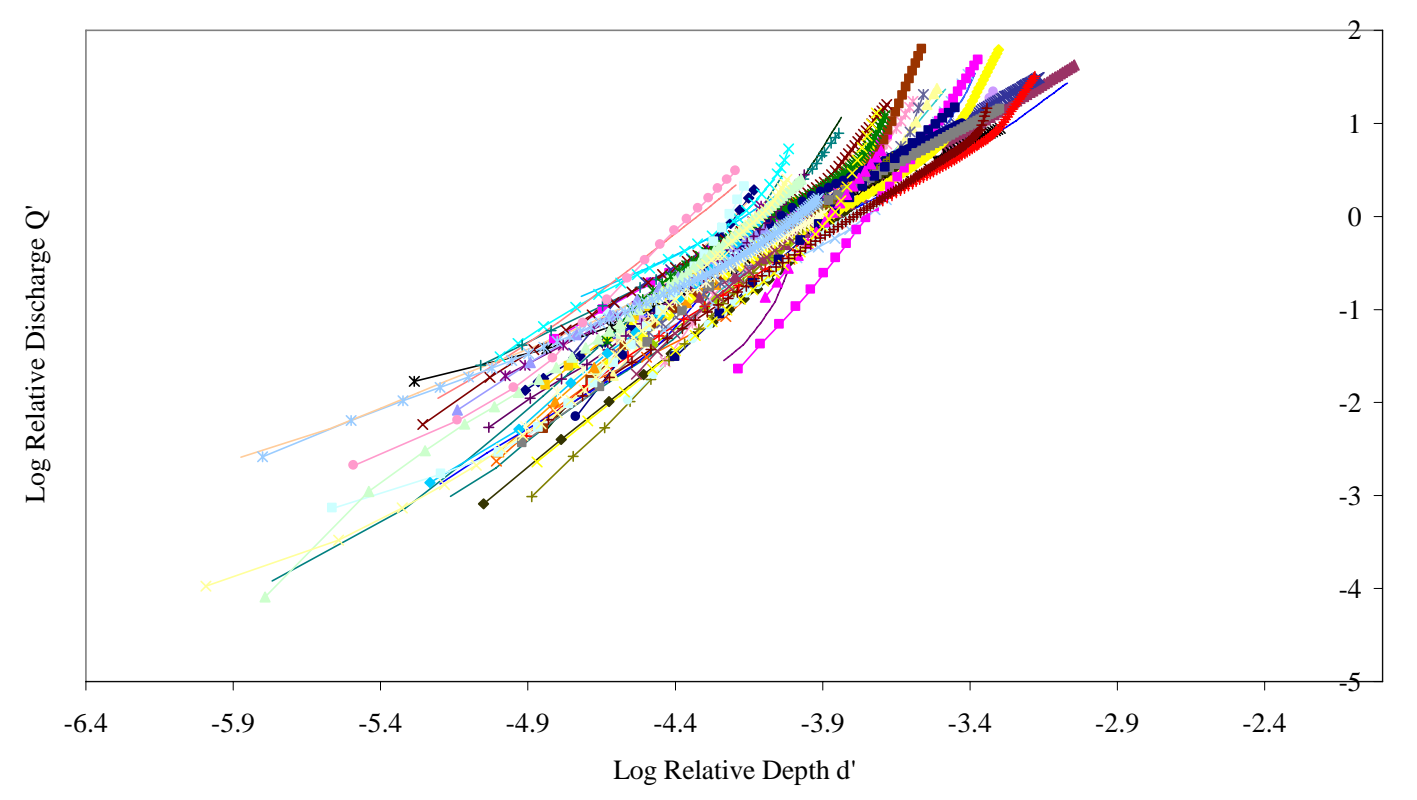

Figure 2. Relative Discharge Versus Relative Depth for Stations in West-Central Florida for Approach 1

\subsubsection{Approach 2: Normalization by Discharge and Depth at Full Channel}

Discharge and depth were normalized as a function of discharge and depth at full channel flow within banks. These two parameters were approximated from the rating data, as the point where a change in the rating slope occurs (rating break point). The general nondimensional equations for discharge and depth are given by:

$$
\begin{aligned}
& Q^{\prime}=\frac{Q}{Q_{\text {full }}} \\
& d^{\prime}=\frac{d}{d_{\text {full }}}
\end{aligned}
$$


where $Q^{\prime}$ is dimensionless (relative) discharge, $Q$ is measured discharge $\left(\mathrm{L}^{3} \mathrm{~T}^{-1}\right), Q_{\text {full }}$ is discharge at full channel bank flow $\left(\mathrm{L}^{3} \mathrm{~T}^{-1}\right), d^{\prime}$ is dimensionless (relative) water depth, $d$ is stream water depth (L) and $d_{\text {full }}$ is water depth at full channel bank flow (L). As in the first approach, equation (7) is described in terms of depth of water instead of stage.

The generalized relation based on relative discharge and depth was defined with a log-linear equation as in Approach 1. For this model, the non-dimensional dischargedepth relation was defined with zero intercept. Figure 3 shows the relative discharge versus relative depth for all stations under study, using the USGS rating data. A general value for slope was defined and the final equation for this approach is:

$$
\log Q^{\prime}=1.9 \log d^{\prime}
$$

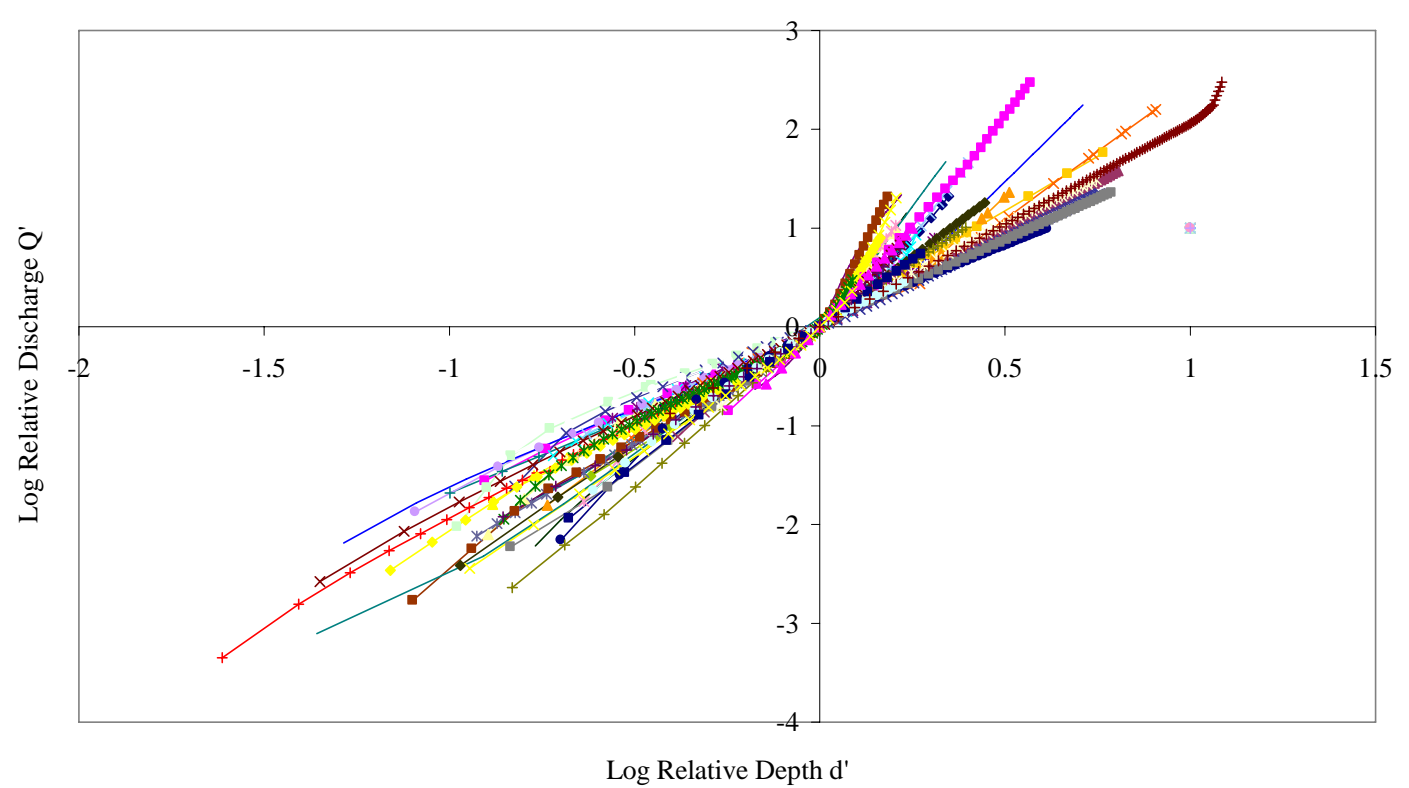

Figure 3. Relative Discharge Versus Relative Depth for Stations in West-Central Florida for Approach 2 
A value of discharge and depth at full channel banks is required to generate the rating in un-gauged stations. Known values of discharge at full channel banks were related to drainage area and known values of depth were related to the square root of the drainage area. The resulting trend line showed a small correlation of the two parameters, 0.45 for discharge and 0.20 for depth.

Results from this model were compared to the USGS rating data. As in the first approach, some stations matched a portion of the data, while other stations completely differed. The average relative error compared to the USGS data varied from 8 to $50 \%$ for $33 \%$ of the stations, 51 to $100 \%$ in $26 \%$ of the stations and more than $100 \%$ in the remaining 41\% (poorer performance than Approach 1).

\subsubsection{Approach 3: Normalization of Discharge and Depth at Ten Percent \\ Exceedence Flow}

Discharge and depth were normalized as a function of the value of the discharge reported to be exceeded ten percent of the time and the corresponding depth. The rationale for selecting the ten percent exceedance value as the scaling factor, is that most rivers in the West Central Florida area have well defined incised channels and most discharges at or below the $90^{\text {th }}$ percentile $(10 \%$ exceedance) are contained within banks (Lewelling, 2004). Because bankfull discharge typically increases with drainage area, high flow values as $\mathrm{Q}_{10}$ in this case, were considered to represent a better relation to drainage area. For streams with relatively high friction of groundwater flow, $\mathrm{Q}_{10}$ is also indicative of a runoff dominated flow period. 
The general non-dimensional equations for discharge and depth are given by:

$$
\begin{aligned}
& Q^{\prime}=\frac{Q}{Q_{10}} \\
& d^{\prime}=\frac{d}{d_{10}}
\end{aligned}
$$

where $Q^{\prime}$ is dimensionless (relative) discharge, $Q$ is measured discharge $\left(\mathrm{L}^{3} \mathrm{~T}^{-1}\right), Q_{10}$ is discharge exceeded ten percent of time $\left(\mathrm{L}^{3} \mathrm{~T}^{-1}\right), d^{\prime}$ is dimensionless (relative) water depth (L), $d$ is stream water depth and $d_{10}$ is water depth corresponding to the $10 \%$ discharge exceedence (L). As in the previous approaches, the relative depth is described in terms of depth of water instead of stage.

The generalized relation based on relative discharge and depth was also defined with a log-linear equation with zero intercept. Table 4 shows data of discharge and depth for the $10 \%$ discharge exceedance and the slope of the corresponding relative discharge versus relative depth rating, for the thirty-five stations where data were available. A very high correlation coefficient of 0.996 was obtained from the fitted USGS data for this approach using specific slopes (Slope ${ }_{10}$ in Table 4). Thus, these slopes represent the rating of each particular station quite well. Plots of these ratings are shown in Figure 4. The slope was defined and the final equation for this approach is:

$$
\log Q^{\prime}=1.77 \log d^{\prime}
$$

A value of discharge and depth exceeded $10 \%$ of the time was required to generate the rating in un-gauged stations. Known values of discharge as $\mathrm{Q}_{10}$ were related to drainage area and values of depth as $d_{10}$ were related to the square root of the drainage 
area. The resulting trend line showed a better correlation of the two parameters, 0.94 for discharge and 0.62 for depth. Figures 5 and 6 show data and trend line for discharge and depth, respectively.

Table 4. Discharge and Depth for the 10\% Discharge Exceedance and the Slope of the Corresponding Rating for Calibration Data Set

\begin{tabular}{|c|c|c|c|c|c|}
\hline ID & USGS Station Name & $\begin{array}{c}\text { USGS } \\
\text { Gage \# }\end{array}$ & Slope $_{10}$ & $\begin{array}{c}\mathrm{Q}_{10} \\
\text { (CMS) }\end{array}$ & $\begin{array}{l}\mathrm{d}_{10} \\
(\mathrm{~m})\end{array}$ \\
\hline 5 & Payne Creek Nr Bowling Green, Fl & 2295420 & 1.34 & 7.5 & 1.3 \\
\hline 6 & Peace River At Fort Meade, Fl & 2294898 & 1.73 & 15.5 & 1.8 \\
\hline 7 & Peace River At Arcadia Fl & 2296750 & 1.74 & 76.5 & 2.8 \\
\hline 8 & Little Manatee River Nr Wimauma, Fl & 2300500 & 1.72 & 11.0 & 1.9 \\
\hline 9 & Little Manatee River Nr Ft. Lonesome Fl & 2300100 & 1.72 & 2.2 & 1.3 \\
\hline 10 & North Prong Alafia River At Keysville Fl & 2301000 & 2.1 & 8.5 & 1.8 \\
\hline 11 & Alafia River At Lithia Fl & 2301500 & 1.67 & 20.5 & 1.9 \\
\hline 12 & Peace River At Bartow Fl & 2294650 & 2.57 & 17.1 & 1.6 \\
\hline 13 & Horse Creek Nr Myakka Head Fl & 2297155 & 1.6 & 2.1 & 0.8 \\
\hline 15 & Charlie Creek Nr Gardener, Fl & 2296500 & 1.98 & 21.2 & 2.4 \\
\hline 16 & South Prong Alafia River Nr Lithia, Fl & 2301300 & 1.9 & 6.3 & 1.5 \\
\hline 17 & Horse Creek Nr Arcadia, Fl & 2297310 & 1.9 & 15.0 & 2.4 \\
\hline 18 & Peace River At Zolfo Spring, FL & 2295637 & 1.61 & 41.1 & 2.6 \\
\hline 19 & Trout Creek Near Sulphur Springs Fl & 2303350 & 2.34 & 1.6 & 0.7 \\
\hline 20 & Cypress Creek At Worthington Gardens FL & 2303420 & 2.37 & 3.6 & 1.3 \\
\hline 21 & Peace Canal Nr. Wahneta & 2293987 & 2.48 & 9.0 & 1.3 \\
\hline 22 & Bowlegs Creek Nr. Ft. Meade & 2295013 & 2.27 & 2.2 & 0.9 \\
\hline 24 & Joshua Creek@ Nocatee & 2297100 & 2.19 & 7.8 & 1.7 \\
\hline 28 & Myakka River Nr Sarasota & 2298830 & 2.71 & 19.4 & 2.0 \\
\hline 29 & Deer Prairie@Power Line & 2299120 & 2.6 & 3.8 & 1.3 \\
\hline 30 & Big Slough Canal Nr Myakka & 2299410 & 2.29 & 2.7 & 1.0 \\
\hline 31 & Walker Creek Nr Sarasota & 2299861 & 1.92 & 0.4 & 0.4 \\
\hline 35 & Braden River Nr Lorranie & 2300032 & 1.91 & 2.4 & 1.2 \\
\hline 38 & Bullfrog Creek Near Wimauwa & 2300700 & 1.95 & 2.3 & 1.0 \\
\hline 41 & Blackwater Ck Nr Knights & 2302500 & 1.84 & 5.3 & 0.9 \\
\hline 42 & Hills R. Nr Zephyrhills & 2303000 & 1.96 & 14.9 & 1.6 \\
\hline 43 & Baker Creek At Mcintosh Ro & 2303205 & 2.22 & 1.2 & 0.5 \\
\hline 48 & Delaney Creek Nr Tampa & 2301750 & 2.74 & 0.7 & 0.4 \\
\hline 50 & Tiger Creek Nr Babson Park & 2268390 & 2.53 & 1.9 & 0.9 \\
\hline 51 & Livingston Ck Nr Frostproof & 2269520 & 1.91 & 3.7 & 1.1 \\
\hline 52 & Carter Creek Nr Sebring & 2270000 & 2.64 & 1.5 & 1.0 \\
\hline 53 & Josephine Ck Nr Desoto & 2271500 & 2.3 & 4.8 & 1.1 \\
\hline 57 & Brooke Creek@ Van Dyke & 2307200 & 2.85 & 0.3 & 0.4 \\
\hline 62 & Anclote River Near Elfers & 2310000 & 2.1 & 4.9 & 1.7 \\
\hline 63 & Pitha R. Nr Fivay Junction & 2310280 & 2.7 & 0.5 & 0.4 \\
\hline
\end{tabular}




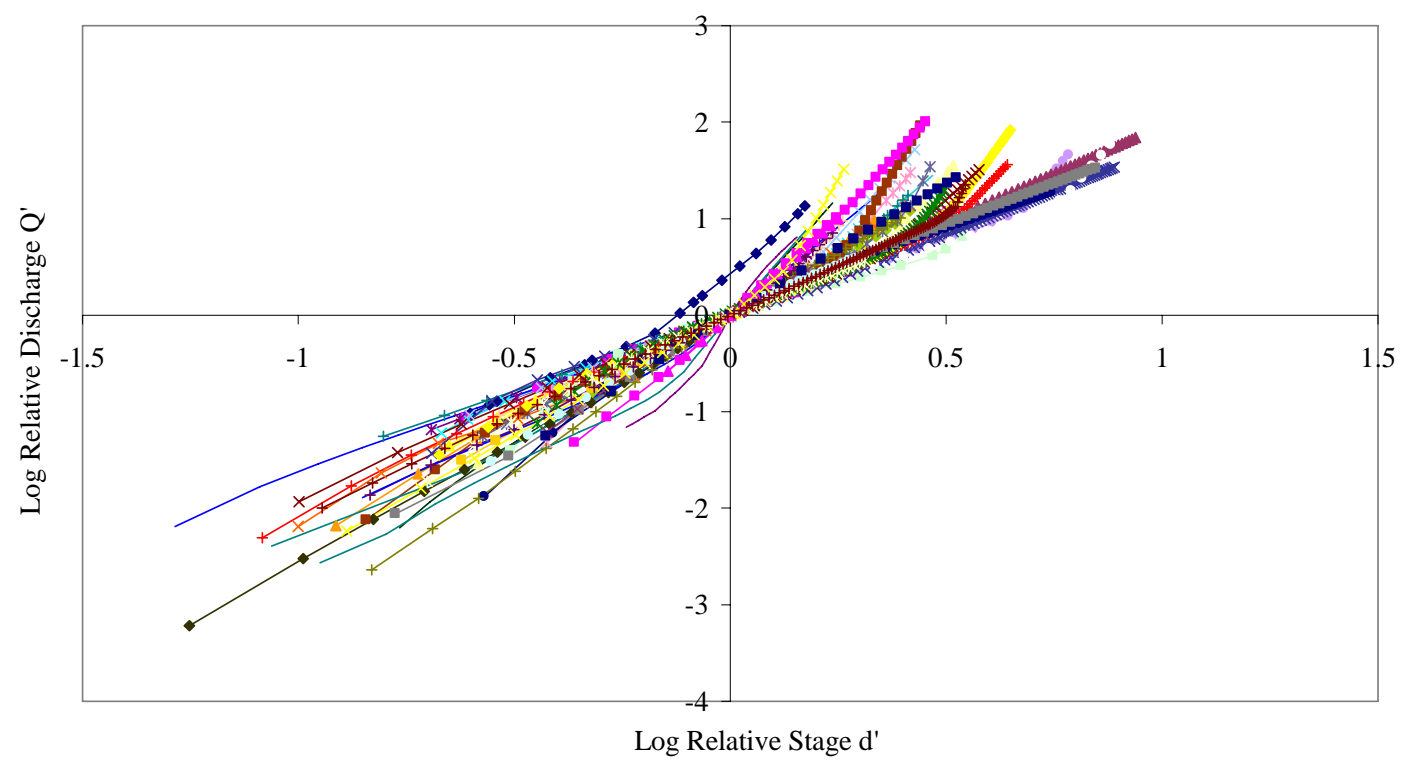

Figure 4. Relative Discharge Versus Relative Depth for Stations in West-Central Florida for Approach 3

Results from this model were compared to the USGS rating data. As in the previous approaches, some stations provided a good fit while others completely differed. However, in this approach, the general model matched a larger portion of the data compared to the other approaches. This supports the idea that this model could better represent a larger range of the stream depth-discharge behavior. The average relative error compared to the USGS data varied from 20 to $50 \%$ for $42 \%$ of the stations, 51 to $100 \%$ in $48 \%$ of the stations and more than $100 \%$ in the remaining $10 \%$. 


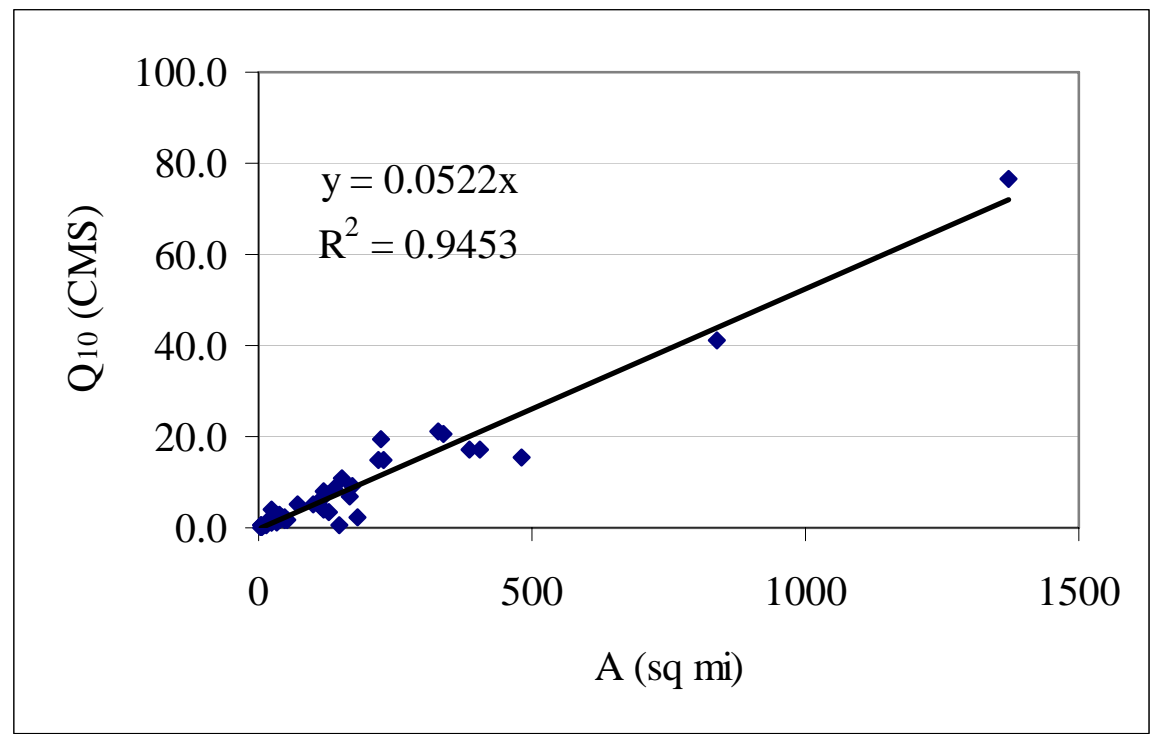

Figure 5. Correlation Between Discharge as $\mathrm{Q}_{10}$ and Drainage Area for Approach 3

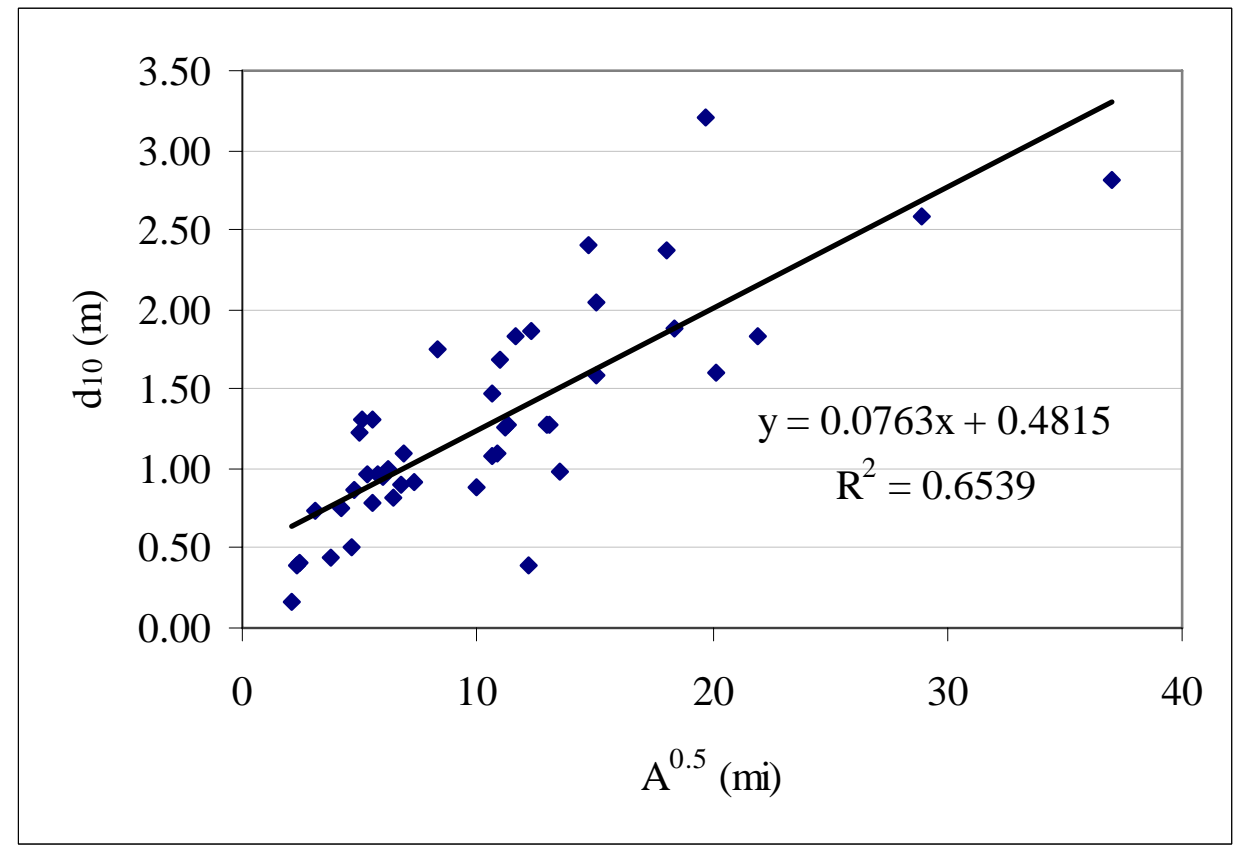

Figure 6. Correlation Between Depth as $\mathrm{d}_{10}$ and Square Root of the Drainage Area for Approach 3 


\section{MODEL DEVELOPMENT}

From the analysis of the three different approaches, it is recognized that even though the slopes in the intermediate-flow region have a similar behavior, they vary within a specific range (Figure 7). Also, the high-flow regions exhibited log-linear behavior with considerably different slopes than the intermediate-flow regions (Figure 8). Based on this, two different mathematical relationships are proposed for each of the flows regions.

\subsection{Theoretical Background for Model Development}

Certain physical characteristics at the gauging section or in the channel bed, known as station controls, stabilize the stage and discharge relation (Gupta, 2004). It is common practice to locate the streamflow gauging station in a section control with the purpose of making the rating more stable. A section control can be a natural or man-made obstruction, such as a riffle, rock, weir or spillway. For engineered structures as in the case of weirs and spillways, by creating an obstruction, critical depth is forced to occur and a unique relationship between stage and discharge results. This simple relation between stage and discharge also exists for natural obstructions. The control characteristics of the station will determine the particular features of the gauging site rating curve, including the rating slope. 


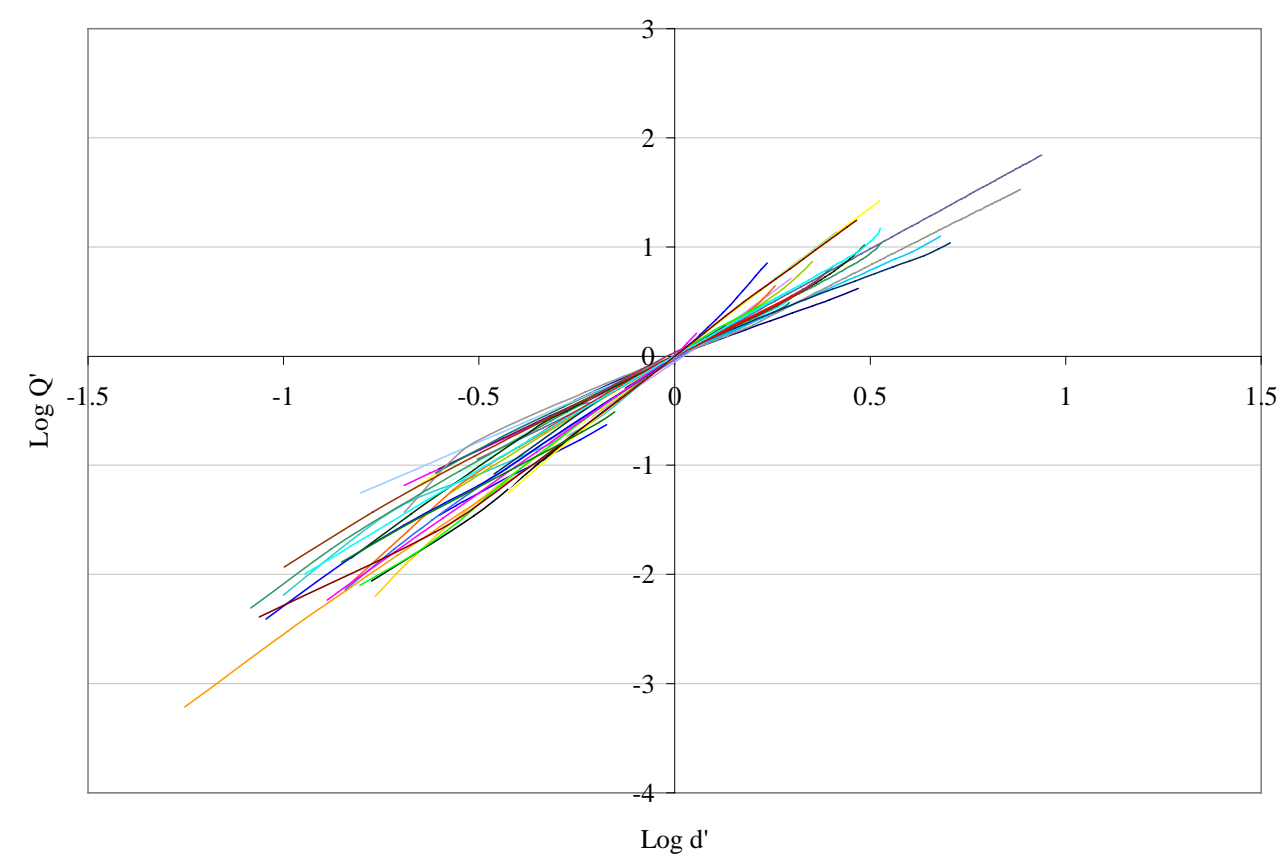

Figure 7. Relative Discharge (Log Q') Versus Relative Depth (Log d') for the Intermediate-Flow Region

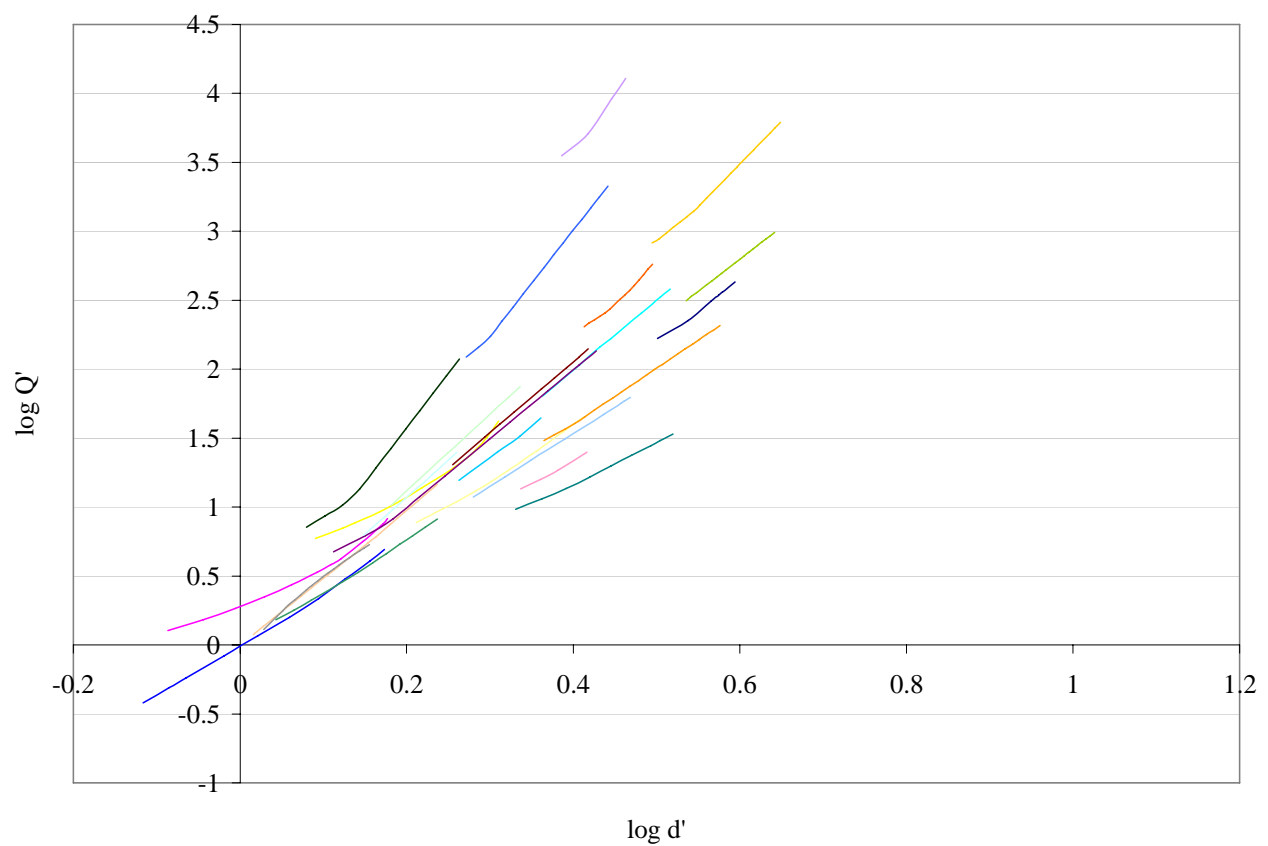

Figure 8. Relative Discharge (Log Q') Versus Relative Depth (Log d') for the High-Flow Region 
Hence, the difference in streamflow behavior ( ie. rating slope) between the two regions and within the same flow region can be examined by presuming simple control at stream sections.

\subsubsection{Analysis for Simple Control Sections}

Consider that streamflow is downstream controlled at a section by one of the following cases: sharp crested uncontracted; sharp crested contracted; V-notch; Broad crested weir.

All weir relations are represented by $Q=f\left(K, H^{n}\right)$, with $\mathrm{K}$ being all the constant parameters (discharge coefficient, weir length, contraction) and $n=3 / 2$ for uncontracted, moderately contracted rectangular and trapezoidal weirs and 5/2 for V- notches. Using some hypothetical data for stage and discharge and normalization parameters, nondimensional rating curves (Q’ vs. H') were developed for the assumed control sections. The dimensional form of $\mathrm{C}$ was used for the weir equations.

Assuming a horizontal_uncontracted section, the weir equation is:

$$
Q=C L H^{\frac{3}{2}}
$$

with C values between 3.2 and 4.4 and a typical value of 3.3. Figure 9 shows the nondimensional discharge and depth, plotted on log-log scale for this case. Data used in this figure is shown in Appendix A. 


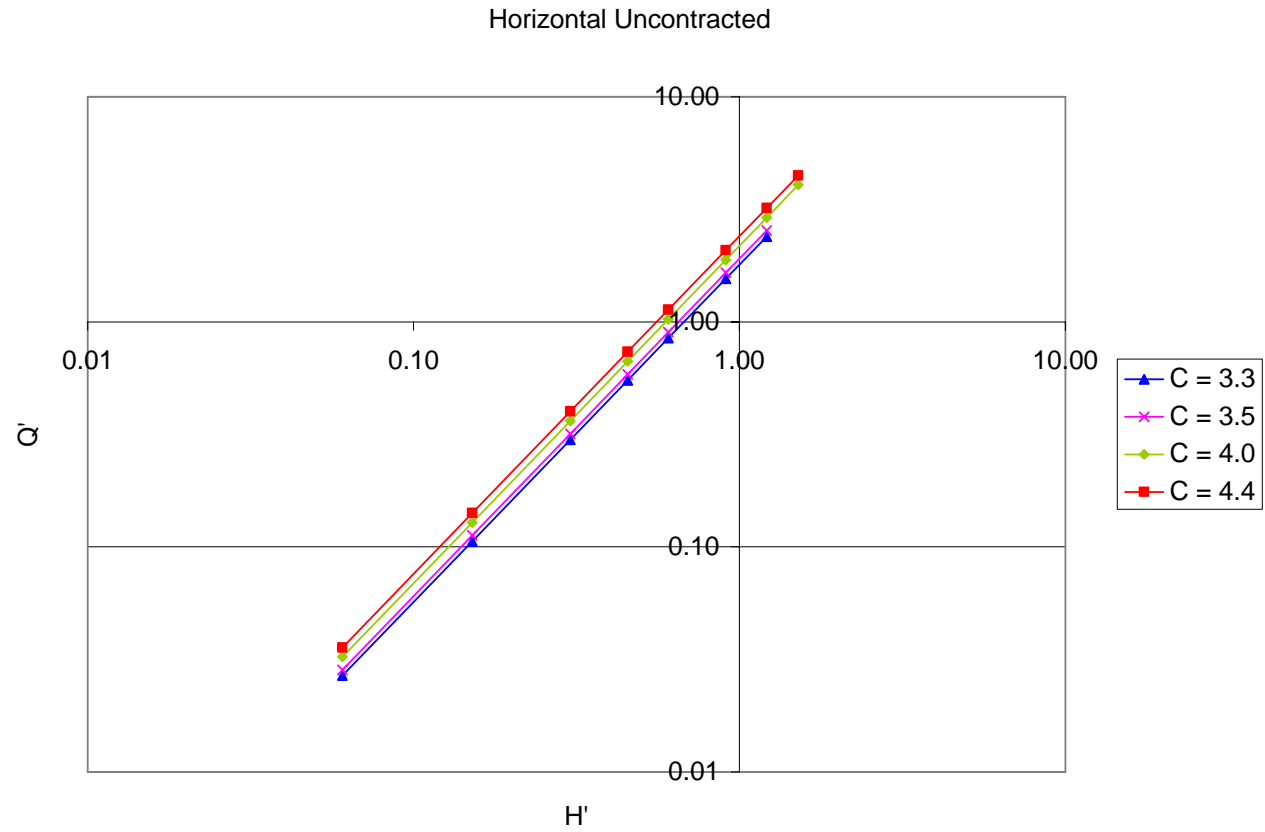

Figure 9. Q’ vs. H’ for Horizontal_Uncontracted Section for Varying Coefficients C

For a horizontal_contracted section, the weir equation is:

$$
Q=C(L-0.2 H) H^{\frac{3}{2}}
$$

with $C$ values between 3.2 and 4.4 and a typical value of 3.3. Figure 10 shows the nondimensional discharge and depth, plotted on log-log scale for this case. Data used in this figure is shown in Appendix B.

For a V-Notch Section section, the weir equation is:

$$
Q=C H^{\frac{3}{2}}
$$

with C values between 2 and 4.3 with a typical value of 2.5 for $90^{\circ} \mathrm{V}$-Notch. Figure 11 shows the non-dimensional discharge and depth, plotted on log-log scale for this case. Data used in this figure is shown in Appendix C. 


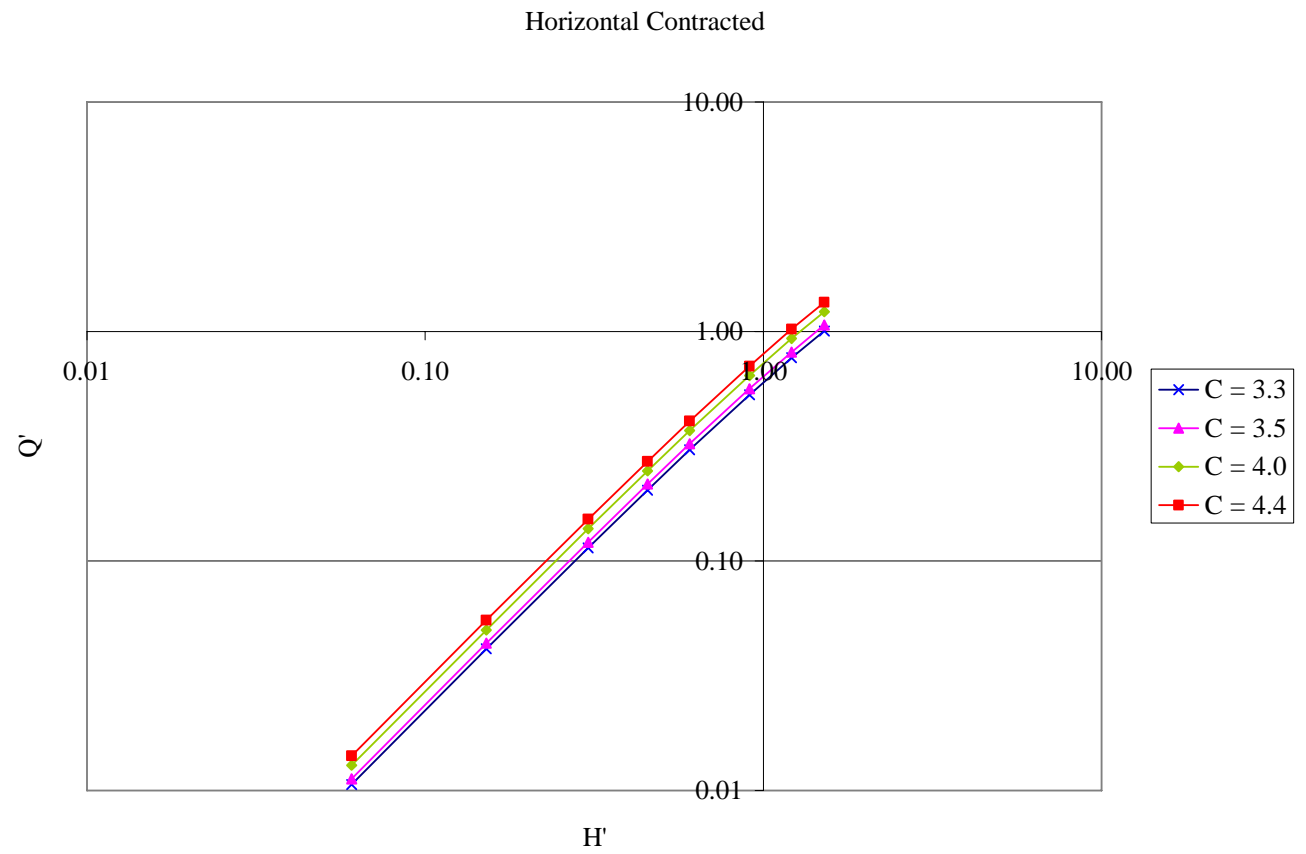

Figure 10. Q’ vs. H’ for Horizontal_Contracted Section for Varying Coefficients C

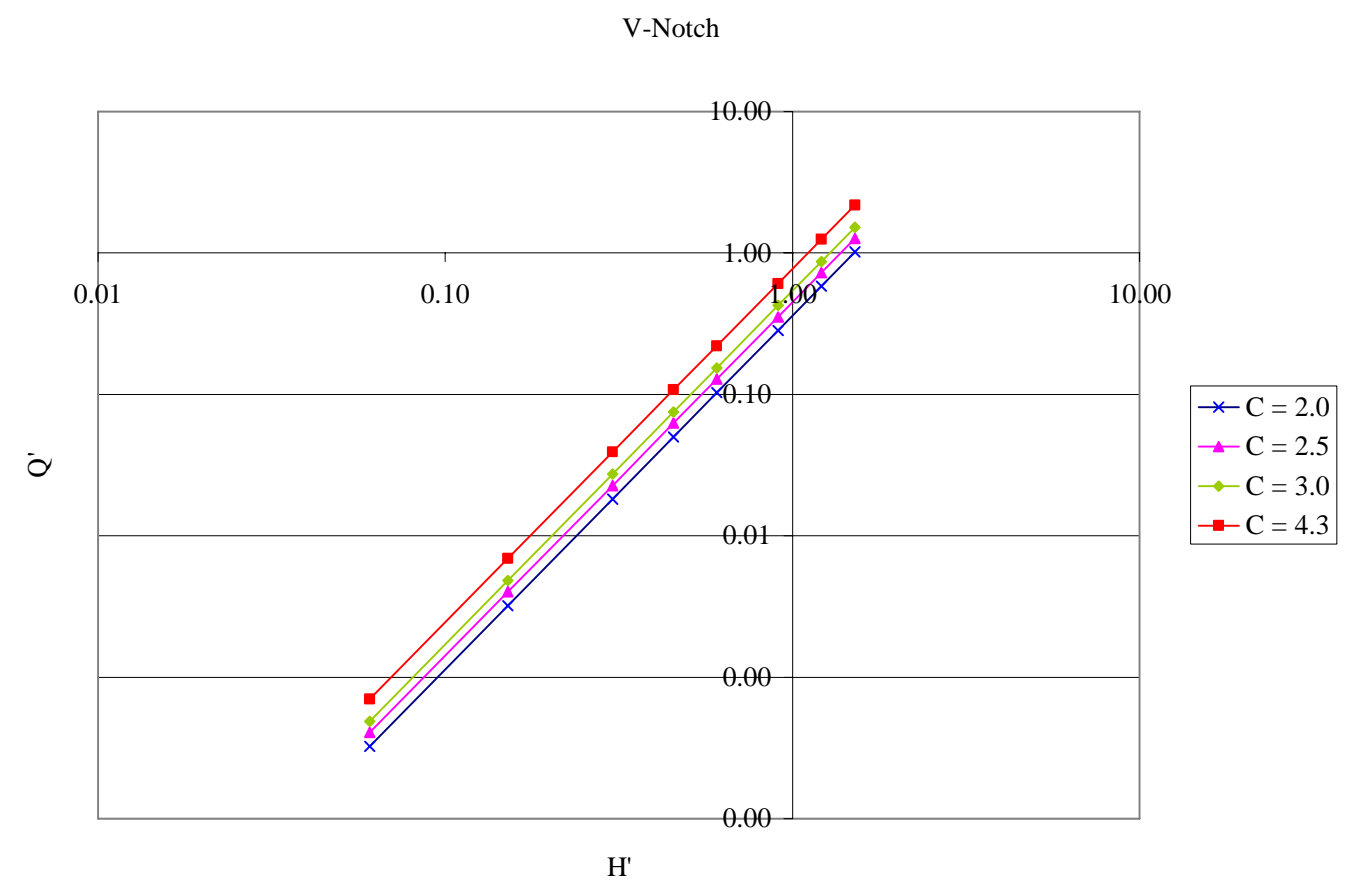

Figure 11. Q' vs. H’ for V-Notch Section for Varying Coefficients C 
For a Broad Crested Weir section, the weir equation is:

$$
Q=C L H^{\frac{3}{2}}
$$

with $\mathrm{C}$ values between 2.34 and 3.3 and a typical value of 2.63. Figure 12 shows the nondimensional discharge and depth, plotted on log-log scale for this case. Data used in this figure is shown in Appendix D.

Results for the typical $\mathrm{C}$ value for each of the evaluated control sections are shown in Figure 13.

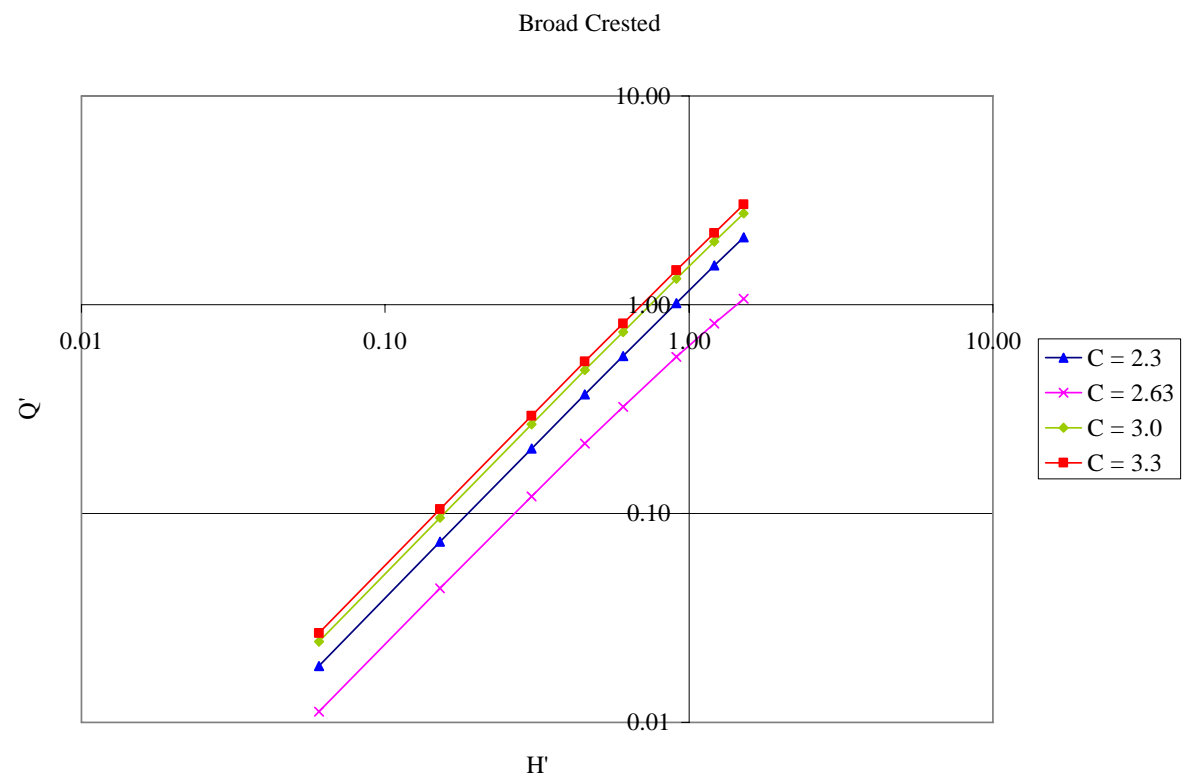

Figure 12. Q’ vs. H’ for Broad Crested Weir Section for Varying Coefficients C

From Figures 9 to 12, the effect of varying the discharge coefficients for each control section shape is basically a shift in the resulting rating. The discharge coefficient lumps together the effects of the approach velocity head with the contraction and head losses. Even though the analysis did not consider the variation of $\mathrm{C}$ with head, both the velocity head and discharge coefficient increase with stage. Thus, for the same head and crest length, a larger discharge coefficient will result in a larger discharge. 


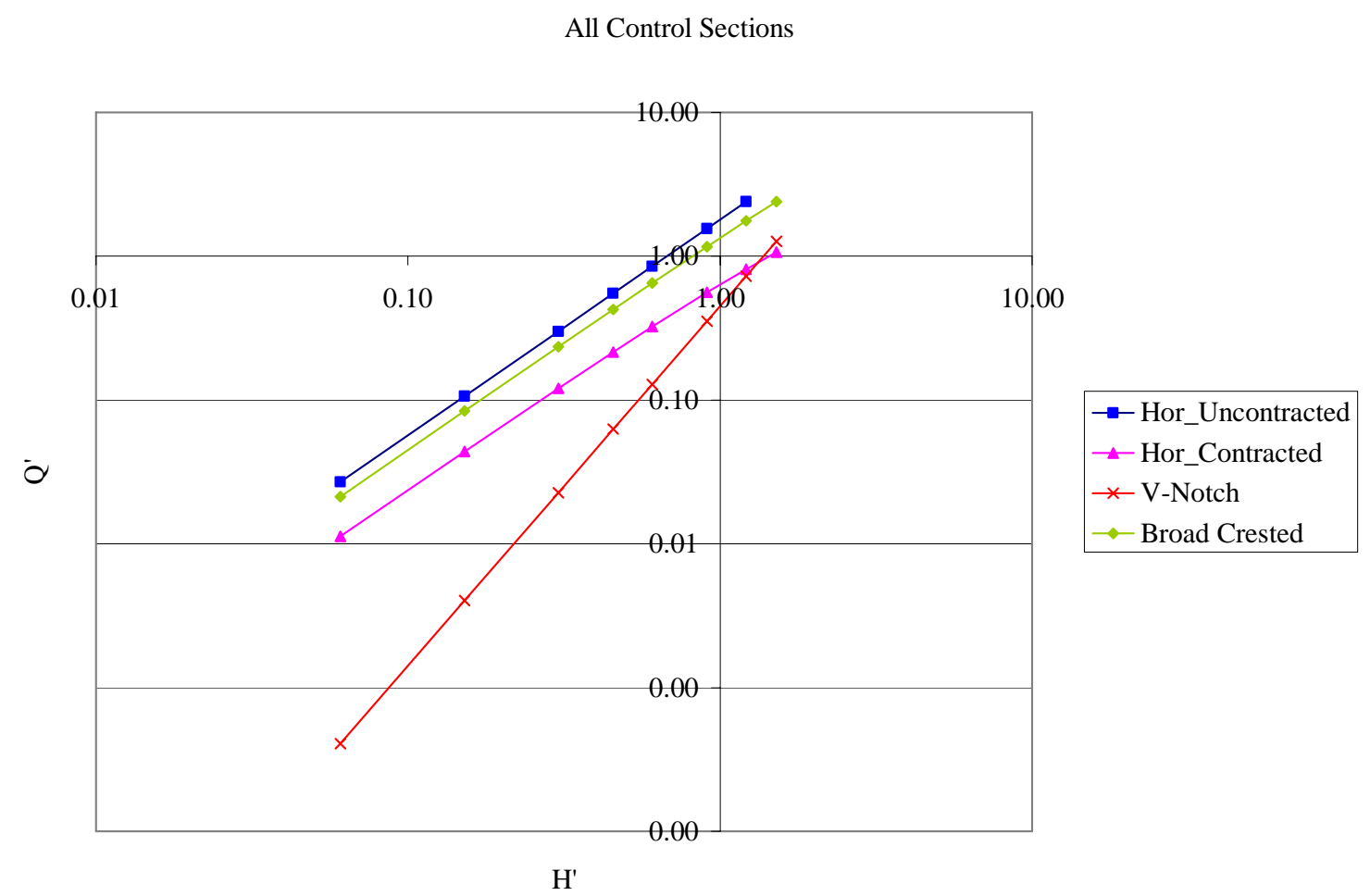

Figure 13. Q’ vs. H’ for All Control Sections for Typical Values for C

Figure 13 presents the results for all control section shapes. Similarly to the effect of varying $\mathrm{C}$, the effect of varying the section shape is a shift in the resulting rating except for the $\mathrm{V}$ notch. The discharge capacity of a rectangular versus a broad crested weir is different, therefore the shift in the ratings, however the three equations use the same exponent. The exponent in the V-Notch section is different/larger than the rectangular and broad crested sections which is reflected in the different and in this case steeper slope.

It is worth to notice that the slope of the non-dimensional relations does not change with the varying $C$ for the same control section shape. This is a clear indicative that the relation slope is a direct function of the exponent and is not affected by all the constant parameters included in $\mathrm{K}$. 
By observing the slopes in the non-dimensional rating curves for each of the stations being studied, most of the values fall between 1.5 and 2.5. Therefore, the degree of contraction could easily explain the variation in slope within the intermediate-flow region.

Thus, from the weir equation for the control section:

$$
\log Q=\log K+\log H^{n} \quad \text { or } \quad \log Q=\log K+n \log H
$$

Where $n=3 / 2$ or $5 / 2$ is the slope of the non-dimensional relations.

It can also be shown that uncontracted (e.g., uniform) wide flows approach $n$ values of 5/3 as an upper limit for turbulent flows. To explore this, a plot with the uncontracted and V-notch sections and non-dimensional curves using Manning's equation was created (Figure 14) for a rectangular and trapezoidal section. The behavior of the Manning's relation is similar to the weirs' behavior but with a different slope.

\subsubsection{Analysis for Compound Control Sections}

In compound control sections, the low/normal flows are managed by, for example, a Vnotch, and larger flows would require, for example, a trapezoidal weir. For these cases, the two profiles would form a compound weir. The simplest way to calculate the discharge over a compound weir is applying the discharge equation corresponding to each segment of the weir and up to the head of that segment.

Assuming a compound weir consisting of a V-Notch or Horizontal and a Trapezoidal (Cipottelli) Weir (standard equations follow), the non-dimensional relation was created. Figure 15 show results, using typical values for C. Data used in this figure is shown in Appendix E. 


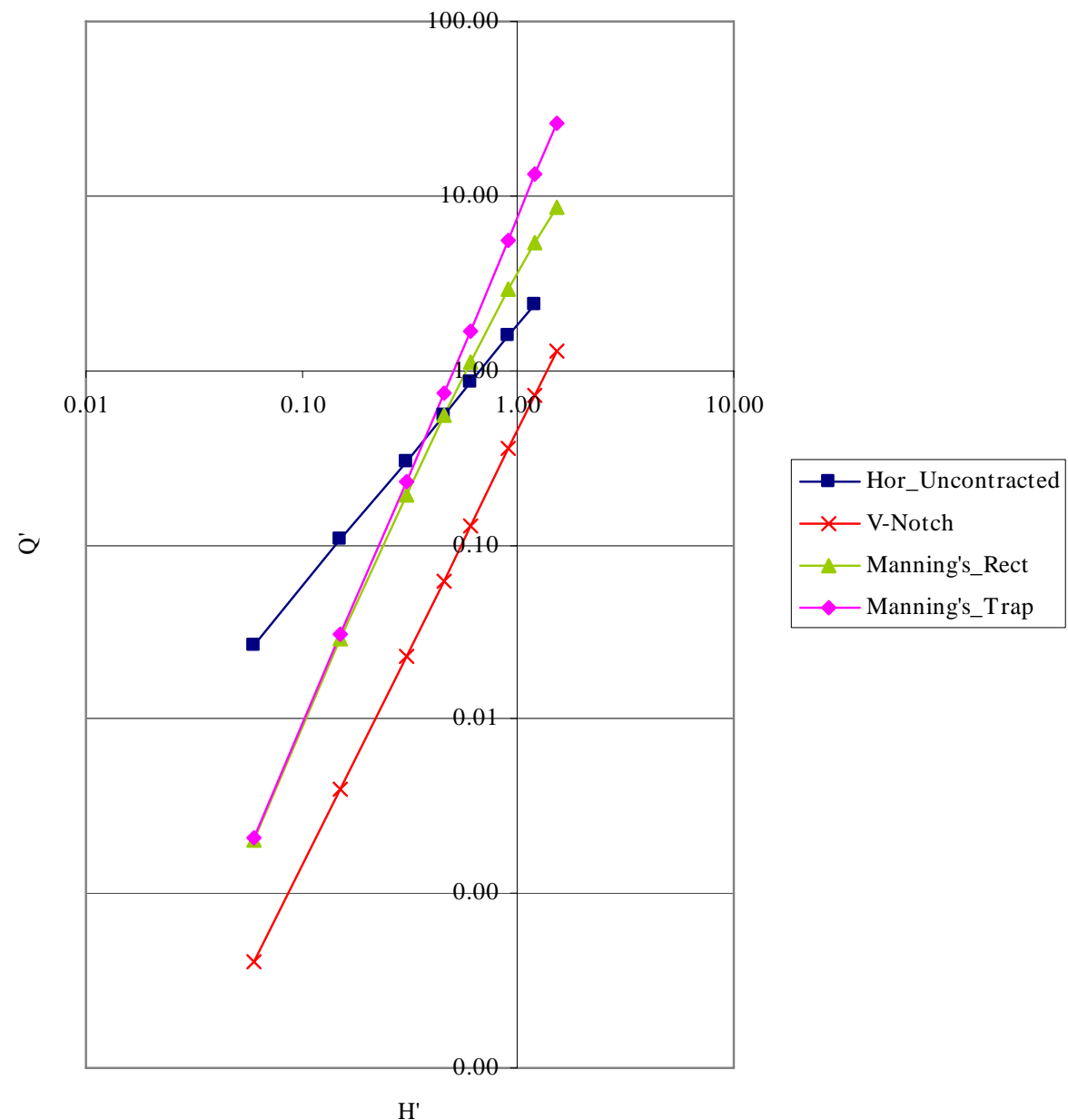

Figure 14. Q’ vs. H' for Uncontracted and V-Notch Weirs and Manning’s Equation

The equation for a trapezoidal section is:

$$
Q=C L H^{\frac{3}{2}}
$$

Figure 15 could explain the different/steeper slopes observed in the high-flow regions. In compound high-flow control sections (channel and out-of banks flood plain sections) there is a different degree of contraction. The low/normal flows are managed by cross sections with a relative degree of contraction (similar to a V-notch or uncontracted weir), and larger flows would be managed by cross sections with a higher degree of 
contraction (similar to a trapezoidal weir). For these cases, when plotting Q vs. H, the two profiles would form a compound weir as shown in Figure 15. This will result in a break in the resulting rating at the point where the flow changes from channel flow (low and intermediate) to floodplain flow (high); there is a break in the rating curve, with the high-flow range having a steeper slope.

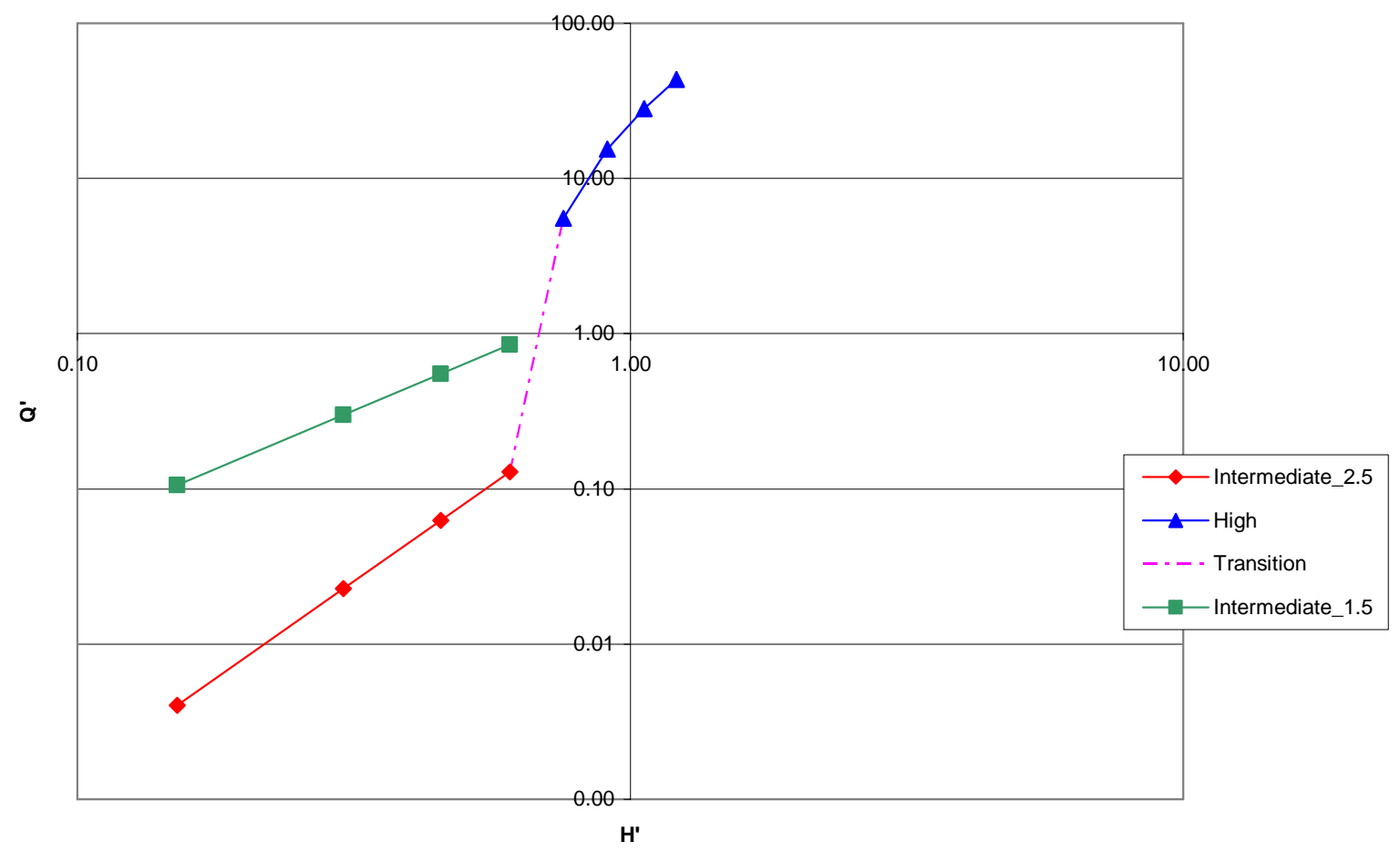

Figure 15. Q’ vs. H’ for Compound Weir Consisting of a V-Notch and a Trapezoidal

Rating data also show a third flow region corresponding to extreme low flows. Low flows are dominated by contribution of groundwater baseflow. Hydraulically they may not be fully turbulent, exhibiting parabolic (non log-linear) relationship for discharge-depth rating. Most ratings are also very unstable for low flows as channel debris and shifting live bed conditions highly influence the rating behavior. For example, 
most low-water discharge measurements have different gage stage at zero flow (GZF) and consequently, do not define the same rating or adapt to logarithmic plotting (Kennedy, 1984). This condition renders it harder to represent in a general model, thus this study did not consider the mathematical representation of low flows. At present, the author believes that it is doubtful if any generalized mathematical model can be developed for the very lowest flow conditions.

\subsection{Model for the Intermediate-Flow Region}

The model for the intermediate-flow region was developed using a least square regression analysis. Only discharge and water depth values corresponding to the intermediate-flow region were included in the analysis. The upper limit of the intermediate-flow region was approximated from the rating data, as the point where a change in the rating slope occurs (i.e., rating break point) (See Figure 16).

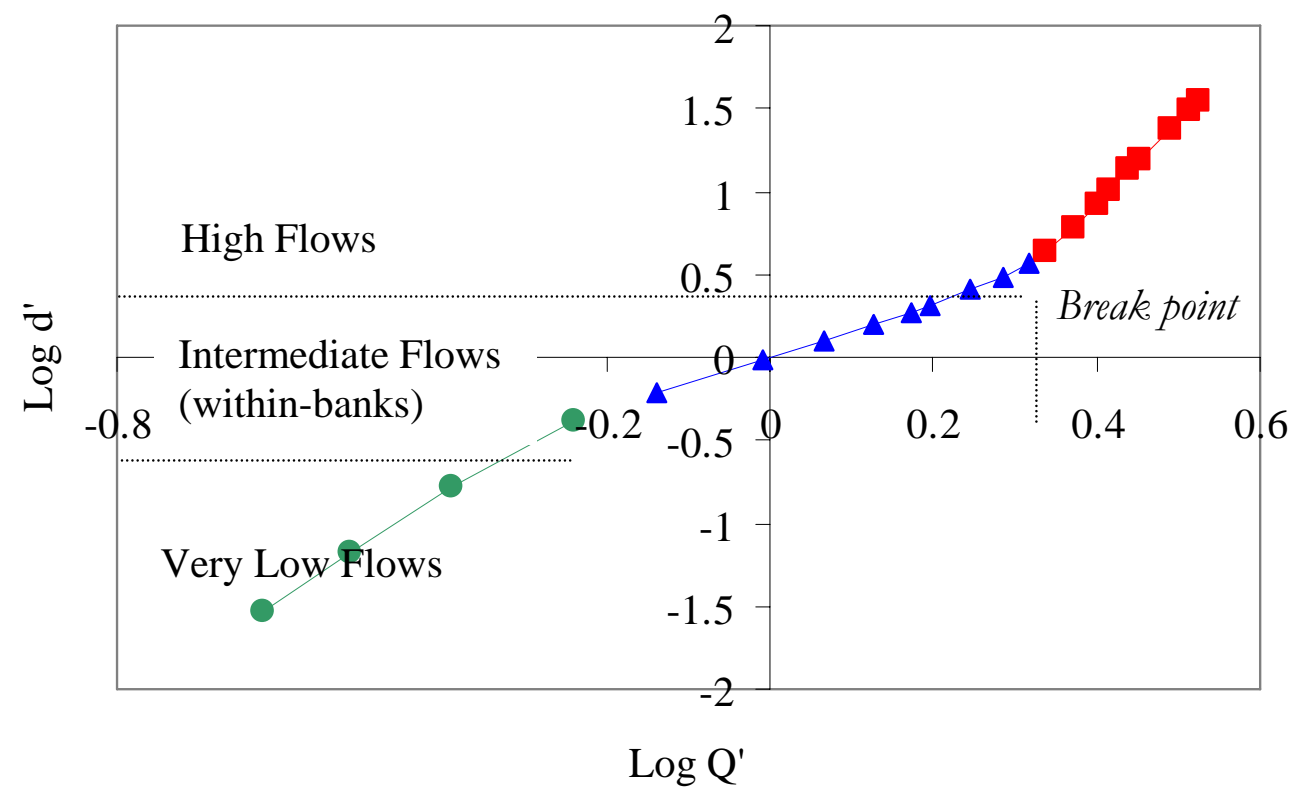

Figure 16. Generalized Log-Linear Rating Behavior 
The generalized relation based on relative discharge and depth was defined with a log-linear equation with zero intercept. For the forty-three stations in the study, the best fit slope was found to be 2.0 for the West-Central Florida study area. The mathematical model was described as:

$$
\log Q^{\prime}=2 \log d^{\prime}
$$

Table 5 shows the statistics of the model.

Table 5. Statistics of the Regression Model for the Intermediate Flows Region

\begin{tabular}{cccccc}
\hline $\mathrm{R}^{2}$ & Adj $\mathrm{R}^{2}$ & RMSE & Coeff Var & $\mathrm{F}$ Value & $\operatorname{Pr}>\mathrm{F}$ \\
\hline 0.95 & 0.95 & 0.1862 & 291.3 & 21319.3 & $<.0001$ \\
\hline Variable & Coefficient & SE & t Value & $\operatorname{Pr}>|\mathrm{t}|$ & VIF \\
\hline $\mathrm{d}$ & 2.0 & 0.01445 & 146.01 & $<.0001$ & 1 \\
\hline
\end{tabular}

Results from this model were compared to the USGS rating data. The accuracy of the prediction was measured in terms of the relative error. Predicted values were first calculated using values of $\mathrm{Q}_{10}$ and $\mathrm{d}_{10}$ specific for each station. The average relative error was less than $20 \%$ for $58 \%$ of the stations; $21 \%$ to $30 \%$ for $16 \%$ of the stations; $31 \%$ to $50 \%$ for $12 \%$ of the stations; and larger than $51 \%$ for $14 \%$ of the stations. Basin characteristics data and relative error for the specific model is shown in Appendix F.

A value of discharge and depth exceeded $10 \%$ of the time is required to generate the ratings in un-gauged stations. As in the Approach 3, known values of discharge as $\mathrm{Q}_{10}$ were related to drainage area, but a better correlation was found by relating values of depth $\left(d_{10}\right)$ to $Q_{10}$. The correlation coefficient for $d_{10}$ was improved from 0.62 to 0.86 . 
The corresponding regression equations for $\mathrm{Q}_{10}$ and $\mathrm{d}_{10}$ are:

$$
\begin{aligned}
& Q_{10}=0.0522 A \\
& d_{10}=0.6505 Q_{10}^{0.4053}
\end{aligned}
$$

Where $\mathrm{Q}_{10}$ is in CMS, drainage area is in square miles and $\mathrm{d}_{10}$ is in meters. Figures 17 and 18 show data and regression equations for discharge and depth, respectively.

Discharge was then predicted using the model with $\mathrm{Q}_{10}$ and $\mathrm{d}_{10}$ estimated from the regression equations. The average relative error compared to the USGS data was less than $20 \%$ for $23 \%$ of the stations; $21 \%$ to $30 \%$ for $27 \%$ of the stations; $31 \%$ to $50 \%$ for $24 \%$ of the stations; and larger than 51\% for the remaining 26\%. These results are comparable to the ones obtained with the specific known values.

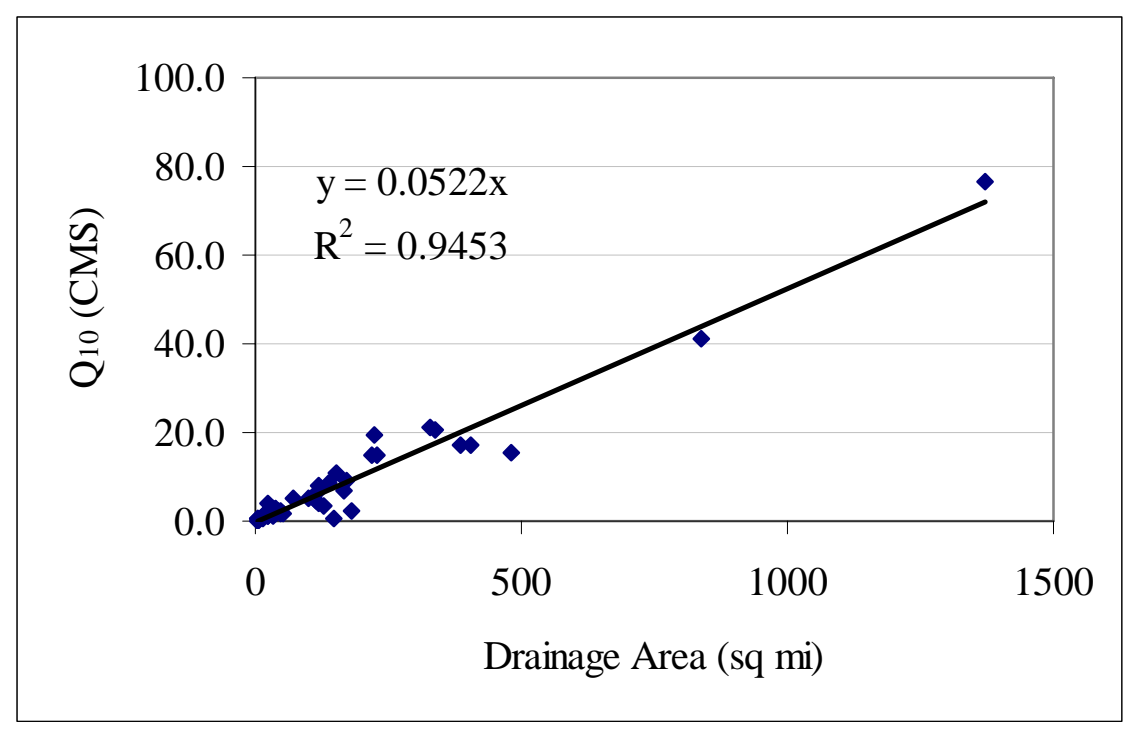

Figure 17. Data and Regression Equation for $\mathrm{Q}_{10}$ 


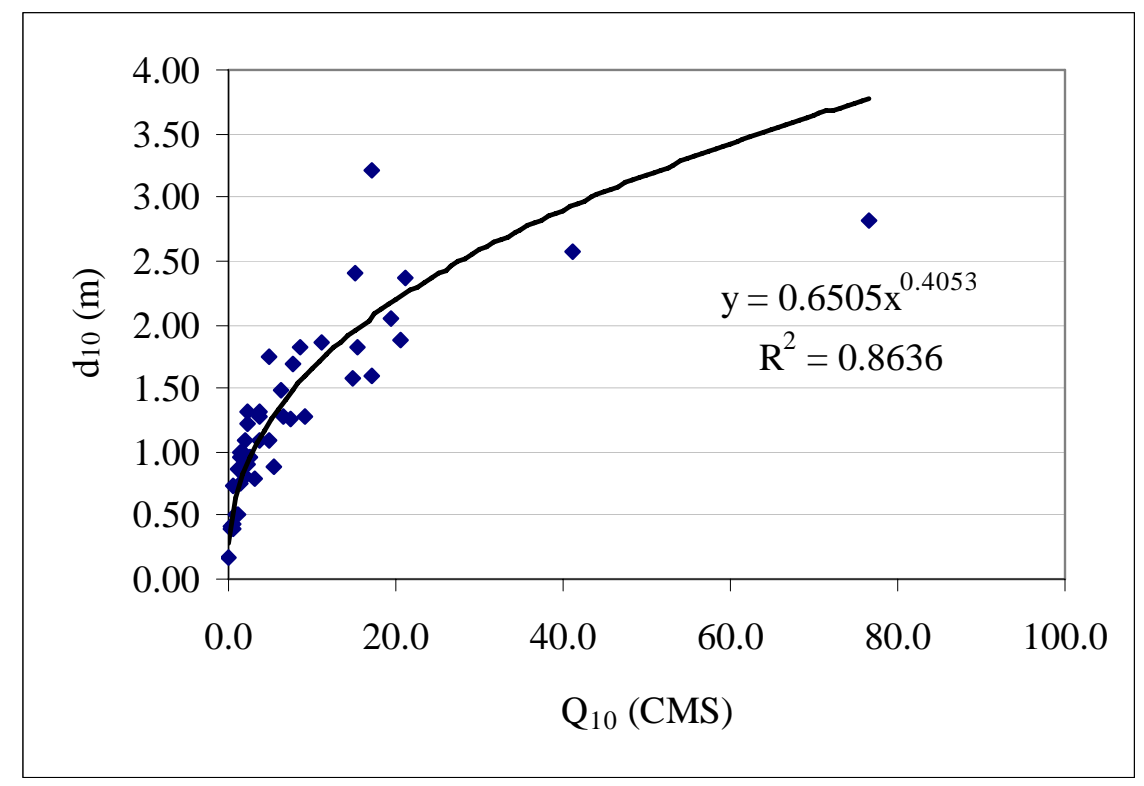

Figure 18. Data and Regression Equation for $\mathrm{d}_{10}$

\subsection{Model for the High-Flow Region}

The slopes in the high-flow region, although different from the slopes in the intermediate region, exhibit similar behaviors among them but in this case, with a very different intercept.

The model for this region was developed by error minimization using the least mean square procedure. Not all stations in the study area have data in the high-flow region, thus the analysis was performed for those stations where high flows were available, for a total of twenty-seven stations. Using the specific intercept for each station, the best fit slope was found to be 5.0 for the West-Central Florida study area. The mathematical model was described as:

$$
\log Q^{\prime}=5 \log d^{\prime}+b_{\text {station }}
$$

Where $b_{\text {station }}$ is the specific intercept for each station. 
The model was tested using the specific intercept for each station and results were compared to the USGS rating data. The average relative error was less than $20 \%$ for $33 \%$ of the stations; $21 \%$ to $30 \%$ for $7 \%$ of the stations; $31 \%$ to $50 \%$ for $4 \%$ of the stations; and larger than $51 \%$ for $56 \%$ of the stations. Basin characteristics data and relative error for the specific model is shown in Appendix G.

A value for the intercept is required to generate the rating in un-gauged stations. The intercept is related to the discharge where the high-flow region departs from the intermediate-flow region, believed to be the out-of-bank condition above which floodplain flows become hydraulically significantly (shown as break point in Figure 16). Therefore, those values of discharge of departure (transition to out-of bank flow) $\left(\mathrm{Q}_{\mathrm{dep}}\right)$ were identified from the rating data and were related to drainage area. The corresponding depth of departure $\left(\mathrm{d}_{\mathrm{dep}}\right)$ was related to $\mathrm{Q}_{\text {dep }}$. The resulting trend line showed a correlation, $\mathrm{R}^{2}$ of 0.90 for $\mathrm{Q}_{\mathrm{dep}}$ and 0.86 for $\mathrm{d}_{\mathrm{dep}}$.

The corresponding regression equations for discharge of departure $\left(\mathrm{Q}_{\mathrm{dep}}\right)$ and depth of departure $\left(\mathrm{d}_{\mathrm{dep}}\right)$ are:

$$
\begin{aligned}
& Q_{\text {dep }}=0.16 A \\
& d_{d e p}=0.479 Q_{d e p}^{0.428}
\end{aligned}
$$

Where $\mathrm{Q}_{\mathrm{dep}}$ is in CMS and drainage area is in square miles. Figures 19 and 20 shows data and regression equation for $\mathrm{Q}_{\mathrm{dep}}$ and $\mathrm{d}_{\mathrm{dep}}$, respectively. 
Data from the high-flow region were tested using a linear model with a fixed slope of 5.0 and an intercept calculated from $\mathrm{Q}_{\text {dep }}$ and corresponding $\mathrm{d}_{\mathrm{dep}}$. The results were very poor with most of the stations exhibiting relative errors exceeding, in some cases, $100 \%$. Therefore, it is apparent that more work needs to be done on the general departure threshold.

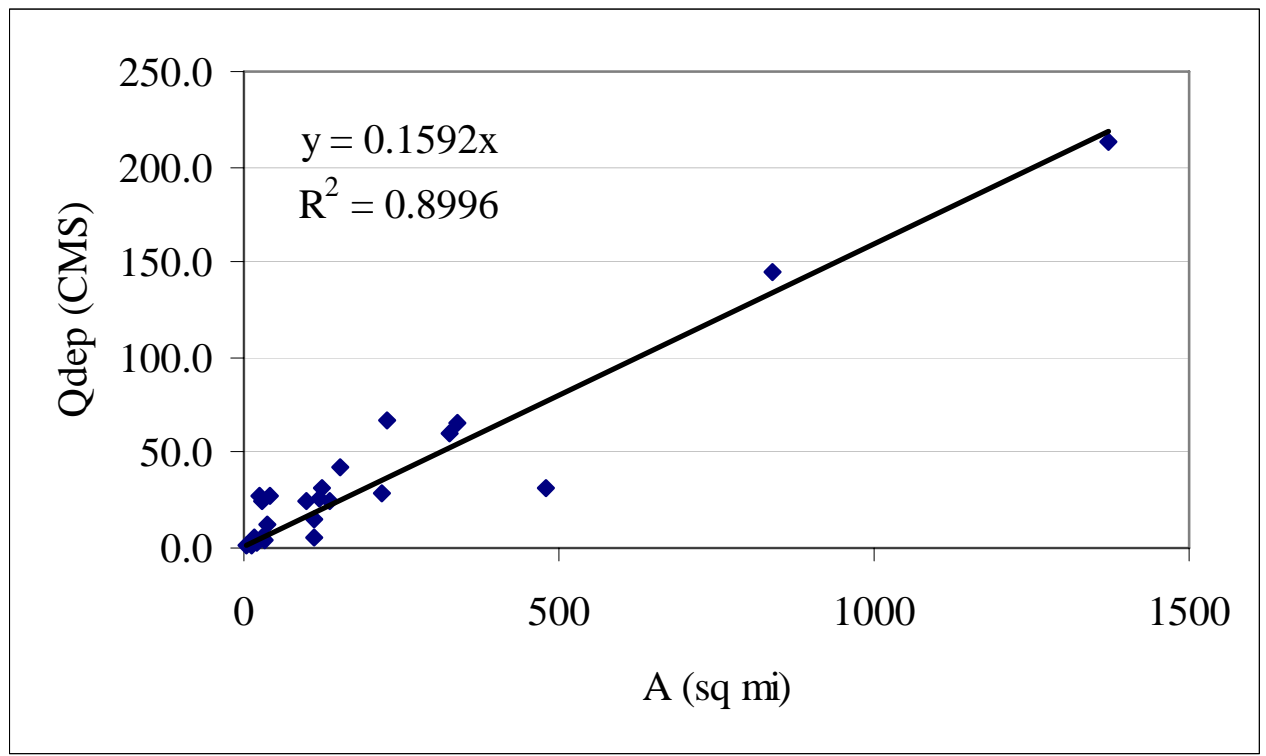

Figure 19. Data and Regression Equation for Discharge of Departure $\left(Q_{\text {dep }}\right)$

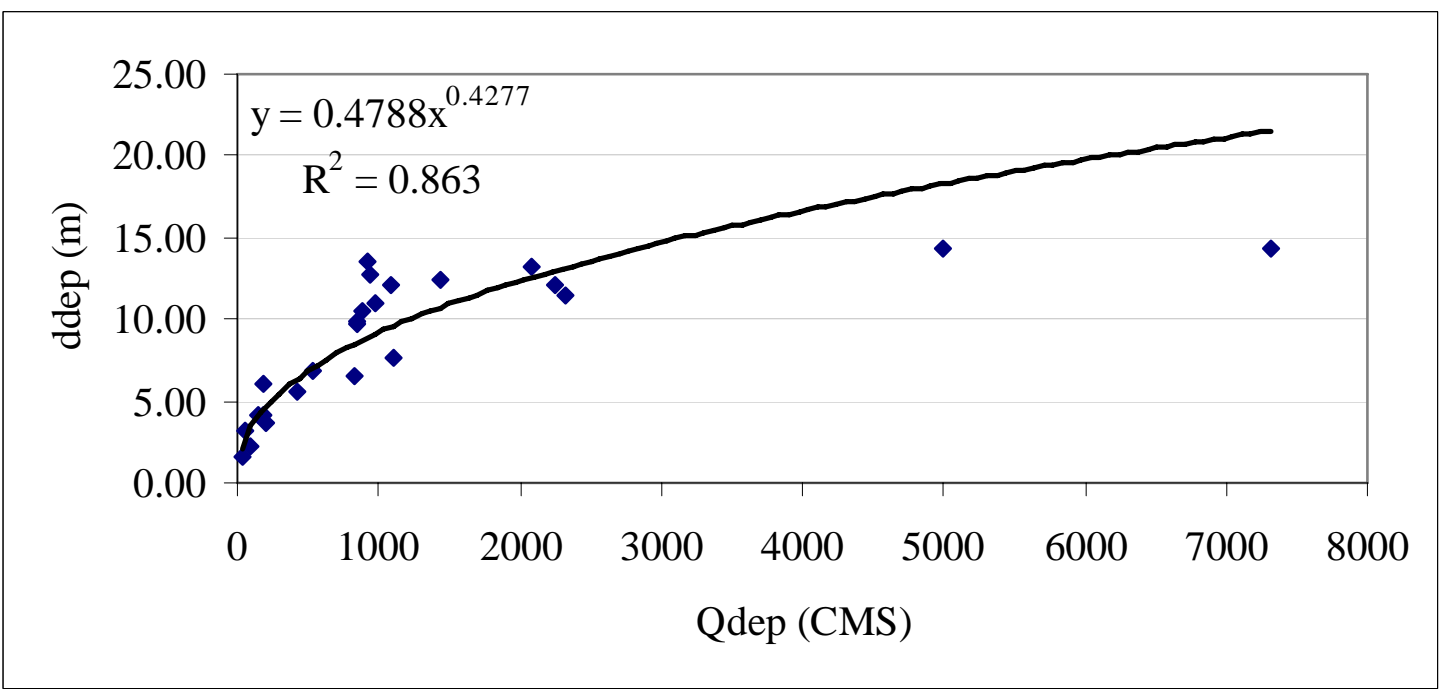

Figure 20. Data and Regression Equation for Depth of Departure $\left(\mathrm{d}_{\mathrm{dep}}\right)$ 


\section{MODEL VERIFICATION}

To measure the success in predicting rating discharge for the intermediate region, the model was verified using data from thirty stations that had not been previously used in development. The stations in the verification data set were randomly selected within the study area. The range of discharge and drainage areas was similar to the stations in the calibration set. Table 6 gives the ranges of values for discharge, depth and drainage area for the verification data set.

Table 6. Ranges of Values for Hydraulic Parameters for Verification Data

\begin{tabular}{lcccccc}
\hline Parameter & & Units & Mean & Std Dev & Minimum & Maximum \\
\hline Discharge & Q & CMS & 31.5 & 54.7 & 0.0 & 393.9 \\
\hline Depth & d & m & 2.00 & 1.47 & 0.00 & 5.89 \\
\hline Drainage Area & A & Sq. mi & 214.39 & 507.49 & 1.46 & 1825.00 \\
\hline
\end{tabular}

The model was tested using the $\mathrm{Q}_{10}$ and $\mathrm{d}_{10}$ calculated from the regression equations. Results from the model were compared to the USGS rating data and the accuracy was measured as the relative error. The average relative error when compared to the USGS data for the intermediate flow was less than 30\% for $43 \%$ of the stations, $31 \%$ to $50 \%$ for $27 \%$ of the stations and larger than $51 \%$ for the remaining $30 \%$. Thus, the error was comparable to the results obtained with the calibration data set. Basin characteristics data and relative error for the specific model is shown in Appendix $\mathrm{H}$.

Because of the lack of accurate results in the high-flow region using the intercept values from the regression equations, the high-flow model was not validated using the verification data set. 


\section{MODEL VALIDATION}

To evaluate the applicability of the proposed model in an area outside West Central Florida, the model was tested at forty stations located in the areas of North Florida, and South Georgia and Alabama (See Table 7 and Figure 21). These stations comprise the validation data set and were selected randomly, with drainage areas varying from 17 to 13600 square miles, with an average of 1830 square miles. The drainage area and $\mathrm{Q}_{10}$ values were taken from the station record, from the Water Resources Data of Florida, Georgia and Alabama, USGS (2004). The rating data corresponds to data actually in use by the USGS for 2005-2006.

Following the same approach as before, this validation was performed using two separate models for data in the intermediate and high flow regions. The limit between the intermediate and high-flow region was also approximated from the rating data, as the point where a change in the rating slope occurs.

As with the stations in West Central Florida, the model was tested using both, the specific values of $\mathrm{Q}_{10}$ and $\mathrm{d}_{10}$, and general values obtained from a regression equation.

For this purpose, a new relation was developed for the non-dimensional parameters. The regression equations for $\mathrm{Q}_{10}$ and $\mathrm{d}_{10}$ including the new stations in the validation set are:

$$
\begin{aligned}
& Q_{10}=0.0522 A \\
& d_{10}=0.6505 Q_{10}^{0.4053}
\end{aligned}
$$


Table 7. Discharge and Depth for the 10\% Discharge Exceedance and the Slope of the Corresponding Rating for Validation Data Set

\begin{tabular}{|c|c|c|c|c|}
\hline Gage \# & USGS Station Name & Slope $_{10}$ & $\begin{array}{c}\mathrm{Q}_{10} \\
\mathrm{CMS}\end{array}$ & $\begin{array}{l}\mathrm{d}_{10} \\
\mathrm{~m}\end{array}$ \\
\hline 2369800 & Blackwater River Near Bradley Al & 1.12 & 106.55 & 4.67 \\
\hline 2361500 & Choctawhatchee River Near Bellwood Al & 1.65 & 89.55 & 2.28 \\
\hline 2378300 & Magnolia River At Us 98 Near Foley, Alabama & 2.80 & 1.13 & 0.49 \\
\hline 2376500 & Perdido River At Barrineau Park, Fl & 1.28 & 40.52 & 1.52 \\
\hline 2374250 & Conecuh River At State Hwy 41 Near Brewton, Al & 1.80 & 203.75 & 3.65 \\
\hline 2373000 & Sepulga River Near Mckenzie Al & 2.02 & 47.89 & 1.25 \\
\hline 2361000 & Choctawhatchee River Near Newton, Al & 1.24 & 54.98 & 1.80 \\
\hline 2363000 & Pea River Near Ariton Al & 1.12 & 39.11 & 1.28 \\
\hline 2372422 & Conecuh River Bel Pt A Dam Nr River Falls, Al & 0.84 & 99.19 & 1.22 \\
\hline 2364500 & Pea River Near Samson Al & 1.63 & 106.55 & 3.68 \\
\hline 2377570 & Styx River Near Elsanor, Al & 1.43 & 22.98 & 1.26 \\
\hline 2374950 & Big Escambia Cr At Sardine Br Nr Stanley Crossroad & 1.06 & 16.97 & 0.62 \\
\hline 2362240 & Little Double Bridges Creek Nr Enterprise, Al & 2.04 & 1.70 & 0.82 \\
\hline 2323000 & Suwannee River Near Bell, Florida & 1.13 & 427.91 & 4.01 \\
\hline 2319800 & River At Dowling Park, Florida & 1.21 & 306.06 & 4.13 \\
\hline 2319000 & Withlacoochee River Near Pinetta, Fla & 1.24 & 129.51 & 2.36 \\
\hline 2322500 & Santa Fe River Near Fort White, Fla & 1.03 & 72.26 & 0.87 \\
\hline 2321500 & Santa Fe River At Worthington Springs, Fla & 1.66 & 31.17 & 2.54 \\
\hline 2330150 & Ochlockonee River Nr Smith Creek, Fla & 1.1 & 121.86 & 2.65 \\
\hline 2330100 & Telogia Creek Nr Bristol, Fla & 1.64 & 12.24 & 1.74 \\
\hline 2359000 & Nr Altha, Fla & 0.94 & 78.21 & 2.03 \\
\hline 2365500 & Choctawhatchee River At Caryville, Fla & 1.84 & 320.23 & 4.63 \\
\hline 2368500 & Shoal River Nr Mossy Head, Fla & 1.42 & 12.36 & 0.90 \\
\hline 2370500 & Big Coldwater Creek Nr Milton, Fla & 1.41 & 25.16 & 1.44 \\
\hline 2376500 & Perdido River At Barrineau Park, Fl & 1.23 & 40.52 & 1.53 \\
\hline 2322700 & R @ Hwy27 Nr Hildreth, Fl & 1.11 & 10.03 & 0.47 \\
\hline 2226500 & Near Waycross, Ga & 1.34 & 81.90 & 3.23 \\
\hline 2228000 & Satilla River At Atkinson, Ga & 1.33 & 170.03 & 3.41 \\
\hline 2314500 & Suwannee River At Us 441, At Fargo, Ga & 1.52 & 74.25 & 3.44 \\
\hline 2226000 & Altamaha River At Doctortown, Ga & 1.2 & 889.83 & 3.59 \\
\hline 23177483 & Withlacoochee River At Mcmillan Rd, Ga & 2.1 & 34.57 & 2.87 \\
\hline 2327500 & Ochlockonee River Near Thomasville, Ga & 2.1 & 35.99 & 2.84 \\
\hline 2329342 & Little Attapulgus Creek At Attapulgus, Ga & 1.32 & 0.68 & 0.38 \\
\hline 2353000 & Flint River At Newton, Ga & 1.42 & 368.40 & 3.33 \\
\hline 2353265 & Ichawaynochaway Creek At Ga 37, Near Morgan, Ga & 1.39 & 12.92 & 1.34 \\
\hline 2354410 & Chickasawhatchee Creek Near Leary, Ga & 3.2 & 8.08 & 0.66 \\
\hline 2354800 & Ichawaynochaway Creek Near Elmodel, Ga & 1.56 & 55.83 & 1.65 \\
\hline 2355662 & Flint River At Riverview Plantation Nr Hopeful, Ga & 1.35 & 402.41 & 3.92 \\
\hline 2357000 & Spring Creek Near Iron City, Ga & 1.93 & 33.44 & 2.63 \\
\hline 2316000 & Alapaha River Near Alapaha, Ga & 2.47 & 42.51 & 3.19 \\
\hline
\end{tabular}




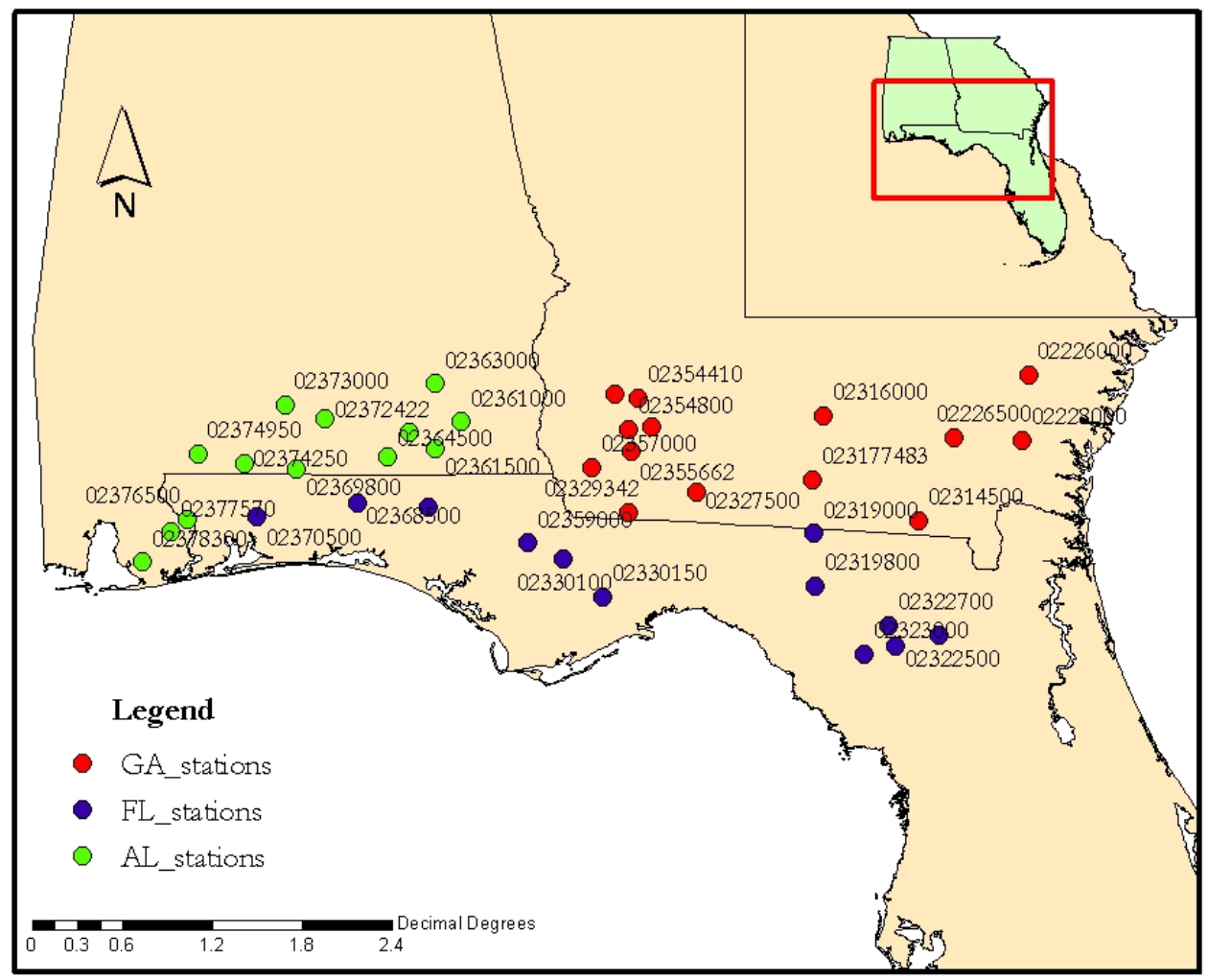

Figure 21. Location of USGS Stations in the Areas of North Florida, Georgia and Alabama

Where $\mathrm{Q}_{10}$ is in CMS, drainage area is in square miles and $\mathrm{d}_{10}$ is in meters. Figures 22 and 23 show data and regression equations for discharge and depth, respectively. As shown, when adding the stations in the validation data set, the correlation coefficient improved slightly for $\mathrm{Q}_{10}$ compared to the regression with just the West Central Florida stations. The regression for $\mathrm{d}_{10}$ shows a poorer correlation but still moderate.

Data for the intermediate flow region was initially tested using the same model developed for West Central Florida stations (Equation 19). The average relative error using values of $Q_{10}$ and $d_{10}$ specific for each station was less than $30 \%$ for $33 \%$ of the 
stations and less than $50 \%$ for $68 \%$ of the stations. The average relative error using values of $\mathrm{Q}_{10}$ and $\mathrm{d}_{10}$ estimated from the regression equations was less than $30 \%$ for $23 \%$ of the stations and less than $50 \%$ for $63 \%$ of the stations. Drainage area data and relative error for the specific model is shown in Appendix I.

In an attempt to improve these results, a model for the intermediate-flow region specific to the data in the validation set was developed using a least square regression analysis. The generalized relation based on relative discharge and depth was defined with a log-linear equation with zero intercept. For the forty stations in the validation data set, the best fit slope was found to be 1.35 . The mathematical model was described as:

$$
\log Q^{\prime}=1.35 \log d^{\prime}
$$

This difference in the rating slope can be observed in the plot of relative discharge versus relative depth for the stations in the validation data set (Figure 24). When compared to the same plot for the stations in West Central Florida (Figure 4), most of the ratings in the validation set show a lower slope.

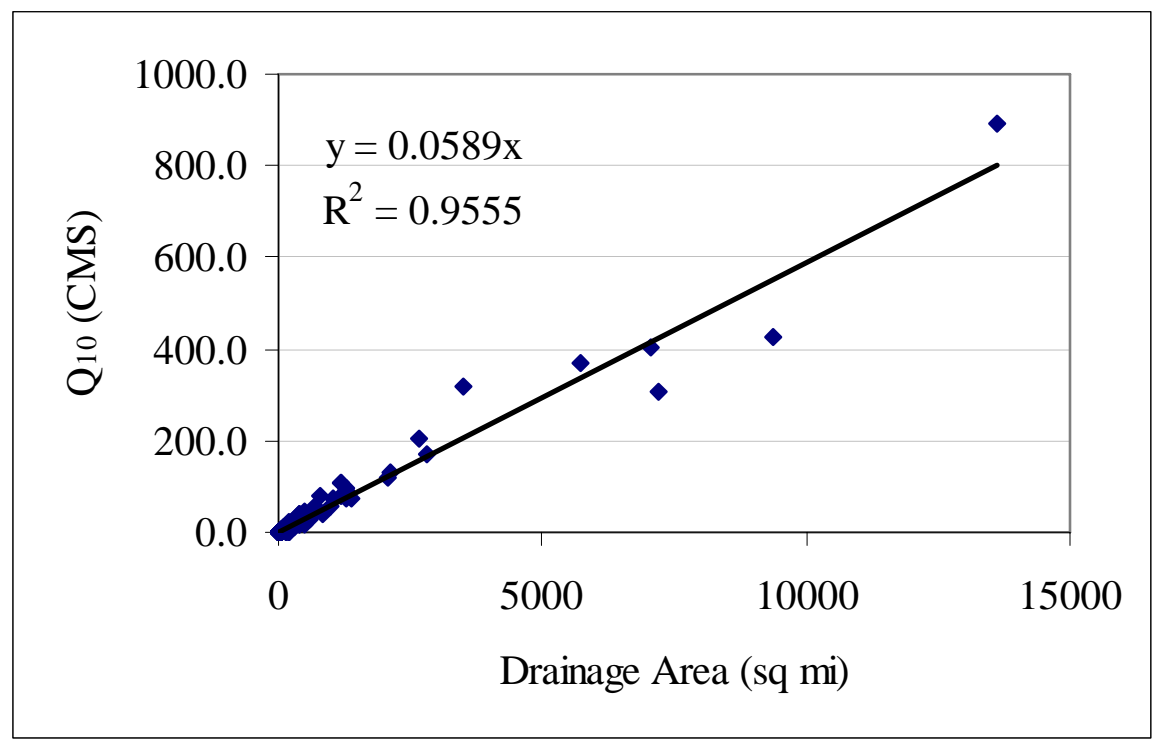

Figure 22. Data and Regression Equation for $\mathrm{Q}_{10}$ Including Validation Data Set 44 


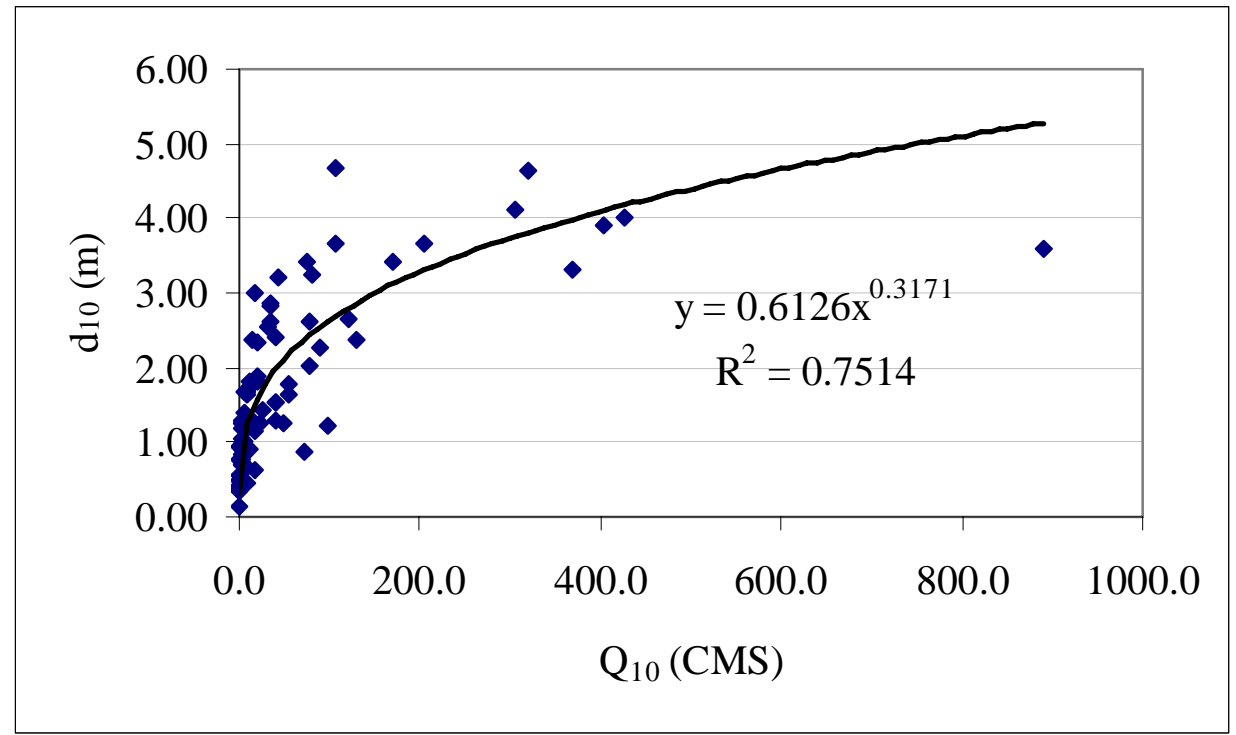

Figure 23. Data and Regression Equation for $\mathrm{d}_{10}$ Including Validation Data Set

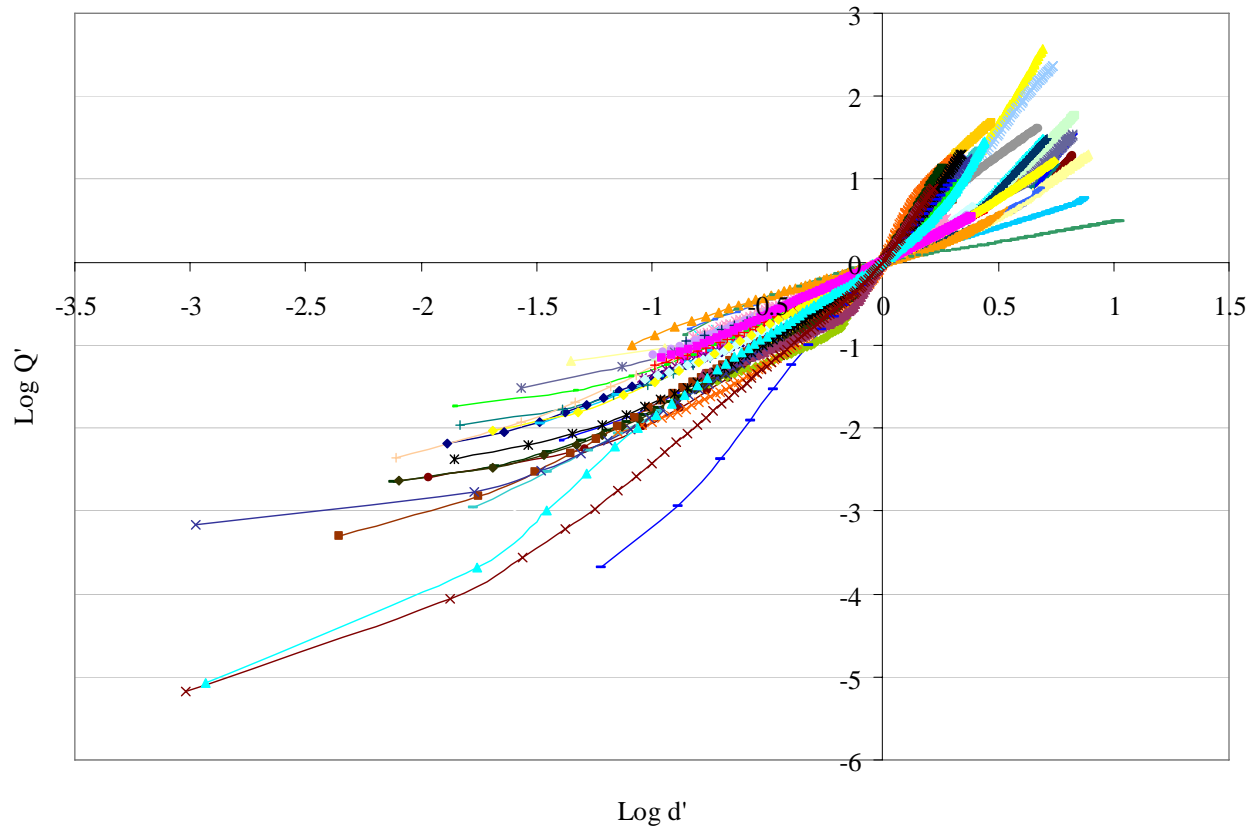

Figure 24. Relative Discharge (Log Q') Versus Relative Depth (Log d') for Stations in North Florida, Alabama and Georgia 
The lower rating slope can be explained by looking at the watershed characteristics. The stations in the validation data set have a much larger drainage area than the stations used in the calibration and verification data set. As indicated, the mean drainage area in the data validation set is 1830 square miles, that compared to 138 sq. miles in the calibration set and 214 sq. miles in the verification set, in average is much larger. Large drainage areas are associated with flatter average channel slope and consequently larger water depths for the mean discharge than the smaller sized watersheds. As a result, the ratings at the larger watersheds will exhibit higher values of depth for the mean discharge, resulting in flatter rating slopes. Figure 25 shows the relation of drainage area and channel slope and water depth, for some stations in Florida, Georgia and Alabama. In this figure, water depth is shown as $d_{10}$ as a representative value for the streams.

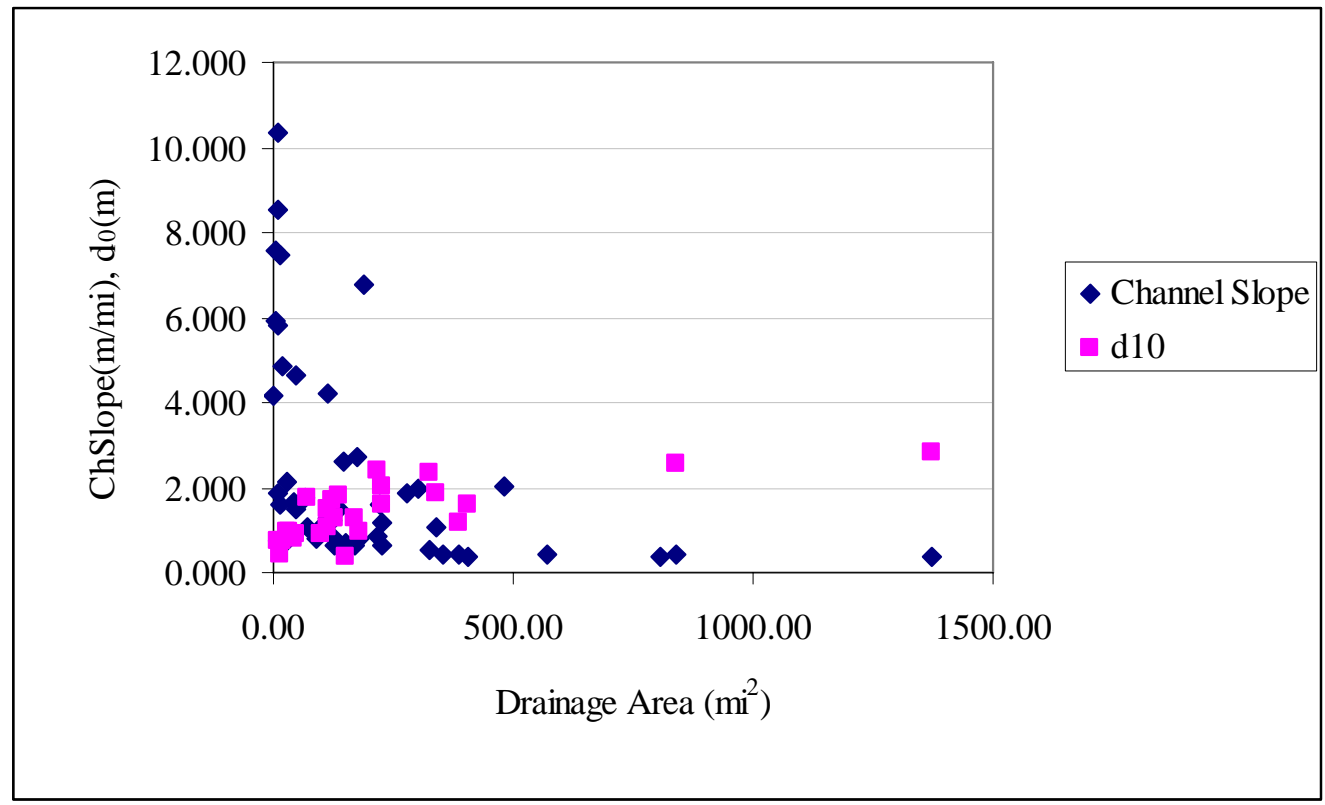

Figure 25. Relation Between Drainage Area and Channel Slope and Water Depth $\left(\mathrm{d}_{10}\right)$ for Some Stations in Florida, Georgia and Alabama 
The bankfull channel dimensions could also be a factor in the flatter slope. A study for regional channel characteristics in Florida streams (Metcalf, 2004) demonstrated that streams in Northwest Florida have much larger bankfull areas and discharge than other areas of Florida. The study attributes the difference to precipitation and geologic runoff factors in the Northern Florida area. Also, some reviewed studies on development of regional curves (Cinotto, 2003; Keaton, 2005; Moody, 2003; Kuck, 2000) show drainage area as the main factor for the variability in bankfull characteristics (ie. bankfull area). This supports the rationalization presented previously of larger drainage areas in the validation data set as the possible reason for the flatter slope. When testing Equation 27, the average relative error using values of $\mathrm{Q}_{10}$ and $\mathrm{d}_{10}$ specific for each station was less than $30 \%$ for $58 \%$ of the stations and less than $50 \%$ for $78 \%$ of the stations. These results are much better than the ones obtained with Equation 19 and comparable with the results obtained for West Central Florida stations. The average relative error using values of $\mathrm{Q}_{10}$ and $\mathrm{d}_{10}$ estimated from the regression equations was less than $30 \%$ for $25 \%$ of the stations and less than $50 \%$ for $63 \%$ of the stations. These results are comparable to the ones obtained with Equation 19.

A similar approach was used for the high flow region. A model specific to the high flow data in the validation set was developed by the least square regression procedure. Using the specific intercept for each station, the best fit slope was found to be 2.9 for the stations in the validation set. The mathematical model was described as:

$$
\log Q^{\prime}=2.9 \log d^{\prime}+b_{\text {station }}
$$

Where $b_{\text {station }}$ is the specific intercept for each station. 
The model was tested using the specific intercept for each station and results were compared to the USGS rating data. The average relative error using values of $\mathrm{Q}_{10}$ and $\mathrm{d}_{10}$ specific for each station was less than $30 \%$ for $36 \%$ of the stations and less than $50 \%$ for $48 \%$ of the stations. Due to the poor results obtained using a general equation for the intercept for the high flow region in the calibration data set, no general model was developed for the validation data set. Drainage area data and relative error for the specific model is shown in Appendix $\mathrm{J}$. 


\section{RESULTS AND DISCUSSION}

The main purpose of this research was to develop a generalized equation for rating stream depth-discharge when there is an absence of a rating measurement data set. The equation will describe the depth-discharge rating by recognizing and individually describing the intermediate and high-flow regions. A secondary interest was to provide a simple equation which could be used in model calibration.

From the three explored approaches, the general model based on the depthdischarge values using the $10 \%$ exceedence flow rate and depth, provided the best overall results. It is important to mention that even though all three explored approaches require some normalization parameters, in the case of Approach 2 and 3, the estimation of the scaling factors, may introduce some potential errors. Nevertheless, even factoring in the error into the analysis, Approach 3 yielded the best results.

A qualitative assessment of results from Approach 3 is shown in Figure 26. The qualitative comparison shows that those stations that provide an apparent "good fit" match only partially the USGS rating data. The matching region corresponds to low and intermediate flows. It is clear from these results that this model does not adequately represent the high flow region. For some stations that upper limit of applicability is around the $\mathrm{Q}_{10}$ and for others is near the rating break point. However, some stations showed good performance for discharges much larger than $\mathrm{Q}_{10}$ and $\mathrm{Q}_{\text {full }}$ flows. 
In order to quantitatively evaluate the accuracy of the proposed method, values of discharge were obtained using Approach 3 and compared to discharge values from the USGS rating curves. The Student's paired T-test was used as the statistical analysis to measure the differences between the discharge from the USGS rating curves and the discharge estimated by the model. The T-test is commonly used to compare the mean differences between two data sets based on the paired differences of the data. The test statistic assumes that the sampling distribution of the differences is approximately normally distributed and independent of the magnitude of the discharge (Johnson, 1995). The test was performed for each of the stations in the study area. Results are shown in Table 8.

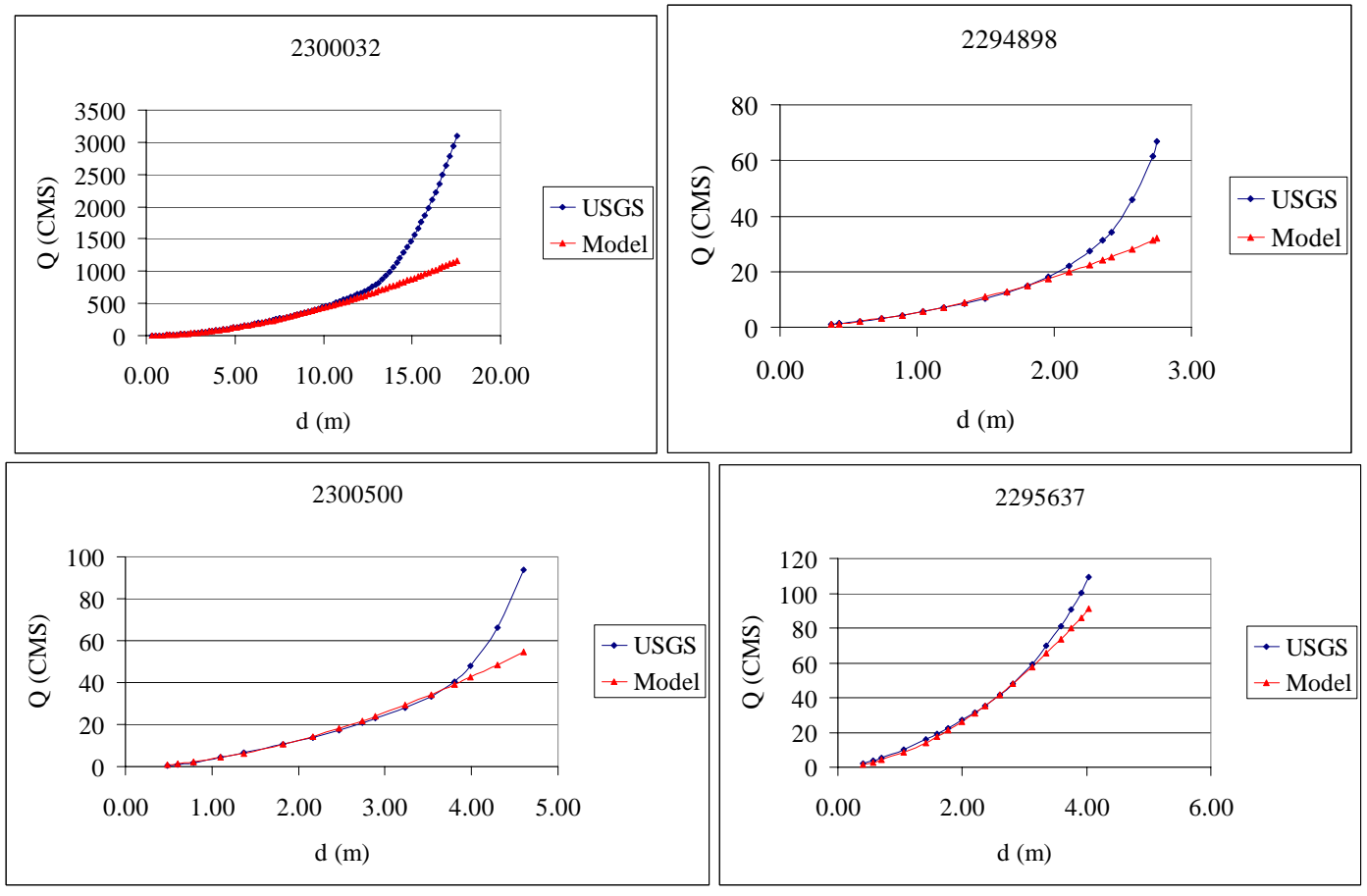

Figure 26. Some Stations that Partially Matched the USGS Rating Data Using Approach 3 
Table 8. Results of T-test for 43 Stations in West-Central Florida

\begin{tabular}{cccccc}
\hline Station & T test & Station & T test & Station & T test \\
\hline 5 & -0.77 & 22 & -1.68 & 44 & -3.21 \\
6 & -0.66 & 23 & -1.39 & 48 & -6.37 \\
7 & -2.85 & 24 & -1.21 & 50 & -0.52 \\
8 & -0.19 & 28 & -3.01 & 51 & 8.06 \\
9 & -1.41 & 29 & -2.63 & 52 & 11.42 \\
10 & -0.38 & 30 & -2.39 & 53 & -2.26 \\
11 & -1.98 & 31 & -5.97 & 54 & -3.10 \\
12 & -1.37 & 32 & -8.55 & 57 & -2.16 \\
13 & -4.64 & 34 & -2.58 & 58 & -1.71 \\
15 & -0.49 & 35 & -3.81 & 63 & -1.60 \\
16 & -1.49 & 37 & -5.95 & 64 & -1.77 \\
17 & 3.06 & 38 & -3.44 & 44 & -3.21 \\
18 & -2.07 & 39 & -2.73 & 48 & -6.37 \\
19 & -1.98 & 41 & -3.75 & 50 & -0.52 \\
20 & 0.47 & 42 & -5.06 & 51 & 8.06 \\
21 & -1.07 & 43 & -8.64 & & \\
\hline
\end{tabular}

Results from the T-test were provided using a 95\% level of confidence. Good model estimation for this level should result in a value within the range of \pm 1.96 for the highest sampling size and \pm 2.23 for the lowest. Approximately $50 \%$ of the stations fall within this range, suggesting that the proposed model might provide a good estimation of the rating curve for better than half of the stations.

To further analyze these results, the relative percent error in discharge was examined. As mentioned earlier, the average relative error of the proposed model compared to the USGS data varies from $20 \%$ to $50 \%$ for $42 \%$ of the stations and $51 \%$ to $100 \%$ in $48 \%$ of the stations. For the flow range between the $\mathrm{Q}_{90}$ and the $\mathrm{Q}_{10}$ discharge, the average relative error is below $30 \%$ for $47 \%$ of the stations, and below $50 \%$ for $65 \%$ of the stations. Although good performance was seen for many stations for much larger 
than $\mathrm{Q}_{10}$ flows, the higher flows errors indicated that a better definition of model parameters and range of applicability is warranted.

From the analysis of the three approaches it is recognized that the slopes in the intermediate-flow region vary within a specific range and that the high-flow regions exhibited log-linear behavior with considerably different slopes than the intermediateflow regions. Thus, two different mathematical relationships are proposed for each of the flow regions. The model for the intermediate-flow region using specific values of $\mathrm{Q}_{10}$ and $\mathrm{d}_{10}$ provided good overall results with $74 \%$ of the stations exhibiting errors below $30 \%$. When testing the model using values of $\mathrm{Q}_{10}$ and $\mathrm{d}_{10}$ as determined from the regression equations, the results are still reasonably good, with $60 \%$ of the stations with errors below 30\%. Therefore, the regression equations for $\mathrm{Q}_{10}$ and $\mathrm{d}_{10}$ provide a fairly good estimation of these highly sensitive model parameters, with an average relative error of $26 \%$ for $Q_{10}$ and $20 \%$ for $\mathrm{d}_{10}$. Table 9 shows the comparison between the USGS data and model results for some of the stations in the study.

A qualitative assessment of results for the intermediate-flow region is shown in Figures 27A and B. These figures show a comparison using both the specific and general values of $\mathrm{Q}_{10}$ and $\mathrm{d}_{10}$, for some of the stations in the study area. As indicated from the relative errors, when using the proposed model with $\mathrm{Q}_{10}$ and $\mathrm{d}_{10}$ values specific for each station, the matching region (i.e., the region exhibiting excellent performance) with the USGS data is much larger than when the values are estimated from the regression equations. This would be very useful if using the relationship for calibration purposes, where specific values of $\mathrm{Q}_{10}$ and $\mathrm{d}_{10}$ are known for a particular stream; in those cases, a much better performance of the model could be expected. This would also represent a 
good relationship for the stage-discharge characteristics of the particular stream (perhaps even in un-gauged regions).

Table 9. Relative Percent Error for Some Stations in West-Central Florida for the Intermediate and High-Flow Region

\begin{tabular}{|c|c|c|c|c|c|c|c|}
\hline \multicolumn{5}{|c|}{ Station 2300500} & \multirow{2}{*}{\multicolumn{3}{|c|}{ High-Flow Region }} \\
\hline \multicolumn{5}{|c|}{ Intermediate-Flow Region } & & & \\
\hline Q-USGS ${ }^{1}$ & Q-Mod_Specific ${ }^{2}$ & $\mathrm{RE}^{3}$ & Q-Mod_General ${ }^{4}$ & $\mathrm{RE}$ & Q-USGS & Q-Model & $\mathrm{RE}$ \\
\hline CMS & CMS & $\%$ & CMS & $\%$ & CMS & CMS & $\%$ \\
\hline 6.7 & 5.9 & 12.3 & 6.1 & 8.0 & 47.8 & 48.2 & 0.9 \\
\hline 10.6 & 10.6 & 0.2 & 11.1 & 5.2 & 66.0 & 70.0 & 6.1 \\
\hline 23.0 & 27.2 & 18.6 & 28.6 & 24.5 & 170.9 & 180.4 & 5.5 \\
\hline 40.7 & 47.6 & 17.0 & 49.9 & 22.8 & 393.1 & 414.0 & 5.3 \\
\hline \multicolumn{8}{|c|}{ Station 2301300} \\
\hline \multicolumn{5}{|c|}{ Intermediate-Flow Region } & \multicolumn{3}{|c|}{ High-Flow Region } \\
\hline Q-USGS & Q-Mod_Specific & $\mathrm{RE}$ & Q-Mod_General & $\mathrm{RE}$ & Q-USGS & Q-Model & $\mathrm{RE}$ \\
\hline CMS & CMS & $\%$ & CMS & $\%$ & CMS & CMS & $\%$ \\
\hline 0.6 & 0.4 & 26.5 & 0.4 & 23.4 & 11.6 & 9.3 & 19.8 \\
\hline 1.6 & 1.3 & 19.1 & 1.4 & 15.7 & 21.9 & 19.5 & 10.7 \\
\hline 3.2 & 2.8 & 10.7 & 3.0 & 7.0 & 41.3 & 35.7 & 13.4 \\
\hline 5.3 & 5.2 & 2.3 & 5.4 & 1.8 & 54.0 & 46.1 & 14.5 \\
\hline 6.0 & 6.0 & 0.3 & 6.2 & 4.0 & & & \\
\hline \multicolumn{8}{|c|}{ Station 2297310} \\
\hline \multicolumn{5}{|c|}{ Intermediate-Flow Region } & \multicolumn{3}{|c|}{ High-Flow Region } \\
\hline Q-USGS & Q-Mod_Specific & $\mathrm{RE}$ & Q-Mod_General & $\mathrm{RE}$ & Q-USGS & Q-Model & $\mathrm{RE}$ \\
\hline CMS & CMS & $\%$ & $\mathrm{CMS}$ & $\%$ & CMS & CMS & $\%$ \\
\hline 0.3 & 0.3 & 24.2 & 0.4 & 9.6 & 37.2 & 30.3 & 18.5 \\
\hline 1.9 & 1.6 & 16.8 & 2.3 & 20.4 & 89.1 & 66.6 & 25.3 \\
\hline 5.3 & 4.8 & 8.9 & 6.9 & 31.8 & 121.7 & 88.3 & 27.5 \\
\hline 12.1 & 12.1 & 0.2 & 17.5 & 44.3 & 270.0 & 181.7 & 32.7 \\
\hline 23.2 & 24.8 & 7.0 & 35.9 & 54.8 & & & \\
\hline $\begin{array}{l}\text { Q-USGS = } \\
\text { 98) } \\
\text { 2-Mod_Spe } \\
\text { E = relativ }\end{array}$ & $\begin{array}{l}\text { ic }=\text { model results } \\
\text { rror }\end{array}$ & g relc & $\begin{array}{l}\text { nship data (Wate } \\
\text { nd } \mathrm{d}_{10} \text { values spec }\end{array}$ & Resourc & station & lorida, US & \\
\hline
\end{tabular}

The model for the high-flow region using specific values of $\mathrm{Q}_{10}$ and $\mathrm{d}_{10}$ provided reasonably good overall results with $40 \%$ of the stations with errors below $30 \%$. A 
qualitative assessment of results for the high-flow region is shown in Figures 28A and B. Table 6 shows the results for some of the stations in the study.

As mentioned, when testing the model using values of $\mathrm{Q}_{\text {dep }}$ as determined from the regression equations, the errors were larger than $100 \%$ in most of the stations. The regression equation for $\mathrm{Q}_{\text {dep }}$ provides a poor estimation of the parameter, with an average relative error of 57\%. The lack of accuracy in the prediction of the high-flow region model with a general intercept is mostly due to the lack of an equation that better describes the $\mathrm{Q}_{\text {dep }}$ parameter.

From testing the model with the verification data set, the average relative error when compared to the USGS data for the intermediate flow was less than $50 \%$ for $70 \%$ of the stations. Thus, the error was comparable to the results obtained with the calibration data set.

Testing the model in some stations at North Florida, and South Alabama and Georgia, show some reasonable relative errors but not as good as the results obtained for West Central Florida. Using a model with a different slope, developed for those particular stations improved the results significantly. The larger watershed size in this area could explain the different, lower slope of the ratings, considering that large sized watersheds will exhibit higher values of depth for the mean discharge, resulting in flatter rating slopes.

It is important to mention that when comparing a fixed USGS rating relationship to actual historical USGS physical measurements, the average relative error among the stations was found to be around $90 \%$. Thus, results from the proposed models may still 
be comparable to the accuracy of a well established rating when compared to a particular flow measurement.
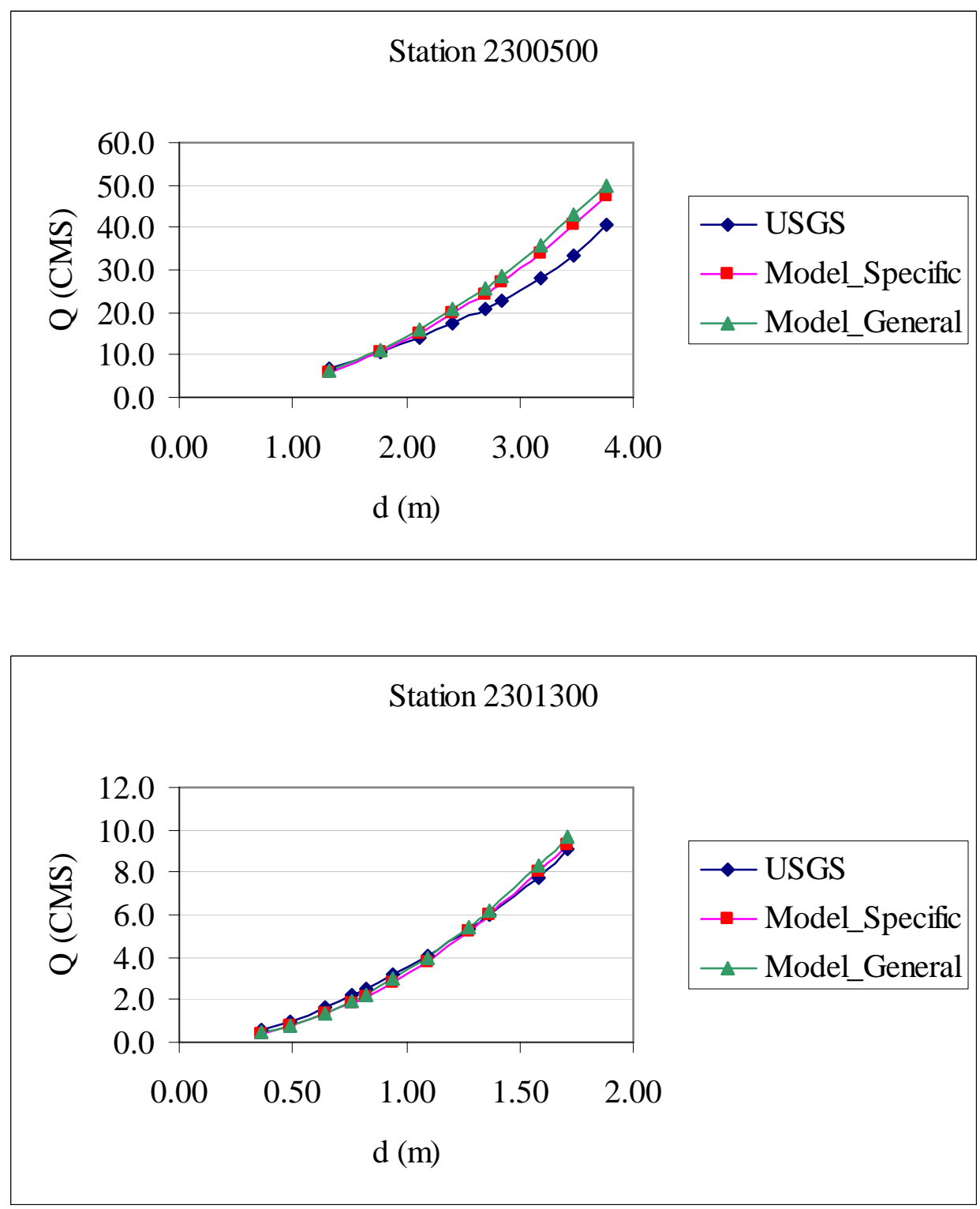

Figure 27. Comparison of USGS Rating with Model Results, for the Intermediate-Flow Region, for Some Stations in the Study Area 

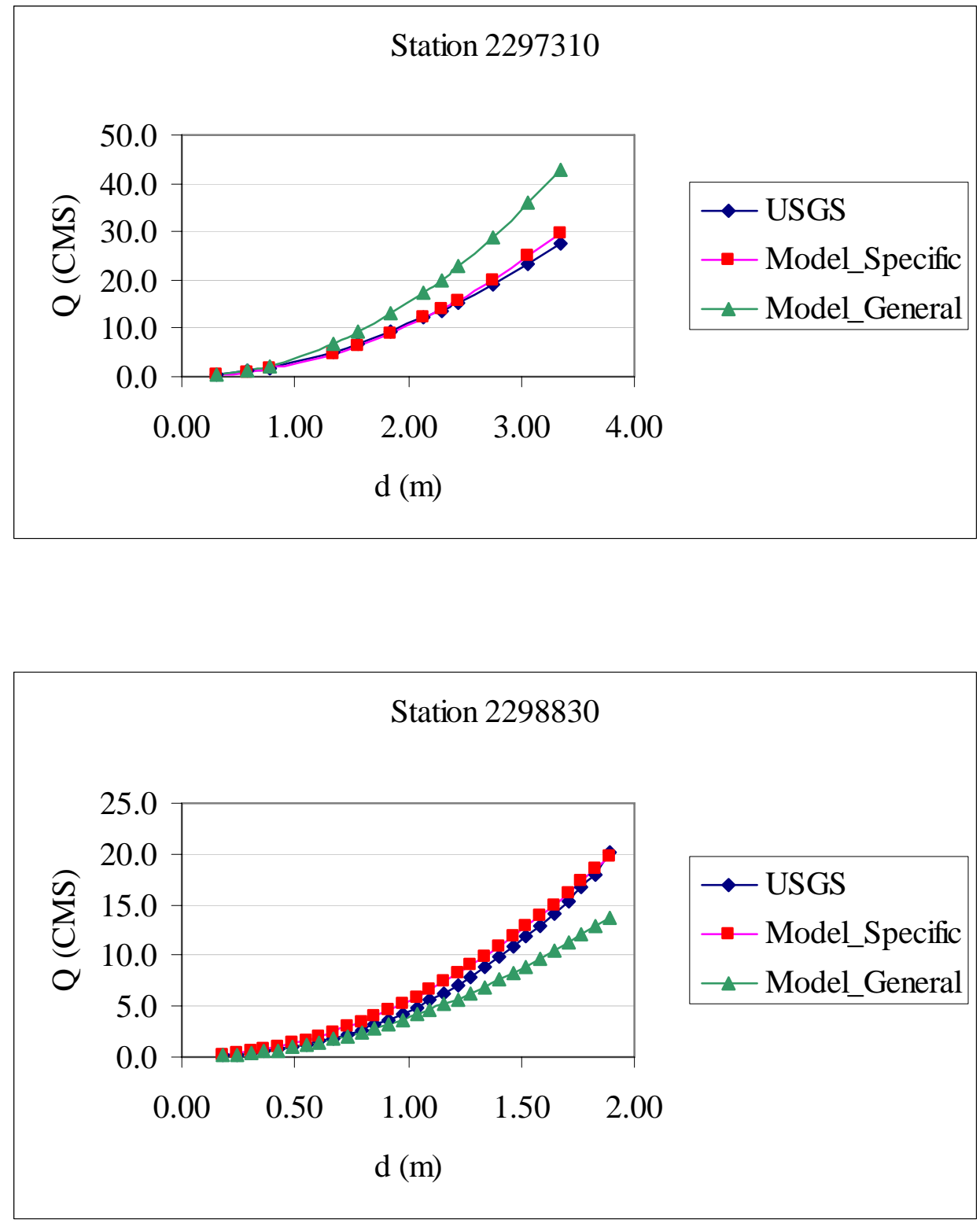

Figure 27. (Continued) 

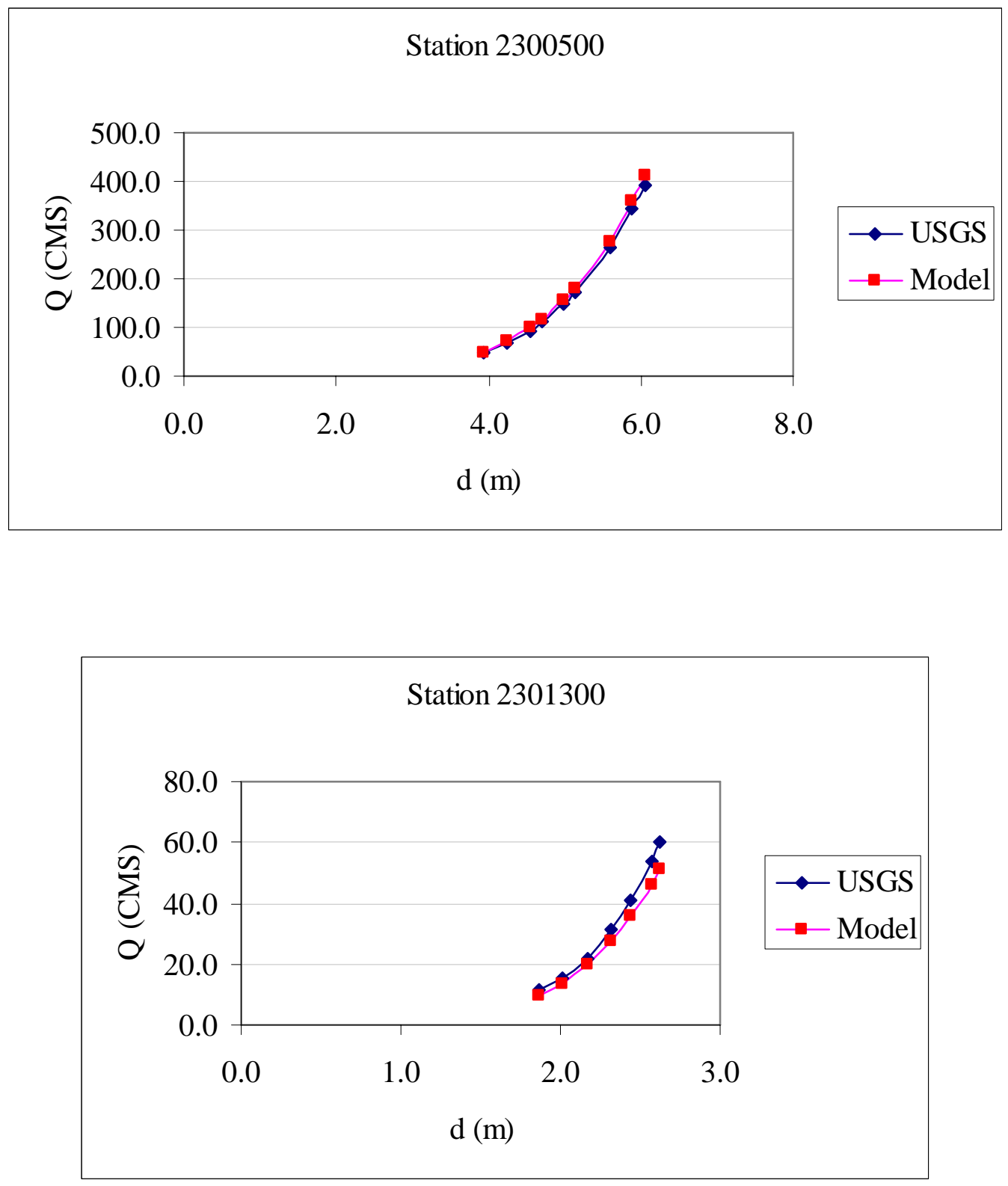

Figure 28. Comparison of USGS Rating with Model Results, for the High-Flow Region, for Some Stations in the Study Area 

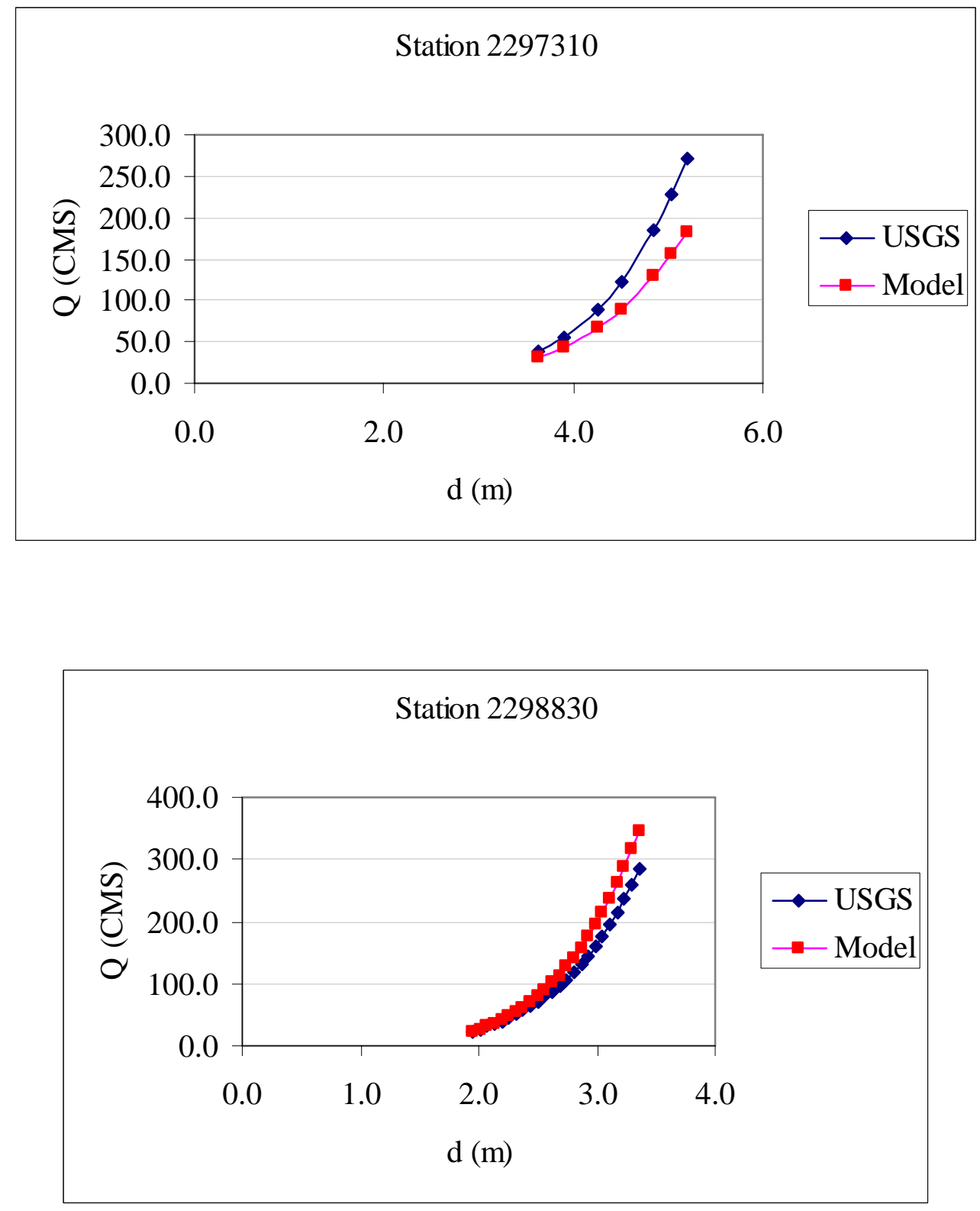

Figure 28. (Continued) 


\section{CONCLUSIONS}

This study provides a generalized mathematical expression that describes depth-discharge relationships for stream gauging stations in West-Central Florida, for the intermediate and high-flow regions. The study also provides the parameters required to estimate rating curves when there is limited or no measured data available.

Despite using stage-discharge by the conventional methods, this study used the channel depth instead of stage elevation to define the rating curve. This approach provided the advantage of being easier to correlate to a reference in un-gauged streams and it was contended to be more realistic in terms of the physical processes of the system.

For the intermediate-flow region, rating curves developed in mild-sloped streams of West-Central Florida, provided by USGS data plotted in log-log scale, exhibit linear behavior with similar slopes and approximate zero intercept. Also, the high-flow regions exhibited log-linear behavior with considerably different slopes than the intermediateflow regions, and different intercepts. Thus two different mathematical relationships can be defined for each of the flow regions.

In this study, the difference in streamflow behavior between the two regions and within the same flow region was examined by presuming simple control at stream sections (e.g., behaving as weirs). The variation of the rating slopes within the range of 1.5 to 2.5 in the intermediate-flow region could be due to streamflow being controlled at a section that is through a relative degree of contraction (e.g., behaving either as 
rectangular, trapezoidal or V-notch section with discharge coefficients between 3/2 and 5/2). For the high-flow region, steeper rating slopes are undoubtedly indicating a higher degree of contraction and non-uniform flow. The different frictional conditions and cross section characteristics of floodplain flows (e.g., with or without houses) also plays a role in the behavior.

A log-linear equation with zero intercept and a slope of 2.0 is proposed for the intermediate-flow region for the West-Central Florida study area as a general mathematical model. The model is defined using the $10 \%$ exceedence flow rate $\left(\mathrm{Q}_{10}\right)$ and corresponding depth $\left(\mathrm{d}_{10}\right)$. The $\mathrm{Q}_{10}$ was shown to be reasonably well correlated to the watershed drainage area and the $\mathrm{d}_{10}$ showed a reasonable good correlation to the $\mathrm{Q}_{10}$, thus a regression equation was defined to obtain general values for those two parameters.

A log-linear equation with a slope of 5.0 and an intercept specific for each station is proposed for the high-flow region for the West-Central Florida study area. The model uses the same $\mathrm{Q}_{10}$ and $\mathrm{d}_{10}$ parameters defined for the intermediate-flow region. The intercept is related to the discharge where the high-flow region departures from the intermediate-flow region $\left(\mathrm{Q}_{\mathrm{dep}}\right)$. General values for intercept were obtained by defining a regression equation of $\mathrm{Q}_{\mathrm{dep}}$ as a function of drainage area.

The accuracy of the proposed two-region model was examined statistically. Results show that for the intermediate-flow region, the average relative error is below $50 \%$ for $86 \%$ of the stations when using values of $\mathrm{Q}_{10}$ and $\mathrm{d}_{10}$ specific for each station; and below $50 \%$ for $74 \%$ of the stations when using values of $Q_{10}$ and $d_{10}$ from the regression equations. For the high-flow region, the average relative error is below $50 \%$ for $44 \%$ of the stations when using values of the intercept specific for each station. When 
using values of the intercept from the regression equations the errors are higher than $100 \%$. Thus, this is not a good predictive approach. The accuracy in the prediction of the high-flow region model with a general intercept could be improved with an equation that better describes the $\mathrm{Q}_{\text {dep }}$ parameter. Other expressions may exist for this parameter but no insight yet exists as to how it could be better estimated in the absence of site specific data.

Results from verifying the intermediate flow region model in thirty stations that had not been previously used in developing the model, showed to be comparable to the ones obtained with the calibration data set.

The model was validated by testing in some stations at North Florida, and South Alabama and Georgia. Using the model with a slope developed specific for those particular stations showed the best results. A log-linear equation with zero intercept and a slope of 1.35 is proposed for the intermediate-flow region for those areas. The different, lower slope of the ratings in those areas may be due to the size of the watersheds.

It is interesting to note that the accuracy of the proposed models may be comparable to (or better than) the discrepancies between a fixed USGS rating relationship and periodic physical flow measurement. Therefore, the use of similar general rating relationships in West-Central Florida or elsewhere should prove to be a useful method to populate model data sets (subject to calibration through simple parameterization) when limited field data exist for model stream sections. 


\section{REFERENCES}

Atabay, S. and D. Knight, 1999. Stage-Discharge and Resistance Relationships for Laboratory Alluvial Channels with Overbank Flow. In: Proceedings of the $7^{\text {th }}$ International Symposium on River Sedimentation (A. W. Jayawardena, J. H. Lee and Z. Y. Wang). Hong Kong, pp. 223-229.

Bhattacharya, B. and D. Solomatine, 2000. Application of Artificial Neural Network in Stage-Discharge Relationship. In: Proceedings of the $4^{\text {th }}$ International Conference of Hydroinformatics, Iowa City, USA.

Cinotto, P., 2003. Development of Regional Curves of Bakfull-Channel Geometry and Dischage for Streams in the Non-Urban, Piedmont Physiographic Province, Pennsylvania and Maryland. U.S. Geological Survey Water Resources Investigations Report 03-4014, 33 p.

Dawdy, D., W. Lucas, and W. Wang, 2000. Physical Basis of Stage-Discharge Ratings. In: Proceedings of the $8^{\text {th }}$ International Symposium on Stochastic Hydraulics, Beijing, China. (A.A. Balkema). Rotterdam, pp. 561-564.

Deka, P. and V. Chandramouli, 2003. A Fuzzy Neural Network Model for Deriving the River Stage-Dischage Relationship. Hydrological Sciences, 48(2): pp. 197-209.

Dingman, C., Bjerklie, D., S. Vorosmarty, C. Bolster, and R. Congalton. 2003. Evaluating the potential for measuring river discharge from space. Journal of Hydrology, 278: pp. 17-38.

Dingman, L. and K. Sharma, 1997. Statistical Development and Validation of Discharge Equations for Natural Channels. Journal of Hydrology, 199: pp. 13-35.

Dymond, J. and R. Christian, 1982. Accuracy of Discharge Determined from a Rating Curve. Hydrological Sciences, 4 (12): pp. 493-504.

Ervine, D., B. Willetts, R. Sellin and M. Lorena, 1993. Factors Affecting Conveyance in Meandering Compound Flows. Journal of Hydraulic Engineering, 119 (12): pp. 13831399.

Fenton, J. and R. Keller, 2001. The Calculation of Streamflow from Measurements of Stage. Cooperative Research Centre for Catchment Hydrology, Technical Report $01 / 6$. 
Franchini, M., P. Lamberti and P. Di Giammarco. Rating Curve Estimation Using Local Stages, Upstream Discharge Data and a Simplified Hydraulic Model. Hydrologic Earth Systems Sciences. 3: pp. 524-548.

Gotvald, A., J. Fisher, C. Oberst and D. Calhoun, 2004. Water Resources Data, Georgia, Water Year, 2004. Water Data Report FL-04-1. U.S. Geological Survey.

Gupta, R., 2001. Hydrology and Hydraulic Systems. Waveland Press, Illinois.

Hammett, K. and M. DelCharco, 2005. Estimating the Magnitude and Frequency of Floods for Streams in West-Central Florida, 2001. U.S. Geological Survey Scientific Investigation Report Techniques 2005-5080.

Johnson, R., 1995. Just the Essentials of Elementary Statistics. Wadsworth, California.

Jothityangkoon, C. and M. Sivapalan, 2003. Towards Estimation of Extreme Flows: Examination of the Roles of Runoff Process Changes and Floodplain Flows. Journal of Hydrology, 281 (3): pp 206-230.

Kamula, R., 2000. Flow over Weirs with Application to Fish Passage Facilities, PhD. Dissertation, University of Oulu, Finland.

Kane, R., 2004. Water Resources Data, Florida, Water Year 2004: Volume 3A, Southwest Florida Surface Water, USGS.

Keaton, J., T. Messinger and E. Doheny, 2005. Development and Analysis of Regional Curves for Streams in the Non-Urban Valley and Ridge Physiographic Province, Maryland, Virginia and West Virginia. U.S. Geological Survey Scientific Investigation Report 2005-5076, 116 p.

Kennedy, E., 1984. Discharge Ratings at Gauging Stations. Techniques of Water Resources Investigations of the U.S. Geological Survey, USGS Book 3, Chapter A10.

Kuck, T., 2000. Regional Hydraulic Geometry Curves of the South Umpqua Area in Southwestern Oregon. Stream Systems Technology Center. $<$ http://www.stream.fs.fed.us/news/streamnt/jan00/jan00_3.htm>.

Leopold L. and T. Maddock, 1953. The Hydraulic Geometry of Stream Channels and Some Physiographic Implications. U.S. Geological Survey Professional Paper 252, $64 \mathrm{p}$.

Lewelling, B., 2003. Extent of Areal Inundation of Riverine Wetlands along Five River Systems in the Upper Hillsborough River Watershed, West-Central Florida. U.S. Geological Survey Scientific Investigation Report 2004-5133, 49 p. 
Lewis, J., 1998. Enhancements of River Forecasts Using Dynamic Hydraulic Flow Routing. In: Proceedings of the $78^{\text {th }}$ Annual AMS Meeting. Phoenix, Arizona.

Mazvimavi, D., S. Burgers and A. Stein, 2006. Identification of Basing Characteristics Influencing Spatial Variation of River Flows. International Journal of applied Earth Observation and Geoinformation, 8 (3): pp. 165-172.

Metcalf, C., 2004. Regional Channel Characteristics for Maintaining Natural Fluvial Geomorphology in Florida Streams. U.S. Fish and Wildlife Service Report BD470. <http://www.dot.state.fl.us/Research-Center/Completed_Proj/Summary_EMO/FDOT_BD470.pdf>.

Moody, T., M. Wirtanen and S. Yard, 2003. Regional Relationship for Bankfull Stage in Natural Channels of the Arid Southwest. Arid SW Regional Report 2003. $<$ http://www.naturalchanneldesign.com/Reports/Arid\%20SW\%20Report.pdf>.

Moramarco, T. and V. Singh, 2001. Simple Method for Relating Local Stage and Remote Discharge. Journal Hydrologic Engineering, 6 (1): pp. 78-81.

Psinakis, W., D.Lambeth, V. Stricklin and M. Treece. Water Resources Data, Alabama, Water Year, 2004. Water Data Report AL-04-1. U.S. Geological Survey.

Rantz, S. et al., 1982. Measurement and Computation of Streamflow: Volume 2. Computation of Discharge. Water Supply Paper 2175, USGS, pp. 285-631.

Rating Curve Data. U.S. Geological Survey. 2006. $<$ http://waterdata.usgs.gov/nwisweb/data/exsa_rat>.

Savage, B. and M. Johnson, 2001. Flow Over Ogee Spillway: Physical And Numerical Model Case Study. Journal of Hydraulic Engineering, 127 (8): pp. 640-649.

Shesha, M. and A. Shivapur, 2003. Generalized Head-Discharge Equation For Flow Over Sharp-Crested Inclined Inverted V-Notch Weir. Journal of Irrigation and Drainage Engineering, 130 (4): 325-330.

Sivapalan, M., C. Jothityangkoon, and M. Menabde, 2001. Linearity and Nonlinearity of Basin Response as a Function of Scale: Discussion of Alternative Definitions. Water Resources Research, 38 (2).

Szilagyi, J., G. Balint, B. Gauzer and P. Bartha, 2005. Flow Routing with Unknown Rating Curves Using a State-Space Reservoir-Cascade-Type Formulation. Journal of Hydrology, 311 (1-4): pp. 219-229. 
Tillery, A., J. Phillips and J. Capesius, 2001. Potential Errors Associated with StageDischarge Relations for Selected Streamflow-Gaging Stations, Maricopa County, Arizona. U.S. Geological Survey Water Resources Investigation Report 00-4224, $54 \mathrm{p}$.

U.S. Geological Survey. Water Resources Data, Florida, Water Year, 2004. Water Data Report FL-04-4.

Westphal, J., D. Thompson, G. Stevens and C. Strauser, 1999. Stage-Discharge Relations on the Middle Mississippi River. Journal of Water Resources Planning and Management. 125 (1), pp. 48-53. 
APPENDICES 
Appendix A: Results from Weir Analysis in Channel Controlled by a Horizontal_Uncontracted Section

Table 10. Results from Weir Analysis in Channel Controlled by a Horizontal_Uncontracted Section

\begin{tabular}{cccccccc}
\hline $\mathrm{C}=$ & 3.3 & & & $\mathrm{C}=$ & 3.5 & & \\
$\mathrm{H}$ & $\mathrm{Q}$ & $\mathrm{H}^{\prime}$ & $\mathrm{Q}^{\prime}$ & $\mathrm{H}$ & $\mathrm{Q}$ & $\mathrm{H}^{\prime}$ & $\mathrm{Q}^{\prime}$ \\
$\mathrm{m}$ & $\mathrm{CMS}$ & & & $\mathrm{m}$ & $\mathrm{CMS}$ & & \\
0.06 & 0.08 & 0.06 & 0.03 & 0.06 & 0.09 & 0.06 & 0.03 \\
0.15 & 0.33 & 0.15 & 0.11 & 0.15 & 0.35 & 0.15 & 0.11 \\
0.30 & 0.94 & 0.30 & 0.30 & 0.30 & 0.99 & 0.30 & 0.32 \\
0.46 & 1.72 & 0.45 & 0.55 & 0.46 & 1.82 & 0.45 & 0.58 \\
0.61 & 2.65 & 0.61 & 0.85 & 0.61 & 2.81 & 0.61 & 0.90 \\
0.91 & 4.86 & 0.91 & 1.56 & 0.91 & 5.15 & 0.91 & 1.65 \\
1.22 & 7.48 & 1.21 & 2.40 & 1.22 & 7.93 & 1.21 & 2.55 \\
1.52 & 10.46 & 1.52 & 3.35 & 1.52 & 11.09 & 1.52 & 3.56 \\
$\mathrm{C}=$ & 4 & & & $\mathrm{C}=$ & 4.4 & & \\
$\mathrm{H}$ & $\mathrm{Q}$ & $\mathrm{H}$ & $\mathrm{Q}$ & $\mathrm{H}$ & $\mathrm{Q}$ & $\mathrm{H}^{\prime}$ & $\mathrm{Q}$ \\
$\mathrm{m}$ & $\mathrm{CMS}$ & & & $\mathrm{m}$ & $\mathrm{CMS}$ & & \\
0.06 & 0.10 & 0.06 & 0.03 & 0.06 & 0.11 & 0.06 & 0.04 \\
0.15 & 0.40 & 0.15 & 0.13 & 0.15 & 0.44 & 0.15 & 0.14 \\
0.30 & 1.13 & 0.30 & 0.36 & 0.30 & 1.25 & 0.30 & 0.40 \\
0.46 & 2.08 & 0.45 & 0.67 & 0.46 & 2.29 & 0.45 & 0.73 \\
0.61 & 3.21 & 0.61 & 1.03 & 0.61 & 3.53 & 0.61 & 1.13 \\
0.91 & 5.89 & 0.91 & 1.89 & 0.91 & 6.48 & 0.91 & 2.08 \\
1.22 & 9.07 & 1.21 & 2.91 & 1.22 & 9.98 & 1.21 & 3.20 \\
1.52 & 12.67 & 1.52 & 4.07 & 1.52 & 13.94 & 1.52 & 4.47 \\
\hline
\end{tabular}


Appendix B: Results from Weir Analysis in Channel Controlled by a Horizontal_Contracted Section

Table 11. Results from Weir Analysis in Channel Controlled by a Horizontal_Contracted Section

\begin{tabular}{cccccccc}
\hline $\mathrm{C}=$ & 3.3 & & \multicolumn{5}{c}{$\mathrm{C}=$} \\
$\mathrm{H}$ & $\mathrm{Q}$ & $\mathrm{H}^{\prime}$ & $\mathrm{Q}^{\prime}$ & $\mathrm{H}$ & $\mathrm{Q}$ & $\mathrm{H}^{\prime}$ & $\mathrm{Q}^{\prime}$ \\
$\mathrm{m}$ & $\mathrm{CMS}$ & & & $\mathrm{m}$ & $\mathrm{CMS}$ & & \\
0.06 & 0.03 & 0.06 & 0.01 & 0.06 & 0.00 & 0.06 & 0.01 \\
0.15 & 0.13 & 0.15 & 0.04 & 0.15 & 0.00 & 0.15 & 0.04 \\
0.30 & 0.36 & 0.30 & 0.11 & 0.30 & 0.01 & 0.30 & 0.12 \\
0.46 & 0.64 & 0.45 & 0.20 & 0.46 & 0.01 & 0.45 & 0.22 \\
0.61 & 0.95 & 0.61 & 0.31 & 0.61 & 0.02 & 0.61 & 0.32 \\
0.91 & 1.65 & 0.91 & 0.53 & 0.91 & 0.03 & 0.91 & 0.56 \\
1.22 & 2.39 & 1.21 & 0.77 & 1.22 & 0.03 & 1.21 & 0.81 \\
1.52 & 3.14 & 1.52 & 1.01 & 1.52 & 0.04 & 1.52 & 1.07 \\
$\mathrm{C}=$ & 4 & & & $\mathrm{C}=$ & 4.4 & & \\
$\mathrm{H}$ & $\mathrm{Q}$ & $\mathrm{H}$ & $\mathrm{Q}^{\prime}$ & $\mathrm{H}$ & $\mathrm{Q}$ & $\mathrm{H}^{\prime}$ & $\mathrm{Q}$ \\
$\mathrm{m}$ & $\mathrm{CMS}$ & & & $\mathrm{m}$ & $\mathrm{CMS}$ & & \\
0.06 & 0.04 & 0.06 & 0.01 & 0.06 & 0.00 & 0.06 & 0.01 \\
0.15 & 0.16 & 0.15 & 0.05 & 0.15 & 0.00 & 0.15 & 0.06 \\
0.30 & 0.43 & 0.30 & 0.14 & 0.30 & 0.01 & 0.30 & 0.15 \\
0.46 & 0.77 & 0.45 & 0.25 & 0.46 & 0.01 & 0.45 & 0.27 \\
0.61 & 1.15 & 0.61 & 0.37 & 0.61 & 0.02 & 0.61 & 0.41 \\
0.91 & 2.00 & 0.91 & 0.64 & 0.91 & 0.03 & 0.91 & 0.71 \\
1.22 & 2.90 & 1.21 & 0.93 & 1.22 & 0.03 & 1.21 & 1.02 \\
1.52 & 3.80 & 1.52 & 1.22 & 1.52 & 0.04 & 1.52 & 1.34 \\
\hline
\end{tabular}


Appendix C: Results from Weir Analysis in Channel Controlled by a V-Notch Section

Table 12. Results from Weir Analysis in Channel Controlled by a V-Notch Section

\begin{tabular}{cccccccc}
\hline $\mathrm{C}=$ & 2 & & & $\mathrm{C}=$ & 2.5 & & \\
$\mathrm{H}$ & $\mathrm{Q}$ & $\mathrm{H}^{\prime}$ & $\mathrm{Q}^{\prime}$ & $\begin{array}{c}\mathrm{H} \\
\mathrm{m}\end{array}$ & $\begin{array}{c}\mathrm{Q} \\
\mathrm{CMS}\end{array}$ & $\mathrm{H}^{\prime}$ & $\mathrm{Q}^{\prime}$ \\
$\mathrm{m}$ & $\mathrm{CMS}$ & & & 0.06 & 0.00 & 0.06 & 0.00 \\
0.06 & 0.00 & 0.06 & 0.00 & 0.06 & 0.15 & 0.01 \\
0.15 & 0.01 & 0.15 & 0.01 & 0.15 & 0.01 & 0.15 \\
0.30 & 0.06 & 0.30 & 0.02 & 0.30 & 0.07 & 0.30 & 0.02 \\
0.46 & 0.16 & 0.45 & 0.03 & 0.46 & 0.20 & 0.45 & 0.04 \\
0.61 & 0.32 & 0.61 & 0.05 & 0.61 & 0.40 & 0.61 & 0.06 \\
0.91 & 0.88 & 0.91 & 0.09 & 0.91 & 1.10 & 0.91 & 0.12 \\
1.22 & 1.81 & 1.21 & 0.15 & 1.22 & 2.27 & 1.21 & 0.18 \\
1.52 & 3.17 & 1.52 & 0.20 & 1.52 & 3.96 & 1.52 & 0.25 \\
$\mathrm{C}=$ & 3 & & & $\mathrm{C}=$ & 4.3 & & \\
$\mathrm{H}$ & $\mathrm{Q}$ & $\mathrm{H}^{\prime}$ & $\mathrm{Q}^{\prime}$ & $\mathrm{H}$ & $\mathrm{Q}$ & $\mathrm{H}^{\prime}$ & $\mathrm{Q}^{\prime}$ \\
$\mathrm{m}$ & $\mathrm{CMS}$ & & & $\mathrm{m}$ & $\mathrm{CMS}$ & & \\
0.06 & 0.00 & 0.06 & 0.00 & 0.06 & 0.00 & 0.06 & 0.00 \\
0.15 & 0.02 & 0.15 & 0.01 & 0.15 & 0.02 & 0.15 & 0.01 \\
0.30 & 0.09 & 0.30 & 0.03 & 0.30 & 0.12 & 0.30 & 0.04 \\
0.46 & 0.23 & 0.45 & 0.05 & 0.46 & 0.34 & 0.45 & 0.07 \\
0.61 & 0.48 & 0.61 & 0.08 & 0.61 & 0.69 & 0.61 & 0.11 \\
0.91 & 1.33 & 0.91 & 0.14 & 0.91 & 1.90 & 0.91 & 0.20 \\
1.22 & 2.72 & 1.21 & 0.22 & 1.22 & 3.90 & 1.21 & 0.31 \\
1.52 & 4.75 & 1.52 & 0.30 & 1.52 & 6.81 & 1.52 & 0.44 \\
\hline
\end{tabular}


Appendix D: Results from Weir Analysis in Channel Controlled by a Broad Crested Weir

Table 13. Results from Weir Analysis in Channel Controlled by a Broad Crested Weir

\begin{tabular}{cccccccc}
\hline $\mathrm{C}=$ & 2.3 & & \multicolumn{5}{c}{$\mathrm{C}=$} \\
$\mathrm{H}$ & $\mathrm{Q}$ & $\mathrm{H}^{\prime}$ & $\mathrm{Q}^{\prime}$ & $\mathrm{H}$ & $\mathrm{Q}$ & $\mathrm{H}^{\prime}$ & $\mathrm{Q}^{\prime}$ \\
$\mathrm{m}$ & $\mathrm{CMS}$ & & & $\mathrm{m}$ & $\mathrm{CMS}$ & & \\
0.06 & 0.06 & 0.06 & 0.02 & 0.06 & 0.07 & 0.06 & 0.02 \\
0.15 & 0.23 & 0.15 & 0.07 & 0.15 & 0.26 & 0.15 & 0.08 \\
0.30 & 0.64 & 0.30 & 0.21 & 0.30 & 0.73 & 0.30 & 0.24 \\
0.46 & 1.16 & 0.45 & 0.38 & 0.46 & 1.33 & 0.45 & 0.44 \\
0.61 & 1.77 & 0.61 & 0.59 & 0.61 & 2.02 & 0.61 & 0.68 \\
0.91 & 3.18 & 0.91 & 1.09 & 0.91 & 3.64 & 0.91 & 1.24 \\
1.22 & 4.80 & 1.21 & 1.67 & 1.22 & 5.49 & 1.21 & 1.91 \\
1.52 & 6.56 & 1.52 & 2.34 & 1.52 & 7.50 & 1.52 & 2.67 \\
$\mathrm{C}=$ & 3 & & & $\mathrm{C}=$ & 3.3 & & \\
$\mathrm{H}$ & $\mathrm{Q}$ & $\mathrm{H}^{\prime}$ & $\mathrm{Q}$ & $\mathrm{H}$ & $\mathrm{Q}$ & $\mathrm{H}^{\prime}$ & $\mathrm{Q}$ \\
$\mathrm{m}$ & $\mathrm{CMS}$ & & & $\mathrm{m}$ & $\mathrm{CMS}$ & & \\
0.06 & 0.08 & 0.06 & 0.02 & 0.06 & 0.08 & 0.06 & 0.03 \\
0.15 & 0.30 & 0.15 & 0.10 & 0.15 & 0.33 & 0.15 & 0.11 \\
0.30 & 0.83 & 0.30 & 0.27 & 0.30 & 0.92 & 0.30 & 0.30 \\
0.46 & 1.51 & 0.45 & 0.50 & 0.46 & 1.67 & 0.45 & 0.55 \\
0.61 & 2.31 & 0.61 & 0.77 & 0.61 & 2.54 & 0.61 & 0.85 \\
0.91 & 4.15 & 0.91 & 1.42 & 0.91 & 4.57 & 0.91 & 1.56 \\
1.22 & 6.26 & 1.21 & 2.18 & 1.22 & 6.88 & 1.21 & 2.40 \\
1.52 & 8.55 & 1.52 & 3.05 & 1.52 & 9.41 & 1.52 & 3.35 \\
\hline
\end{tabular}


Appendix E: Results from Weir Analysis in Channel Controlled by a Compound Weir consisting of a V-Notch and a Trapezoidal Weir

Table 14. Results from Weir Analysis in Channel Controlled by a Compound Weir consisting of a V-Notch and a Trapezoidal Weir

\begin{tabular}{ccccccc}
\hline $\mathrm{H}$ & $\mathrm{Qv}$ & $\mathrm{Qt}$ & Qcomb & Htotal & $\mathrm{H}^{\prime}$ & $\mathrm{Q}^{\prime}$ \\
$\mathrm{m}$ & $\mathrm{CMS}$ & $\mathrm{CMS}$ & $\mathrm{CMS}$ & $\mathrm{m}$ & & \\
0.15 & 0.013 & 0.331 & & 0.013 & 0.15 & 0.01 \\
0.30 & 0.071 & 0.935 & & 0.071 & 0.30 & 0.02 \\
0.46 & 0.195 & 1.718 & & 0.195 & 0.45 & 0.04 \\
0.61 & 0.401 & 2.645 & & 0.401 & 0.61 & 0.06 \\
0.15 & & & 16.882 & 17.283 & 0.76 & 0.17 \\
0.30 & & & 47.751 & 48.151 & 0.91 & 0.37 \\
0.46 & & & 87.723 & 88.124 & 1.06 & 0.63 \\
0.61 & & & 135.059 & 135.460 & 1.21 & 0.93 \\
\hline
\end{tabular}




\section{Appendix F: Basin Characteristics Data and Relative Error for Stations in Calibration Data Set for Intermediate-Flow Region}

Table 15. Basin Characteristics Data and Relative Error for Stations in Calibration Data Set for Intermediate-Flow Region

\begin{tabular}{|c|c|c|c|c|c|c|c|c|c|}
\hline Gage \# & S10 & $\begin{array}{l}\text { Q10 } \\
\text { CMS }\end{array}$ & $\begin{array}{c}\mathrm{d} 10 \\
\mathrm{~m}\end{array}$ & $\begin{array}{c}\text { Ch Slope } \\
\%\end{array}$ & $\begin{array}{l}\text { Slope } \\
\mathrm{m} / \mathrm{m}\end{array}$ & $\begin{array}{c}\text { Area } \\
\mathrm{mi}^{2}\end{array}$ & $\begin{array}{c}\text { \% Wetland } \\
\%\end{array}$ & $\begin{array}{c}\text { DTWT } \\
\mathrm{m}\end{array}$ & $\begin{array}{c}\mathrm{RE} \\
\%\end{array}$ \\
\hline 2295420 & 1.34 & 7.5 & 1.3 & 2.14 & 0.010876 & 125.2 & 10.25 & 4.34 & 52 \\
\hline 2294898 & 1.73 & 15.5 & 1.8 & & 0.0108763 & 479.6 & 23.89 & 5.83 & 16 \\
\hline 2296750 & 1.74 & 76.5 & 2.8 & 1.3 & 0.0088 & 1372.9 & 19.88 & 3.55 & 25 \\
\hline 2300500 & 1.72 & 11.0 & 1.9 & & 0.00738 & 151.7 & 12.58 & 3.714 & 15 \\
\hline 2300100 & 1.72 & 2.2 & 1.3 & & 0.0060 & 30.9 & 12.59 & 3.88 & 12 \\
\hline 2301000 & 2.1 & 8.5 & 1.8 & 4.96 & 0.01 & 136 & 5.1 & 4.765 & 2 \\
\hline 2301500 & 1.67 & 20.5 & 1.9 & 3.45 & 0.0088 & 339.4 & 12.87 & 4.77 & 23 \\
\hline 2294650 & 1.6 & 6.2 & 1.6 & 1.25 & 0.0120 & 404.7 & 26.03 & 5.20 & 10 \\
\hline 2297155 & 1.6 & 2.1 & 0.8 & 5.5 & 0.0050 & 40.9 & 13.01 & 3.50 & 53 \\
\hline 2296500 & 1.98 & 21.2 & 2.4 & 1.68 & 0.0061 & 326.5 & 19.63 & 3.51 & 4 \\
\hline 2301300 & 1.9 & 6.3 & 1.5 & 4.17 & 0.0070 & 112.2 & 11.52 & 4.53 & 11 \\
\hline 2297310 & 1.9 & 15.0 & 2.4 & 2.79 & 0.004779 & 217.3 & 17.71 & 3.50 & 8 \\
\hline 2295637 & 1.61 & 41.1 & 2.6 & 1.38 & 0.00994 & 839.1 & 19.55 & 4.15 & 15 \\
\hline 2303350 & 2.34 & 1.6 & 0.7 & 2.44 & 0.005 & 17.3 & 27.52 & 3.46 & 10 \\
\hline 2303420 & 2.37 & 3.6 & 1.3 & 2.65 & 0.010444 & 128.7 & 30.54 & 3.68 & 20 \\
\hline 2293987 & 2.45 & 9.0 & 1.3 & & 0.014 & 170.7 & 31.14 & 3.68 & 21 \\
\hline 2295013 & 2.36 & 2.2 & 0.9 & 4.96 & 0.007 & 46.3 & 25.21 & 4.135 & 17 \\
\hline 2297220 & 2.25 & 1.9 & 1.1 & & 0.004 & 47.9 & 19.27 & 3.24 & 29 \\
\hline 2297100 & 2.19 & 7.8 & 1.7 & 4.06 & 0.004 & 120.9 & 10.96 & 3.37 & 2 \\
\hline 2298830 & 2.71 & 19.4 & 2.0 & 2.14 & 0.00455 & 225.5 & 22.18 & 3.28 & 22 \\
\hline 2299120 & 2.6 & 3.8 & 1.3 & & 0.001 & 26.1 & 36.82 & 3.02 & 20 \\
\hline 2299410 & 2.29 & 2.7 & 1.0 & 1.23 & 0.002 & 35.8 & 21.99 & 3.20 & 2 \\
\hline 2299861 & 1.94 & 0.4 & 0.4 & & 0.005 & 6 & 7.38 & 3.35 & 24 \\
\hline 2299780 & 1.7 & 3.1 & 0.8 & & 0.005 & 31.1 & 8.92 & 3.32 & 82 \\
\hline 2299684 & 1.48 & 0.1 & 0.2 & & 0.002 & 4.3 & 19.88 & 3.21 & 98 \\
\hline 2300032 & 1.91 & 2.4 & 1.2 & & 0.004 & 25.2 & 13.16 & 3.40 & 17 \\
\hline 2300700 & 1.98 & 2.3 & 1.0 & 7.01 & 0.007 & 28.6 & 12.10 & 3.67 & 14 \\
\hline 2301900 & 4.16 & 0.5 & 0.7 & 6.1 & 0.009 & 9.3 & 12.24 & 4.75 & 55 \\
\hline 2302500 & 1.84 & 5.3 & 0.9 & 3.52 & 0.009011 & 98.6 & 17.79 & 3.23 & 17 \\
\hline 2303000 & 1.89 & 14.9 & 1.6 & 3.87 & 0.005 & 227.2 & 16.82 & 4.09 & 29 \\
\hline 2303205 & 2.22 & 1.2 & 0.5 & & 0.009011 & 21.6 & 13.4 & 4.869 & 3 \\
\hline 2303330 & 8.08 & 17.2 & 3.2 & & 0.01206 & 387.9 & 18.05 & 3.87 & 34 \\
\hline 2303800 & 5.1 & 6.6 & 1.3 & 2.1 & 0.010081 & 167.8 & 32.60 & 5.00 & 56 \\
\hline
\end{tabular}




\section{Appendix F: (Continued)}

Table 15. (Continued)

\begin{tabular}{cccccccccc}
\hline Gage \# & S10 & Q10 & d10 & Ch Slope & Slope & Area & \% Wetland & DTWT & RE \\
& & CMS & $\mathrm{m}$ & $\%$ & $\mathrm{~m} / \mathrm{m}$ & $\mathrm{mi}^{2}$ & $\%$ & $\mathrm{~m}$ & $\%$ \\
2301750 & 2.74 & 0.7 & 0.4 & 5.2 & 0.011 & 14.2 & 8.35 & 3.80 & 41 \\
2268390 & 2.7 & 1.9 & 0.9 & & 0.025 & 53.1 & 18.95 & 6.79 & 4 \\
2269520 & 1.91 & 3.7 & 1.1 & & 0.013 & 118.3 & 32.33 & 4.13 & 14 \\
2270000 & 2.54 & 1.5 & 1.0 & & 0.014 & 39 & 18.90 & 6.17 & 4 \\
2271500 & 2.34 & 4.8 & 1.1 & 3.81 & 0.01275 & 113.2 & 26.96 & 5.37 & 16 \\
2307200 & 2.74 & 0.3 & 0.4 & 1.62 & 0.003 & 5.2 & 33.14 & 3.51 & 38 \\
2307359 & 2.5 & 1.4 & 1.0 & 2.81 & 0.00545 & 33 & 34.68 & 3.31 & 32 \\
2310000 & 2.1 & 4.9 & 1.7 & 3.54 & 0.002821 & 69.6 & 29.61 & 3.43 & 4 \\
2310280 & 2.69 & 0.5 & 0.4 & 2.3 & 0.015 & 148.8 & 13.32 & 3.82 & 35 \\
2310300 & 3.66 & 2.0 & 1.0 & 2.7 & 0.01342 & 181.4 & 17.53 & 3.82 & 48 \\
\hline
\end{tabular}




\section{Appendix G: Basin Characteristics Data and Relative Error for Stations in Calibration Data Set for High-Flow Region}

Table 16. Basin Characteristics Data and Relative Error for Stations in Calibration Data Set for High-Flow Region

\begin{tabular}{ccccccccccc}
\hline Gage \# & $\mathrm{S} 10$ & $\mathrm{~b}$ & $\mathrm{Q} 10$ & $\mathrm{~d} 10$ & Ch & Slope & Area & Wetland & DTWT & $\mathrm{RE}$ \\
& $\%$ & & $\mathrm{CMS}$ & $\mathrm{m}$ & $\%$ & $\mathrm{~m} / \mathrm{m}$ & $\mathrm{mi}^{2}$ & $\%$ & $\mathrm{~m}$ & $\%$ \\
2295420 & 4.42 & -1.54 & 263 & 4.13 & 2.14 & 0.0108 & 125.2 & 10.25 & 4.34 & 145 \\
2294898 & 3.03 & 0.02 & 546 & 6 & & 0.0108 & 479.6 & 23.89 & 5.83 & 2 \\
2296750 & 3.95 & -0.29 & 2700 & 9.24 & 1.3 & 0.0088 & 1372.9 & 19.88 & 3.55 & 8 \\
2300500 & 4.95 & -1.03 & 389 & 6.1 & & 0.0073 & 151.7 & 12.58 & 3.71 & 5 \\
2300100 & 4.77 & -0.34 & 77 & 4.3 & & 0.0060 & 30.9 & 12.59 & 3.88 & 0.5 \\
2301000 & 5.14 & -0.67 & 299 & 6 & 4.96 & 0.01 & 136 & 5.1 & 4.76 & 6.2 \\
2297155 & 5.73 & -2.83 & 74 & 2.66 & 5.5 & 0.0050 & 40.9 & 13.01 & 3.50 & 70 \\
2296500 & 4.54 & -0.66 & 747 & 7.76 & 1.68 & 0.0061 & 326.5 & 19.63 & 3.51 & 47 \\
2301300 & 5.37 & -0.42 & 224 & 4.84 & 4.17 & 0.0070 & 112.2 & 11.52 & 4.53 & 13 \\
2297310 & 5.56 & -0.62 & 530 & 7.9 & 2.79 & 0.0047 & 217.3 & 17.71 & 3.50 & 27 \\
2295637 & 3.83 & -0.36 & 1450 & 8.45 & 1.38 & 0.0099 & 839.1 & 19.55 & 4.15 & 129 \\
2303350 & 3.83 & -0.35 & 55 & 2.45 & 2.44 & 0.005 & 17.3 & 27.52 & 3.46 & 223 \\
2297100 & 7.40 & -1.91 & 275 & 5.54 & 4.06 & 0.004 & 120.9 & 10.96 & 3.37 & 98 \\
2298830 & 4.88 & 0.00 & 686 & 6.7 & 2.14 & 0.0045 & 225.5 & 22.18 & 3.28 & 14 \\
2299410 & 7.50 & -1.37 & 95 & 3.13 & 1.23 & 0.002 & 35.8 & 21.99 & 3.20 & 87 \\
2299684 & 4.75 & -2.44 & 4.2 & 0.55 & & 0.002 & 4.3 & 19.88 & 3.21 & 14 \\
2300032 & 4.65 & -1.43 & 85 & 4 & & 0.004 & 25.2 & 13.16 & 3.40 & 71 \\
2300700 & 5.83 & -1.87 & 82 & 3.16 & 7.01 & 0.007 & 28.6 & 12.10 & 3.67 & 64 \\
2302500 & 4.01 & -0.81 & 187 & 2.89 & 3.52 & 0.0090 & 98.6 & 17.79 & 3.23 & 218 \\
2303000 & 5.52 & -1.46 & 525 & 5.2 & 3.87 & 0.005 & 227.2 & 16.82 & 4.09 & 4 \\
2303330 & 4.80 & 0.08 & 606 & 10.53 & & 0.01206 & 387.9 & 18.05 & 3.87 & 21 \\
2271500 & 3.80 & -0.06 & 171 & 3.55 & 3.81 & 0.0127 & 113.2 & 26.96 & 5.37 & 56 \\
2307359 & 6.95 & -0.36 & 50 & 3.17 & 2.81 & 0.0054 & 33 & 34.68 & 3.31 & 76 \\
\hline & & & & & & & & & &
\end{tabular}


Appendix H: Basin Characteristics Data and Relative Error for Stations in Verification Data Set for Intermediate-Flow Region

Table 17. Basin Characteristics Data and Relative Error for Stations in Verification Data Set for Intermediate-Flow Region

\begin{tabular}{cccc} 
ID & station & $\begin{array}{c}\mathrm{A} \\
\mathrm{mi}^{2}\end{array}$ & $\begin{array}{c}\text { RE } \\
\%\end{array}$ \\
2 & 2299950 & 67 & 32 \\
3 & 2294491 & 145 & 44 \\
4 & 2294217 & 59.5 & 12 \\
37 & 2300530 & 7.3 & 26 \\
44 & 2303300 & 57.7 & 24 \\
49 & 2267000 & 46 & 57 \\
54 & 2270500 & 388.5 & 68 \\
58 & 2307323 & 229 & 108 \\
65 & 2236350 & 41.8 & 40 \\
66 & 2310800 & 107.6 & 45 \\
67 & 2310947 & 352.8 & 47 \\
68 & 2311500 & 419.6 & 48 \\
69 & 2312000 & 572.6 & 24 \\
70 & 2312180 & 88 & 85 \\
72 & 2312500 & 805.9 & 32 \\
73 & 2262900 & 84 & 36 \\
74 & 2266300 & 84.6 & 57 \\
75 & 2298760 & 20 & 15 \\
76 & 2300032 & 25.8 & 19 \\
77 & 2300500 & 149 & 24 \\
78 & 2306774 & 17.8 & 15 \\
79 & 2313000 & 1825 & 79 \\
80 & 2300018 & 50.6 & 25 \\
81 & 2301738 & 2.6 & 113 \\
83 & 2300300 & 38.4 & 32 \\
84 & 2305851 & 2.59 & 29 \\
85 & 2301740 & 6.5 & 24 \\
86 & 2301745 & 2 & 78 \\
87 & 2301793 & 1.46 & 58 \\
\hline & & & \\
79
\end{tabular}


Appendix I: Drainage Area and Relative Error for Stations in Validation Data Set for Intermediate-Flow Region

Table 18. Drainage Area and Relative Error for Stations in Validation Data Set for Intermediate-Flow Region

\begin{tabular}{|c|c|c|}
\hline Station & $\begin{array}{c}\text { Area } \\
\mathrm{mi}^{2}\end{array}$ & $\begin{array}{c}\mathrm{RE} \\
\%\end{array}$ \\
\hline 2369800 & 1182 & 24 \\
\hline 2361500 & 1280 & 15 \\
\hline 2378300 & 16.6 & 40 \\
\hline 2376500 & 394 & 3 \\
\hline 2374250 & 2661 & 17 \\
\hline 2373000 & 470 & 9 \\
\hline 2361000 & 686 & 7 \\
\hline 2363000 & 498 & 23 \\
\hline 2372422 & 1273 & 102 \\
\hline 2364500 & 1182 & 11 \\
\hline 2377570 & 192 & 4 \\
\hline 2374950 & 193 & 21 \\
\hline 2362240 & 21.4 & 45 \\
\hline 2323000 & 9390 & 11 \\
\hline 2319800 & 7190 & 6 \\
\hline 2319000 & 2120 & 8 \\
\hline 2322500 & 1017 & 15 \\
\hline 2321500 & 575 & 57 \\
\hline 2330150 & 2080 & 54 \\
\hline 2330100 & 126 & 49 \\
\hline 2359000 & 781 & 26 \\
\hline 2365500 & 3499 & 41 \\
\hline 2368500 & 123 & 4 \\
\hline 2370500 & 237 & 51 \\
\hline 2376500 & 394 & 5 \\
\hline 2322700 & 213 & 344 \\
\hline 2226500 & 1200 & 55 \\
\hline 2228000 & 2790 & 49 \\
\hline 2314500 & 1260 & 41 \\
\hline 2226000 & 13600 & 47 \\
\hline 23177483 & 502 & 14 \\
\hline 2327500 & 550 & 33 \\
\hline 2329342 & 16.9 & 3 \\
\hline
\end{tabular}




\section{Appendix I: (Continued)}

\section{Table 18. (ContinueD)}

\begin{tabular}{ccc}
\hline Station & $\begin{array}{c}\text { Area } \\
\mathrm{mi}^{2}\end{array}$ & $\begin{array}{c}\text { RE } \\
\%\end{array}$ \\
2353000 & 5740 & 4 \\
2353265 & 303 & 6 \\
2354410 & 157 & 106 \\
2354800 & 1000 & 17 \\
2355662 & 7080 & 3 \\
2357000 & 485 & 31 \\
2316000 & 663 & 270 \\
\hline
\end{tabular}


Appendix J: Drainage Area and Relative Error for Stations in Validation Data Set for High-Flow Region

Table 19. Drainage Area and Relative Error for Stations in Validation Data Set for High-Flow Region

\begin{tabular}{|c|c|c|}
\hline Station & $\begin{array}{c}\text { Area } \\
\mathrm{mi}^{2}\end{array}$ & $\begin{array}{c}\mathrm{RE} \\
\%\end{array}$ \\
\hline 2361500 & 1280 & 9 \\
\hline 2378300 & 16.6 & 85 \\
\hline 2376500 & 394 & 2 \\
\hline 2374250 & 2661 & 73 \\
\hline 2373000 & 470 & 205 \\
\hline 2361000 & 686 & 29 \\
\hline 2363000 & 498 & 82 \\
\hline 2377570 & 192 & 8 \\
\hline 2374950 & 193 & 411 \\
\hline 2362240 & 21.4 & 54 \\
\hline 2323000 & 9390 & 42 \\
\hline 2319800 & 7190 & 6 \\
\hline 2319000 & 2120 & 88 \\
\hline 2322500 & 1017 & 451 \\
\hline 2330100 & 126 & 26 \\
\hline 2359000 & 781 & 41 \\
\hline 2365500 & 3499 & 3 \\
\hline 2368500 & 123 & 30 \\
\hline 2370500 & 237 & 47 \\
\hline 2376500 & 394 & 3 \\
\hline 23177483 & 502 & 65 \\
\hline 2327500 & 550 & 75 \\
\hline 2354410 & 157 & 68 \\
\hline 2357000 & 485 & 70 \\
\hline 2316000 & 663 & 76 \\
\hline
\end{tabular}




\begin{abstract}
ABOUT THE AUTHOR
Auristela Mueses-Pérez was born on October 10, 1967 in Dominican Republic. She attended San Judas High School, finishing as the best GPA in 1984. In 1987 she graduated Magna Cum Laude with her Bachelor in Civil Engineering from Instituto Tecnológico Santo Domingo. In 1989 she moved to Puerto Rico to pursue her Master of Science in Water Resources Engineering, at University of Puerto Rico, Mayaguez. She completed her degree in 1991. In 1992 she joins Polytechnic University of Puerto Rico as an Assistant Professor, and was promoted to Associate Professor in 1999. In 2003, she began Ph.D. coursework in the Mayaguez Campus, and after a year she decides to continue her Ph.D. in Water Resources at University of South Florida. She completed her work in the field of non-dimensional rating curves in the summer of 2006. She already took a position as a faculty member at Polytech University in Orlando.
\end{abstract}

